\title{
WestVirginiaUniversity
}

THE RESEARCH REPOSITORY @ WVU

Graduate Theses, Dissertations, and Problem Reports

2018

\section{Mean-swap Variance, Portfolio Theory and Asset Pricing}

Jhan Wang

Follow this and additional works at: https://researchrepository.wvu.edu/etd

Part of the Finance and Financial Management Commons

\section{Recommended Citation}

Wang, Jhan, "Mean-swap Variance, Portfolio Theory and Asset Pricing" (2018). Graduate Theses, Dissertations, and Problem Reports. 7993.

https://researchrepository.wvu.edu/etd/7993

This Dissertation is protected by copyright and/or related rights. It has been brought to you by the The Research Repository @ WVU with permission from the rights-holder(s). You are free to use this Dissertation in any way that is permitted by the copyright and related rights legislation that applies to your use. For other uses you must obtain permission from the rights-holder(s) directly, unless additional rights are indicated by a Creative Commons license in the record and/ or on the work itself. This Dissertation has been accepted for inclusion in WVU Graduate Theses, Dissertations, and Problem Reports collection by an authorized administrator of The Research Repository @ WVU.

For more information, please contact researchrepository@mail.wvu.edu. 


\title{
Mean-Swap Variance, Portfolio Theory and Asset Pricing
}

\author{
Zhan Wang \\ Dissertation submitted \\ to the College of Business and Economics \\ at West Virginia University \\ in partial fulfillment of requirements for degree of
}

Doctor of Philosophy in Business Administration Concentration in Finance

Victor Chow, Ph.D. Chair

Alexander Kurov, Ph.D.

Bingxin Li, Ph.D.

Ann Marie Hibbert, Ph.D.

Eric Olson, Ph.D.

Department of Finance

Morgantown, WV

2018

Keywords: Swap Variance, Symmetry, Asymmetry, Expected Utility Maximization, Stochastic Dominance, Capital Market Equilibrium, CAPM, Beta Coefficient, Behavior Finance

Copyright 2018 Zhan Wang 


\title{
Abstract \\ Mean-Swap Variance, Portfolio Theory \\ and Asset Pricing
}

\author{
Zhan Wang
}

The primary focus of this dissertation is a new risk measure, Swap Variance (SwV), and its applications to expected utility maximization, portfolio theory, and capital asset pricing models (CAPM) with loss aversion and gain preference. Superior to the classical mean-variance (MV) model, the mean-swap variance (MSwV) efficiency is consistent with expected utility maximization for all concave utility without any restriction on the form of either utility function or return distributions. Specifically, the MSwV efficiency is necessary and sufficient to the seconddegree stochastic dominance (SSD). Thus, the SSD optimization can be consistently replicated by the SwV minimization for given means. The consistency between MSwV and SSD implies that the capital market line, Sharp ratio and other portfolio performance measures can now be modified in a generalized framework of expected concave utility maximization without utility or distributional assumptions of the MV model.

Since the MSwV analysis retains the same simplicity as the MV approach, I apply the $\mathrm{MSwV}$ approach to the conventional procedure of portfolio optimization in determining capital market equilibrium. As a result, similar in form to the classical CAPM, the beta coefficient derived from the $\mathrm{MSwV}$ model is a ratio of the co-swap variance between returns on an asset and those on the market portfolio over the market $\mathrm{SwV}$. Although the MSwV beta captures all high order comoments of return and is thus more general than the traditional MV beta, it is insufficient to explain the generalized relationship between expected return and risk under a single factor model. This research explicitly proves the necessity of additional factors in equilibrium for determining the asset return generating process, if the beta of $\mathrm{MSwV}$ is different from that of MV. Empirically, from an out-of-sample analysis, the larger the distinction (both positive and negative) of the MSwV-beta from the MV-beta, then the average return will be significantly higher. This empirical evidence strongly indicates that, in addition to the market factor, additional factors captured by the asymmetric systematic risk help explain the equilibrium risk-return relationship. 
The MV model is valid under the assumption of a rational decision maker. The distinction of MSwV from MV thus captures the behavioral biases of human decision makers. The viewpoint of behavior finance (Benartzi \& Thaler, 1995) demonstrates that loss-aversion appears when investors are unwilling to recognize loss and tend to afford more risk. On the other side, Kumar (2009) posited that individual investors prefer stocks with lottery features, which means a human decision maker may tolerate more risk to pursue potential gain. So, utility on a human decision maker shifts by three primary risk attitudes: loss-aversion for downside asymmetry (significant losses), rational risk-version for symmetry (normal returns), and overly risk-averse for upside asymmetry (substantial gains). Mathematically, the expected utility can be quantified by the $\mathrm{MSwV}$ approach without any restriction on the form of utility and return distribution functions.

The major contribution of this dissertation is the development of a portfolio theory that can capture the loss aversion and gain preference of human decision makers. Based on the portfolio theory, a multi-factor linear model is theoretically formulated. Precisely, the loss aversion (gain preference) factor is captured by the negative (positive) asymmetric beta, and the MV-beta captures the symmetric factor. Therefore, the factor portfolios can be replicated by the zero-cost (long-short) portfolios constructed from the sorted securities concerning the past asymmetric betas. The mimicking portfolio of the symmetric factor is the optimal portfolio without asymmetry. Empirical examinations show that the Fama-Macbeth cross-sectional regression results in asymmetric factor loadings and have significant explanatory power for security returns. 


\section{Table of Contents}

List of Figures and Tables ................................................................................................

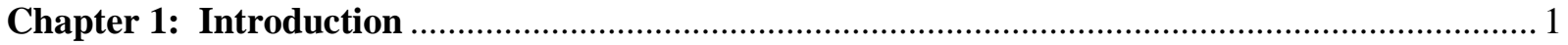

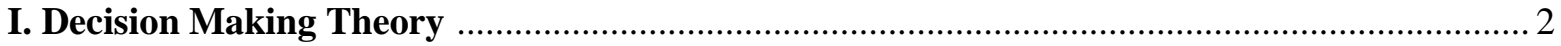

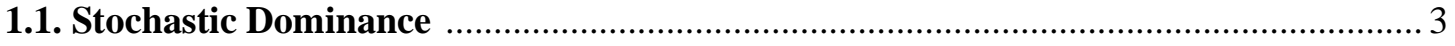

1.2. Markowitz's Mean-Variance Theory …………………………………………..... 6

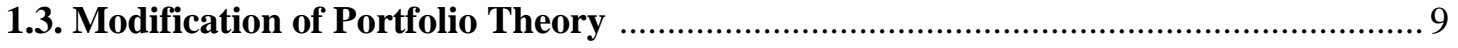

1.4. Behavioral Effects on Portfolio Theory ……………………………………….... 10

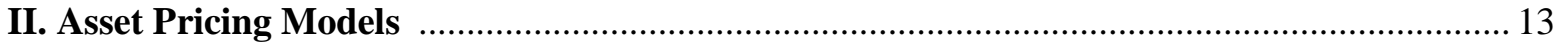

2.1. Criticism of CAPM …………………………………………………………. 14

2.2. Improvement of Asset Pricing Models .................................................................. 15

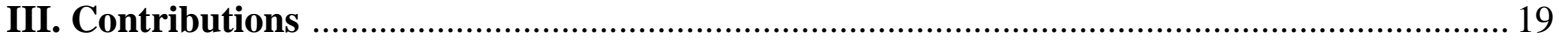

Chapter 2: Mean-Swap Variance Portfolio Theory ……………………………………………. 21

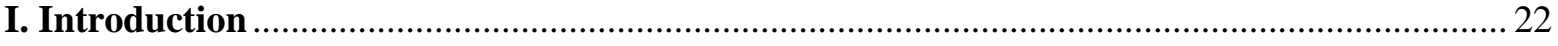

II. Swap-Variance, Asymmetry, and Stochastic Dominance ……………………………....... 27

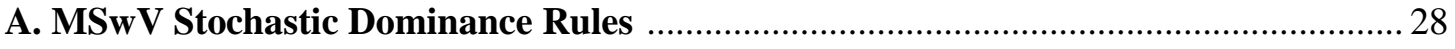

B. MVA and Stochastic Dominance Efficiency ............................................................. 31

III. Co-SwV, Co-Asymmetry and MCSD ……………………............................................ 38

A. The Co-Swap Variance and MCSD .................................................................. 38

B. The Co-Asymmetry and MCSD …………………………………………………. 41

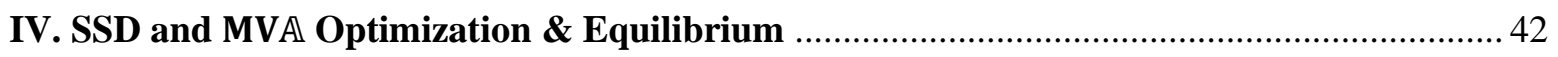

A. Minimum-SwV Portfolios and MSwV Asset Pricing Model ……………………….... 42

B. Minimum-SwV Hedging Approach .................................................................... 44

C. Minimum-Portfolios and MV Asset Pricing Model ………………………………..... 45

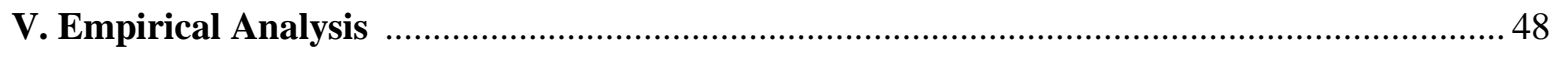

A. The Impact of Return Asymmetry on Portfolio Performance ……………………….... 49 
B. Volatility, Asymmetry, Diversification and Stability ........................................... 50

C. Performance of the Optimal MSwV and MV Market Portfolios ................................. 51

D. Mean-Variance, Mean-Swap Variance and SSD Efficient Sets ...............................53

E. Mean-Variance and Mean-Swap Variance Hedging ................................................. 54

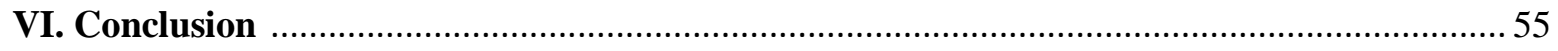

Chapter 3: Mean-Swap Variance Asset Pricing Model .......................................................... 58

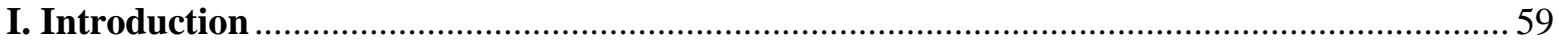

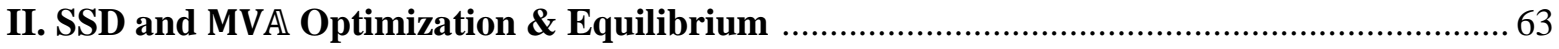

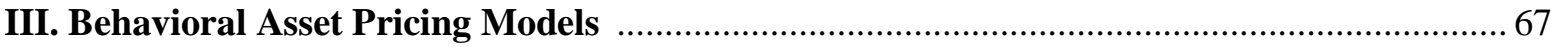

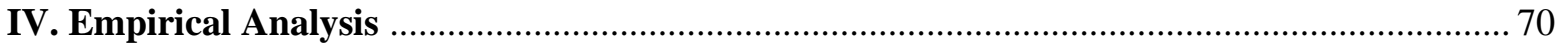

A. Testing for MSwV (SSD) and MVA Asset Pricing Models ….................................. 70

B. Mean-Variance and Mean-Swap Variance Betas .................................................... 72

C. Factor Portfolios Mimicking Loss Aversion and Gain Preference ............................. 73

D. Testing for Behavioral Asset Pricing Model ……..................................................... 77

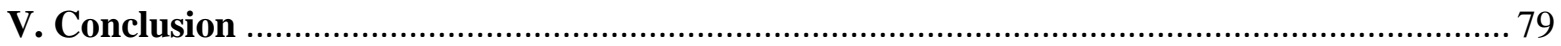

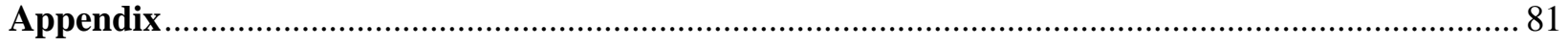

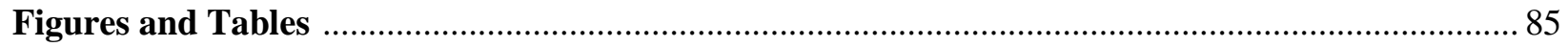

Reference 


\section{List of Figures and Tables}

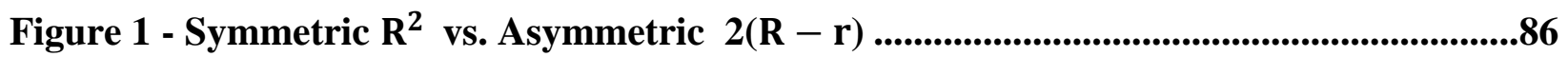

Figure 2 - SSD Efficiency and Portfolio Separation ....................................................................87

Figure 3 - Stochastic Dominance Efficient Frontier and Capital Market Line (CML) .........88

Figure 4 - Moving Pattern of the Optimal Hedge Ratios for S\&P 500 Index .........................89

Figure 5 - Moving Pattern of the Optimal Hedge Ratios on the Crude Oil Markets ...........91

Figure 6 - U-shape mean- $\boldsymbol{\beta}^{\mathbb{A}}$ and the Security Market Plane (SMP) ..............................................93

Table 1 - Summary Statistics for Hedge Funds and Industry Portfolios .................................94

Table 2 - MV, SSD and MVA Sharpe Ratios .......................................................................................96

Table 3 - A Comparison of Market and Factor Portfolios ...............................................................97

Table 4 - MV, SSD and MSwV Efficient sets .............................................................................98

Table 5 - Difference of Hedge Ratio and Volatility Index ..........................................................100

Table 6 - Fama-MacBeth Tests for MSwV (SSD) and MVA Pricing Models ......................101

Table 7 - Fama-MacBeth Tests for the Validity of MVA Pricing Model ..............................102

Table 8 - Descriptive Statistics of Betas ...................................................................................103

Table 9 - Portfolio Sorted by Systematic Exposure to Asymmetries in Returns ..................104

Table 10 - Correlation between Factors ......................................................................................105

Table 11 - Portfolio Sorted by Systematic Exposure to Asymmetries in Returns (Adjusted) 


\section{Chapter 1}

\section{Introduction}




\section{Decision-making Theory}

Decision-making theory pertains to the ideal decision that depends on values, probabilities, and uncertainties. Economists have been concerned with individual decision-making problems for more than 200 years and developed the consumer's decision-making theory in the 1940s. Von Neumann and Morgenstern (1944) proposed the utility theory of risky choices. In utility theory, investors act to maximize their utility, which is considered as the level of relative satisfaction received from consumption, rather than value as in previous studies. This paper is considered the beginning of modern studies on risky decision-making theory. Furthermore, Von Neumann and Morgenstern (1944) demonstrated the properties of an investor's utility. First, an investor has a well-defined preference over any two prospects. That is, if an investor is given two prospects $\mathrm{X}$ and $\mathrm{Y}$, he should prefer $\mathrm{X}$ to $\mathrm{Y}$, prefer $\mathrm{Y}$ to $\mathrm{X}$, or be indifferent between $\mathrm{X}$ and $\mathrm{Y}$. Second, the utility should be transitivity, which means that the investor should prefer A to $\mathrm{C}$ if he prefers $\mathrm{A}$ to $\mathrm{B}$ and prefers B to $\mathrm{C}$. The third property of utility is independence. If an investor prefers A to C and $\mathrm{B}$ to $\mathrm{C}$, then he prefers any mixture between $\mathrm{A}$ and $\mathrm{B}$ to C. Finally, the utility function is continuous. The utility function cannot jump for any small change in the prospect.

The most critical assumption in Von Neumann and Morgenstern's decision-making theory is the rational economic man (REM). There are three essential properties of REM. First, a REM is completely informed, so he knows not only all the actions available to him but also all the outcomes of each activity. Second, a REM is self-interested. He always pursues the highest possible utility for himself but never gives up anything to his opponent in a transaction. The last assumption is 
perfect rationality. A REM can analyze and make the best decision at all times. Another important assumption in utility theory is risk aversion. Investors will choose the expected value with certainty rather than invest in a risky prospect that generates the same expected payoff. Mathematically, an individual's utility function is concave and shows diminishing marginal utility of wealth.

\subsection{Stochastic Dominance}

However, it is complicated to apply utility theory into decision-making across the entire market because investor's preferences and utility function are different, even though they are all considered risk-averse. So, the following studies develop several ranking approaches based on the distributions of security returns and avoid the dilemma of utility patterns. One of the most sophisticated and commonly used theories is stochastic dominance (SD). SD was initially developed in statistics to rank random variables. During the last 50 years, it has become an essential ranking rule in various areas of economics and finance. Quirk and Saposnik (1962) first applied it in decision theory. The paper represented that investors want to have maximum expected utility when they choose portfolios, so a portfolio with a higher expected utility is preferred to a lower expected utility. Under the assumption of the Von Neumann-Morgenstern utility function, the paper proved first-degree stochastic dominance (FSD), which is for all $f, g$ included in the set of probability distributions over income, $f$ is dominated in sense of SD ordering by $g$ if and only if the corresponding cumulative distribution functions, F, satisfy: $F(f) \geq F(g)$ for all $f$ and $g$. The theory of SD and its many theoretical and empirical extensions in economics and finance were 
developed in the late 60s. Hadar and Russell (1969) and Hanoch and Levy (1969) derived seconddegree stochastic dominance (SSD) directly from concave, non-decreasing utility function, which means for any risk-averse investors, portfolio $\mathrm{g}$ is preferred to portfolio $\mathrm{f}$ and is equivalent to portfolio $\mathrm{g}$ which dominates portfolio $\mathrm{f}$ under the sense of SSD. That is, if all investors' utility functions are concave and non-decreasing, $f$ is dominated in the sense of SSD ordering by $g$ if and only if the corresponding cumulative distribution functions, F, satisfy: $\int_{0}^{f} F(s) d s \geq \int_{0}^{g} F(s) d s$ for all $f$ and $g$. After these milestones in SD, Whitmore (1970) suggested the criteria for thirddegree stochastic dominance (TSD), and Whitmore (1989) extended the SD rules to the nth-degree. Among SD rules with all degrees, SSD is the most commonly used because concave, nondecreasing utility is a well-accepted assumption. Moreover, Hadar and Russell (1969) proved that the SSD ranking rule is the necessary and sufficient condition of Von Neumann and Morgenstern's expected utility ranking rule if all the investors are risk-averse. Based on SSD ranking rules, many studies derived SSD portfolio selection models. Kuosmanen (2004, 2007) and Luedtke (2008) presented a method to compare target portfolios with an endogenously selected benchmark portfolio under the SSD rule. Post (2003) developed several empirical tests for SD efficiency and showed that Fama-French size and value factor portfolios are significantly inefficient relative to their SSD benchmark portfolios. Dentcheva and Ruszczyński (2003, 2006) proposed a SSD optimization approach for discrete joint return distributions and showed the relationship with utility optimization. Krokhmal (2007), Kopa and Chovanec (2008), and Fabian and Veszprémi (2008) proposed SSD efficiency tests for higher-moment coherent risk measures (e.g., Conditional Value-at-risk $(\mathrm{VaR}))$ and determined that these risk measures perform very well under the SSD 
framework. Lozano and Gutiérrez (2008) combined data envelopment analysis with SSD rules and showed that SSD efficient portfolios are optimal benchmarks for any rational risk-averse investors. However, there are two inherent difficulties of SD rules to be applied in portfolio theory. First, the approach requires comparing all observations in the distribution between two prospects, which is not convenient. The other difficulty is more important. SD rules can only rank between two prospects and decide which one is preferred, so SD rules cannot be used to derive an optimal portfolio. 


\subsection{Markowitz's Mean-Variance Theory}

Based on expected utility theory and REM assumption, Markowitz (1952, 1956, 1959) developed the mean-variance (MV) theory. To develop a simple approach to portfolio optimization, Markowitz assumes a security's returns are symmetrically distributed in the long term, such that investors' utility function can be considered as quadratic. He worked on the single-period portfolio selection problem using MV criteria, which has become the most frequently used criteria in modern financial portfolio theory. Markowitz uses the weighted average return in each state to quantify the return on a security, while he uses variance to quantify the symmetrical risk on the security, which investors focus on only in the long term. Then the return-risk tradeoff in traditional decision-making theory becomes the MV tradeoff. Under this framework, REM chooses the security with a higher mean and lower variance to maximize his satisfaction. MV portfolio selection is to allocate the total wealth among many assets, including risky assets and risk-free assets. Based on MV criteria, risk-averse investors can form the optimal risky portfolios by selecting the portfolios with the minimum variance for a given expected return or maximum expected return for a given variance. In Markowitz's framework, the portfolio that achieves the minimum variance given the certain expected level of return is said to be an optimal portfolio. The curve that consists with all optimal pairs (return and variance) is called a minimizing-variance frontier. If the expected return of an optimal portfolio is also higher than that of the global minimum portfolio (the upper part of the minimizing-variance frontier), the optimal portfolio is efficient (maximum expected return for each variance level). Then we call the pair of the minimum variance and the maximum expected level of return the efficient frontier. Moreover, if the risk- 
free asset exists, optimal portfolios can consist of a risk-free asset and a tangent portfolio on the efficient frontier when based on a two-fund separation theorem. The tangent line from a risk-free asset to the efficient frontier is the capital market line (CML).

Markowitz's MV theory has become a commonly used approach in portfolio allocation because it derives a simple solution for the decision-making problem. Compared to SD rules, MV can rank securities by only two parameters (mean and variance). Moreover, MV can form optimal portfolios by choosing portfolios with the highest mean return or the smallest variance. In Markowitz's work, a diversification effect is proposed. If an investor holds two securities that are not perfectly corrected, the total risk the investor affords is smaller than the sum of the risk for every single security. Furthermore, the risk reduction increases as the correlation between the two securities decreases. In extreme cases, an investor can form a zero-risk portfolio if the two securities are perfectly negatively correlated. Based on Markowitz's portfolio theory, some alternative risk measures are proposed. Sharpe (1966) invented the Sharpe ratio using an expected excess return (expected return minus risk-free return) per unit of standard deviation of the portfolio, which provided a portfolio risk measure that determined the quality of the portfolio return as a certain level of risk. Sortino and Price (1994) proposed the Sortino ratio by replacing the denominator of the Sharpe ratio with the standard deviation if the portfolio returns below the portfolio's expected returns; this emphasizes the idea that investors are more averse to downside price movements. 
However, numerous following papers demonstrate the limitations of Markowitz's portfolio theory. The most important critique is that investors are not perfectly rational, so they may consider some characteristics on return variation beyond variance in the short term. In other words, Markowitz's assumption that security returns are symmetrically distributed is invalid for human decision makers, especially in the short run. A growing literature shows empirical evidence that high moments are also crucial in portfolio allocation and asset valuation. Starting from Berger and Mandelbrot (1963) and Fama (1963), empirical results show that asset returns and portfolio return distributions are non-normal. Fang and Lai (1997) found that investors forego expected excess return in exchange for the benefit of increase in systematic skewness and expect compensation from higher expected returns for bearing systematic kurtosis. Christie-David and Chaudhry (2001) showed that the third and fourth moments explain the return-generating process in futures markets well. Smith (2007) found that investors care more about skewness when the market is positively skewed than when the market is negatively skewed. Hung (2007) found that skewness and kurtosis are significant in explaining the cross-sectional variation of portfolio returns in U.S. and U.K. markets. Moreno and Rodríguez (2009) found that adding a skewness factor has statistically significant increasing explanation power in mutual fund evaluation. Yang, Zhou, and Wang (2010) provided time series evidence that both conditional U.S. stock co-skewness and bond co-skewness command significant negative risk premiums. You and Daigler (2010) suggested that skewness is also useful in international stock valuation. 


\subsection{Modification of Portfolio Theory}

In response to criticism of MV portfolio theory, researchers propose several new risk measures to modify the return-risk tradeoff relationship in MV portfolio theory. Markowitz's portfolio theory uses variance/standard deviation to quantify an investor's risk. Typically, riskaverse investors choose only portfolios with the smallest standard deviation given a certain expected return. A well-accepted risk measurement after Markowitz's portfolio theory is value-atrisk ( $\mathrm{VaR})$. VaR initiates a new research area that emphasizes the management of downside risk using parametric risk measures, and its purpose is to solve the simple problem of how much can one expect to lose with a given cumulative probability. Compared to MV portfolio theory, VaR focuses on risk itself rather than explaining the relation between return and risk. VaR measurement is popular because of its straightforward intuition and model-free framework. But the traditional $\mathrm{VaR}$ measure inaccurately captures downside risk exposures. So various modified VaR measures are proposed to solve the problems. Li (1999) proposed a new approach that includes high moments of returns and showed that this new approach captured extreme tails much better than the standard VaR method. Favre and Galeano (2002) developed a conditional VaR approach that considers convexity and coherence.

Artzner, Delbaen, Eber, and Heath (1997) proposed coherent risk measures, which are considered a significant milestone in risk measurement. Coherent risk measures can no longer arbitrarily assign a function for risk measurement unless four axioms exist. The first axiom is monotonic risk structure, which means higher risk corresponding to higher expected loss. The second axiom is homogeneous risk, ensuring the risk of a specific stock doesn't depend on the 
quantity purchased. The third axiom is riskless transaction invariance, so the investment on a riskfree asset doesn't afford the risk of loss. The last and most critical axiom is that risk is sub-additive, which ensures coherent risk measures considering diversification effects. According to these four axioms, $\mathrm{VaR}$ is not a coherent risk measure; therefore, some studies develop modified VaR measures to incorporate coherent risk measure properties. Artzner, Delbaen, Eber, and Heath (1997) and Embrechts, Resnick, and Samorodnitsky (1999) developed a conditional VaR approach. This approach measures mean excess loss and is consistent with the idea of coherence. Artzner, Delbaen, Eber, Heath, and Ku (2002) investigated risk management in over a multi-year period and developed an intertemporal tail VaR. Inoue (2003) proposed VaR on the worst conditional expectation and extended Artzner, Delbaen, Eber, and Heath's (1997) coherent risk measure axioms to general probability spaces.

\subsection{Behavioral effects on Portfolio Theory}

Behavior finance becomes more and more important in modern finance. Kahneman won a Nobel Prize in 2002 for his contribution to human judgment and decision-making under uncertainty. Thaler won a Nobel Prize in 2017 for his contribution to behavioral finance theories. Under the viewpoint of behavioral finance, investors are irrational, which is inconsistent with the REM assumption in expected utility theory and thus contradicts SD and MV theories. Thaler suggests that investors overreact to a stock's previous performance, especially to bad performance,

resulting in stock price over-adjustment. Bondt and Thaler (1985) suggested that investors' tendency to overreact to unexpected events affects stock prices and that stocks show price reversals 
after extreme gains or losses. Bondt and Thaler (1987) supported their previous paper using more empirical results and demonstrated that the overreaction effect is not primarily a size effect. Lakonishok, Shleifer, and Vishny (1994) proposed that the high expected return of value strategies compensated suboptimal behaviors instead of fundamental risk. Daniel, Hirshleifer, and Subrahmanyam (1998) incorporated investors' overconfidence and self-attribution into security pricing. They suggested that investors' overconfidence about the precision of private information may imply long-run reversal, but biased self-attribution may result in short-term momentum. Barberis and Shleifer (2003) argued that investors may categorize risky assets into several styles and only consider the overall performance of the whole style, although the assets in the same style have relatively high correlations. Hong, Kubik, and Stein (2005) showed that even mutual fund managers evaluate stock by an over-simplified model. (Such as buying the same stocks as other managers in the same city.)

Prospect theory is one of the most critical areas of finance to concern investors' behavioral biases in decision making. Kahneman and Tversky (1979) suggested that the Von NeumannMorgenstern utility structure cannot fully explain investors' behavior in decision making. They denoted certainty effect to explain the phenomenon that investors tend to underweight events with small probability and overweight events with significant probability. This tendency leads to risk aversion in choices involving gains but risk-loving in choices involving losses. Meanwhile, the paper denoted isolation effect to explain the phenomenon that investors discard components shared by all prospects, which results in inconsistent preference. To modify the utility theory, Kahneman and Tversky (1979) developed an alternative value function theory, which uses decision weight 
instead of distributional weight used in utility theory. The value function is concave for positive returns, generally convex for negative returns, and is more sensitive for losses than for gains. After this original paper in prospect theory, Arkes and Blumer (1985) argued that investors would continue with a losing security simply because they already had invested money, which is consistent with risk-loving in prospect theory. Tversky and Kahneman (1986) showed that investors make decisions based on changes in wealth instead of final wealth. Budescu and Weiss (1987) empirically tested the shape of the value function and suggested that more than $75 \%$ of their observations support the shape of value function. However, many studies argue against prospect theory. Hershey and Schoemaker (1980) challenged that the reflection effect, which is risk-averse versus risk-loving in prospect theory, lost its generality at across-subject and withinsubject levels. They suggested that there may be a revision in the shapes of value functions. Brockner (1992) argued that self-justification is not an explanation for prospect theory's failure to explain continuous actions. Casey (1994) suggested that the comparison between maximum buying price and choice doesn't support the segregation factors in prospect theory.

Opposite of loss aversion in prospect theory, Kumar (2009) demonstrated irrational behaviors on the gain side. The paper showed that individual investors prefer securities with lottery features, especially for poorer, less educated, urban, and Catholic investors. Barber, Lee, Liu, and Odean (2008) empirically supported the idea using data from Taiwan. The paper showed that individual investors suffer $2.8 \%$ of total personal income because of aggressive orders. Bali, Cakici, and Whitelaw (2011) showed extreme positive returns on lottery-like securities using both portfolio-level and firm-level cross-sectional analysis. Fong (2013) investigated the sentiment 
effects on the returns of lottery-like securities using SD approaches and suggested that lottery stock puzzle could be explained only by unusual risk preference and sentiment trading. Eraker and Ready (2015) found that the average returns on off-the-count (OTC) stocks are extremely negative, and they suggested that the negative return premium of OTC securities can be explained by investors' preference for potential gain.

\section{Asset Pricing Models}

Theoretical studies on asset pricing began in the 1960s. Based on Markowitz's meanvariance portfolio theory, Sharpe (1964) and Lintner (1965) proposed the capital asset pricing model (CAPM). The model uses single factor market return to evaluate a risky asset and conveys the notation that securities can be priced so that expected returns will compensate investors for expected risks. In my previous discussion, investors' risk can be decreased through diversification, so only the part of the risk that cannot be diversified should be compensated in asset pricing models. In other words, investors face two types of risk, systematic risk and idiosyncratic risk. Idiosyncratic risk is the component of portfolio risk that can be eliminated by increasing the portfolio size, which is irrelevant to market movements. On the other side, systematic risk is associated with overall movements in the market and cannot be eliminated through portfolio diversification. In CAPM, the expected return of individual securities increases only when its systematic risk increases, which is consistent with the idea that only the systematic risk can be compensated. Sharpe (1964) and Lintner (1965) used covariance between the return on the individual security and the return on the 
market portfolio to estimate the co-movement of the two securities. So the beta coefficient, which is computed using this covariance divided by the variance of market return, in CAPM captures the systematic risk of an individual security. Moreover, because of the linear relation between the expected return and the beta coefficient for individual stocks, a straight line is formed to describe this linear relation, which is called security market line (SML). The slope of SML is the expected return of the market portfolio, and the intercept of SML is the risk-free rate.

\subsection{Criticism of CAPM}

However, CAPM faces some challenges because of the incapability of mean-variance theory to explain irrational activities in financial markets. A lot of papers criticize CAPM because researchers have found inconsistent empirical results with it. Friend and Blume (1970); Jensen, Black, and Scholes (1972); Fama and MacBeth (1973); and Blume and Friend (1973) suggest that the SML should have a higher intercept and lower slope. Reinganum (1981), Stambaugh (1982), Lakonishok and Shapiro (1986), and Fama and French (1992) examine CAPM using early sample period data and suggest that the relation between average return and beta for common stocks is even flatter than previous empirical results. Kothari, Shanken, and Sloan (1995) argue that the weak relationship in CAPM is just a chance result.

Another series of criticism comes from the explanatory power of other variables on expected returns. Basu (1977) showed that common stocks with higher earning-price ratios earn higher returns than estimated by CAPM. Rosenberg, Reid, and Lanstein (1985) showed that future stock returns on higher book-to-market $(\mathrm{B} / \mathrm{M})$ stocks are higher than those captured by CAPM 
betas when stocks are sorted on B/M ratios. Banz (1981) showed that average returns on small stocks are higher than estimated by CAPM. Bhandari (1988) suggested that stocks with higher financial leverages have higher average returns compared to their market betas. Jegadeesh and Titman (1993) proposed the influence of momentum on security returns. They argued that stocks that do well over 3 to 12 months tend to keep their performance during the following few months, and stocks that do poorly continue their lousy performance.

\subsection{Improvement of Asset Pricing Models}

Because CAPM's failure mostly comes from the strict assumption on MV portfolio theory, numerous studies develop a more complicated asset pricing model to release some unrealistic assumptions in CAPM. Merton (1973) built the intertemporal capital asset pricing model (ICAPM). In ICAPM, investors consider not only the portfolio return at the end of the current period but also the tradeoff between consumption and investment, as well as expected future payoffs. ICAPM initials asset pricing studies in multiple periods, instead of the previous one-period model in CAPM.

Another direction for improvement is adding other factors to asset pricing models. This class of papers uses multifactor models to incorporate the influences of other variables, which is consistent with empirical findings. The Fama and French three-factor model is the best accepted modification on CAPM in this area. Fama and French $(1993,1996)$ proposed a three-factor model that includes size and value effects. They show that the returns on the stocks of small firms covary more with one another than with the returns on the stocks of large companies, and returns on high 
$\mathrm{B} / \mathrm{M}$ ratio (value) stocks covary more with one another than with returns on low B/M ratio (growth) stocks. In their model, SMB (small minus big), the difference between the returns on diversified portfolios of small and big stocks quantifies size effect, and HML (high minus low), the difference between the returns on diversified portfolios of high and low $\mathrm{B} / \mathrm{M}$ ratio stocks, quantifies value effect. Based on the Fama-French three-factor model, Carhart (1997) proposed a four-factor model that also reflects momentum effect and showed a short-term persistence in equity returns. Fama and French (2016) expanded their original model by adding two factors that convey information about profitability effect, Robust Minus Weak (RMW) and investment effect, Conservative Minus Aggressive (CMA). The paper demonstrated that securities with positive (negative) exposures to RMW and CMA capture high (low) expected returns. The advantage of this class is that the empirical findings always support their asset pricing models because the factors in multifactor models come from empirical tests. However, due to the lack of theoretical foundation, it is impossible to tell which model is complete. That is, financial scholars can always find new factors that can significantly explain a security's expected return.

Moreover, another class of studies develop the multifactor asset pricing models by considering high moments of asset returns, which started with Kraus and Litzenberger (1976). They derived a two-factor valuation model from a utility maximization problem and showed that systematic skewness, which is ignored by traditional CAPM, cannot be omitted in asset pricing. In their model, the asset return premium includes two parts: 1) the market beta multiplies marginal rates of substitution between expected wealth and standard deviation, and 2) the market gamma multiplies marginal rates of substitution between expected wealth and skewness. Harvey and 
Siddique (2000) used expected market return and expected square of market return as the two factors to capture the variation of stochastic discounting factor (SDF), and showed that skewness risk factor is economically essential in asset pricing models, even when considering the FamaFrench size and value factors. Dittmar (2002) expanded CAPM to four-moment by using a threefactor model. He added expected cube of market return as an extra factor, thereby bringing kurtosis and co-kurtosis into its model. However, a crucial assumption of these models is that market portfolio is efficient, which ensures the SDF can be well approximated as a polynomial in the return of a market portfolio. Chabi-Yo, Leisen, and Renault (2014) showed a three-fund separation theorem with risk-free rate, market portfolio, and skewness portfolio that gave the optimal hedge of the square market portfolio and supported that SDF is quadratic in market return. Although the high-moment asset pricing has theoretical supports from utility theory, it is impossible to incorporate all high moments into asset pricing models.

Opposite to the static analysis discussed in previous paragraphs, Merton (1976) suggested a critical assumption that the underlying stock return is captured only by a stochastic process with a continuous path, and he proposed a more general case that asset return is affected by both continuous and jump process. Based on Merton's jump-diffusion process, Todorov and Bollerslev (2010) and Bollerslev, Li, and Todorov (2016) proposed a new theoretical framework to decompose systematic risk, or beta, and showed that discontinuous beta, compared to continuous beta, entails significant risk premiums. They showed that market jumps reflect true information surprises more than continuous price moves do, and their discontinuous beta could reflect the systematic market price risk more accurately than standard CAPM betas do. However, there are 
several drawbacks intuitively. The first drawback is that they used logarithmic returns to compute betas. The logarithmic return is not additive in portfolio theory, which means that the portfolio return is not equal to the weighted average of security returns in the portfolio. But in a classical asset pricing model, the return must be additive, and a holding period return is used in traditional models. The second drawback is that the logarithmic return is normally distributed based on Merton's (1976) framework (Merton's assumption was still applied on the following papers). So the betas computed based on logarithmic returns are also symmetric. But if we use holding period returns, according to classical asset pricing theories, there are asymmetric components in systematic risk. Moreover, this asymmetry is very important in financial market and risk management. As pointed out in Kim and Zumwalt (1979) and Chen (1982), security behavior in bull and bear markets are different. They used up- and down-market betas to quantify this type of asymmetry, and they showed that investors expected to pay a premium for upside risk and receive a risk premium for downside variation of returns. Ang and Chen (2002) showed that correlation between U.S. stocks and the market are much more significant for downside moves than for upside moves. Campbell and Vuolteenaho (2004) proposed a model with good- and bad-beta and suggested that the bad cash-flow beta has a higher chance of risk than the good discount-rate beta. 


\section{Contributions}

In this dissertation, I develop a new risk measure, swap variance $(\mathrm{SwV})$, and apply it into portfolio theory and asset pricing. $\mathrm{SwV}$ is the moment combination from variance, so it conveys all information about a return's variation beyond only variance, which is the risk measure in Markowitz's portfolio theory. Furthermore, $\mathrm{SwV}$ is a converge form that estimates the infinite degrees of high moments, which keeps the simplicity of mean-variance theory. To investigate riskaverse investors' expected utility maximization using affine utility function, mean-swap variance $(\mathrm{MSwV})$ efficiency is consistent with expected utility maximization for all concave utility without any restriction on the form of either utility function or return distributions. Specifically, the MSwV efficiency is necessary and sufficient to the expected utility efficiency, as well as to second-degree stochastic dominance (SSD) efficiency (Hadar and Russell, 1969).

Based on the MSwV efficiency through expected utility maximization, I apply the MSwV approach to the conventional procedure of portfolio optimization in determining capital market equilibrium. As a result, similar in form to the classical CAPM, the beta coefficient derived from the MSwV model is a ratio of the co-swap variance between returns on an asset and those on the market portfolio over the market $\mathrm{SwV}$. Compared to the MV beta under the assumption of a rational decision maker, the distinction of $\mathrm{MSwV}$ from $\mathrm{MV}$ thus captures the behavioral biases of a human decision maker. Thus, the downside asymmetry in the MSwV model suggests lossaversion (Benartzi \& Thaler, 1995) when investors are unwilling to recognize loss and tend to afford more risk, while upside asymmetry demonstrates gain-preference (Kumar, 2009) that a 
human decision maker may tolerate more risk to pursue potential gain. Considering loss-aversion and gain-preference, the MSwV approach could quantify investors' expected utility without any restriction on the form of utility and return distribution functions.

The major contribution of this dissertation is the development of a portfolio theory that can capture the loss aversion and gain preference of a human decision maker. Based on the portfolio theory, a multifactor linear model is theoretically formulated. Precisely, the loss aversion (gain preference) factor is captured by the negative (positive) asymmetric beta, and the MV-beta captures the symmetric factor. Therefore, factor portfolios can be replicated by zero-cost (longshort) portfolios constructed from the sorted securities concerning the past asymmetric betas. 


\section{Chapter 2 \\ Mean-Swap Variance Portfolio Theory}




\section{Introduction}

As is well known, portfolio models provide a solution that separates the decision process from the question of utility maximization by restricting either the individual utility function or the assets' return distribution. The classical MV portfolio theory and CAPM assume investor utility functions are quadratic or the return distributions of assets are elliptically distributed. These assumptions have been subject to much controversy over the decades. Due to these restrictions, alternative risk-return measures have been proposed. The theory of SD for ranking investment choices does not restrict the class of utility functions, but rather, it derives weak conditions for separation based on probability distributions. The SD ranking rules consider the entire return distribution of assets and thus make no assumption about the form of the underlying probability distributions. Although general, the SD approach is subject to limitations. Levy (2015) noted that SD performs well in applied economics and finance when the problem is the preference for a single asset or policy. But in optimal portfolio selection, SD performs poorly in that one has to search through all possible combinations of assets to find the optimal one.

Alternative models such as the mean-Gini approach (Yitzhaki, 1982; Shalit \& Yitzhaki, 1984) and the mean-lower partial moment (LPM) model (Bawa \& Lindenberg, 1977; Price, Price \& Nantell, 1982; Harlow \& Rao, 1989) attempt to resolve the problems of SD optimization by transforming SD into a simple two-parameter framework. Nevertheless, since mean-Gini and mean-LPM efficiency are necessary but insufficient to the SD efficiency, the utility separation still 
fails to hold without further restrictions on probability distributions. ${ }^{1}$ To the best of my knowledge, for almost half a century, there is still no formal optimization produced for both necessarily and sufficiently constructing SD efficient portfolios that allow developing separation and asset pricing theorems. $^{2}$

In this dissertation, I formally identify all expected utilities as a function of the mean and quantity, called swap-variance $(\mathrm{SwV})$, without any restriction on the form of investors' utility function as well as that of assets' return distribution. ${ }^{3}$ This affine transformation of utility function serves as a theoretical foundation for developing SD optimization and equilibrium fundamentally. Mathematically, $\mathrm{SwV}$ is the twice expected difference of arithmetic and logarithmic returns adjusted by the mean and is a convergence of a polynomial weighted sum of infinite returnmoments:

$$
\mathrm{SwV}=2[E(R-r)-d \mu]=\left(\frac{\sigma}{1+\mu}\right)^{2}+\mathbb{A} \geq 0
$$

where $R$ is the one-period rate of return, $r=\ln (1+R), R-r \geq 0, E$ is the expectation operator, $\mu$ is the expected return of $R, d \mu=\mu-\ln (1+\mu), \sigma^{2}$ is the variance, $\mathbb{A}=\left[\sum_{k=3}^{\infty}(-1)^{k}\left(\frac{2}{k}\right) \frac{\mathcal{M}^{k}}{(1+\mu)^{k}}\right]$, and

\footnotetext{
${ }^{1}$ That is, the SD implies mean-Gin and/or mean-LPM dominance, but not vice versa.

${ }^{2}$ Although Post (2003) has made an important step in this direction in that he introduced a technique to find whether the market portfolio is second degree efficient relative to all diversified portfolios composed from a given set of assets, we still do not have a stochastic dominance equilibrium.

${ }^{3}$ It is well known in financial literature (e.g. Neuberger, 1994; Jiang \& Oomen, 2008) that the variance swap contract can be replicated by a portfolio strategy of shorting a log-contract and simultaneously longing rebalanced forward contracts of the underlying asset. The profit/loss of such replication strategy accumulates to a quantity that is proportional to the realized variance (RV), if the jump-tail of return distribution is absent. In a continuous-time limit, Jiang and Oomen (2008) showed that this quantity, which they call "swap variance ( $\mathrm{SwV}), "$ can be calculated by the accumulated difference between simple returns and log returns.
} 
$\mathcal{M}^{k}=E(R-\mu)^{k}$ is the $k$-th central moment of the return distribution, respectively. ${ }^{4}$ Precisely, the right-hand side of the equation (1) quantifies that $\mathrm{SwV}$ comprises two components. The first is a symmetric (quadratic) variation of returns measured by the mean-adjusted variance, and the second, denoted $\mathbb{A}$ and calculated merely by the difference between $\operatorname{SwV}$ and $\left(\frac{\sigma}{1+\mu}\right)^{2}$, characterizes the asymmetric (polynomial) variation of returns on a risky asset. Intuitively, the fundamental difference between $\mathrm{SwV}$ and variance can be graphically observed from the distinctions of the two random variables, $2(R-r)$ and $R^{2}$, accordingly (see Figure 1). Both variables are non-negative, but $2(R-r)$ is asymmetric in nature, and $R^{2}$ is less (higher) than $2(R-r)$ for negative (positive) $R$. This indicates that the variance understates (overstates) the downside (upside) variation if returns are asymmetrically distributed. Figure 1 also helps to acknowledge that the distinction between $S w V$ and variance is a summary statistic of the asymmetries in returns $(\mathbb{A})$.

\section{[Insert Figure 1 here]}

Noticeably, the alternating signs in the weighted sequence of third and higher order moments in the polynomial formulation of $\mathbb{A}$ suggest that the larger the positive (negative) odd moments then the smaller (larger) the SwV. Since the odd moments distinguish the prospect of

\footnotetext{
${ }^{4} \mathrm{I}$ assume asset returns are bounded with a finite range, $R \in[-1,1]$. Based on Taylor's series of the log-return around $\mu$, I have $r=\ln (1+R)=\ln (1+\mu)+\frac{R-\mu}{1+\mu}-\frac{(R-\mu)^{2}}{2(1+\mu)^{2}}+\sum_{k=3}^{\infty}(-1)^{k-1}\left(\frac{1}{k}\right) \frac{(R-\mu)^{k}}{(1+\mu)^{k}}$. Then, $2 E(R-r)=$ $2[\mu-\ln (1+\mu)]+\frac{E(R-\mu)^{2}}{(1+\mu)^{2}}+\sum_{k=3}^{\infty}(-1)^{k}\left(\frac{2}{k}\right) \frac{E(R-\mu)^{k}}{(1+\mu)^{k}}=2 d \mu+\frac{\sigma^{2}}{(1+\mu)^{2}}+\mathbb{A}$. Moreover, since SwV $=2[E(R-r)-d \mu]=2[\ln (1+E(R))-E(\ln (1+R))]$, and $\ln [E(\cdot)] \geq E[\ln (\cdot)]$ due to the concavity of logarithmic function, SwV must be non-negative.
} 
potential gain/loss, a significantly negative (positive) $\mathbb{A}$ is associated with a prospect of substantial gain (loss) or a possibility of profoundly positive (negative) returns. This indicates that a volatile distribution may not be necessarily risky, if the value of $\mathbb{A}$ is significantly negative. In short, upside (downside) asymmetries in returns lead to relatively low (high) risk exposure so that $\mathrm{SwV}$ is small (larger) than the variance. I explicitly apply this notion of asymmetry embedded in SwV to the theory of expected utility maximization and develop a model for preference of choice that is robust to risk-averse investors who dislike downside-losses but prefer potential upside-gains.

This dissertation reveals that using the mean and $\mathrm{SwV}$ as return-risk tradeoff statistics allows the derivation of both the necessary and sufficient condition for SD, enabling optimizing investors to discard from the efficient set prospects that are stochastically dominated by others. Therefore, under the $\mathrm{MSwV}$ framework, both the knowledge of all prospects' probability distribution and that of investors' preference functions are solved from the decision process with respect to utility maximization. Consequently, the $\mathrm{SwV}$ is able to replace the variance, and the coswap variance can substitute co-variance needed in portfolio theory whenever MV fails to provide consistent results of the utility maximization. This dissertation formulates the $\mathrm{SwV}$ of a portfolio as a weighted sum of co-swap variances of asset returns with the market return and shows that the co-swap variance characterizes all order co-moments of returns between an asset and the portfolio. The efficient set of MSwV portfolios can thus be determined by minimizing a portfolio's SwV for each given mean return. With a risk-free asset, this essay formulates the Sharpe ratio as well as the Modigliani-Modigliani (M2) risk-adjusted performance measure in the MSwV space. The MSwV performance indexes are superior to the classical approaches in that they are sensitive to 
asymmetries, tail thickness, and other characteristics in return distributions that investors care about. Furthermore, as with the MV model, this dissertation applies the MSwV approach to derive the pricing of risky assets in capital market equilibrium. Since my proposed method is independent of the distribution chosen, the asset pricing model of $\mathrm{MSwV}$ provides a consistent evaluation of market systematic risk without imposing any distributional assumption.

The rest of this dissertation is organized as follows: Section II derives the expected utility as a function of mean and $\mathrm{SwV}$. The $\mathrm{SD}$ rules based on distributional moments and $\mathrm{SwV}$ are then defined and proved. I also illustrate that the MVA model serves as an extension of the MSwV and MV approaches for incorporating with asymmetry-preference. Section III shows the derivation of the co-swap variance $(\mathrm{CoSwV})$ as well as its application to MCSD orderings. Section IV demonstrates the application of MSwV and MVA to the determination of SD optimal portfolios. Section V illustrates the empirical analysis, and section VI contains concluding remarks. 


\section{Swap-Variance, Asymmetry, and Stochastic Dominance}

Stochastic dominance provides a way of analyzing risky investment decisions when an investor's utility function $U$ is not fully known but is presumed to be in a class of real-valued functions. An asset $i$ unconditionally and stochastically dominates an asset $j$, if and only if $E U\left(R_{i}\right) \geq E U\left(R_{j}\right)$, where $E U\left(R_{i}\right)$ and $E U\left(R_{j}\right)$ are expected utilities of returns on assets $i$ and $j$, respectively. Without loss of generality, I apply the Taylor-series of the utility function $U(R)$ about mean return, and with some mathematical arrangements, the utility function can be expressed by the following equation:

$$
U(R)=U(\mu)+U^{\prime}(\mu)(R-\mu)+\mathbb{U}(U, \mu, R)[2(R-r)-2 d \mu]
$$

where $U^{\prime} \geq 0, \mathbb{U}(U, \mu, R)=\sum_{k=2}^{\infty} w_{k} \mathfrak{U}^{(k)}$, is a weighted sum of all derivatives of the utility functions. Specifically, $\mathfrak{U}^{(k)}=\left[\frac{[-(1+\mu)]^{k}}{2(k-1) !} U^{(k)}(\mu)\right]$, where $U^{(k)}$ is the $k$-th derivative of the utility function, and $w_{k}=\left[\frac{2(-1)^{k}}{k}\left(\frac{R-\mu}{1+\mu}\right)^{k}\right] /[2(R-r)-2 d \mu] .{ }^{5}$ Next, based on the assumption that utility function and the probability distribution function are continuous and differentiable on $R$, I apply the mean value theorem for integrals in calculus to the expected utility function of returns such that:

\footnotetext{
${ }^{5} U(R)=U(\mu)+U^{\prime}(\mu)(R-\mu)+\sum_{k=2}^{\infty} \frac{1}{k !} U^{(k)}(\mu)(R-\mu)^{k}=U(\mu)+U^{\prime}(\mu)(R-\mu)+$ $\sum_{k=2}^{\infty}\left[\frac{(-1)^{k}(1+\mu)^{k}}{2(k-1) !} U^{(k)}(\mu)\right]\left[\frac{2(-1)^{k}}{k} \frac{(R-\mu)^{k}}{(1+\mu)^{k}}\right]$. Now, let $\mathfrak{U}^{(k)}=\left[\frac{(-1)^{k}(1+\mu)^{k}}{2(k-1) !} U^{(k)}(\mu)\right], B_{k}=\left[\frac{2(-1)^{k}}{k} \frac{(R-\mu)^{k}}{(1+\mu)^{k}}\right]$, $B=\frac{1}{(1+\mu)}(R-\mu)+\sum_{k=2}^{\infty} B_{k}=2(R-r)-2 d \mu$, and $w_{k}=\frac{B_{k}}{B}$. Define $\mathbb{U}(U, \mu, R)=\sum_{k=2}^{\infty} w_{k} \mathfrak{U}^{(k)}=$ $\frac{1}{B} \sum_{k=2}^{\infty} \mathfrak{U}^{(k)} B_{k}$. We have $\sum_{k=2}^{\infty} \mathfrak{U}^{(k)} B_{k}=\mathbb{U}(U, \mu, R)[2(R-r)-2 d \mu]$, and consequently, $U(R)=U(\mu)+$ $U^{\prime}(\mu)(R-\mu)+\mathbb{U}(U, \mu, R)[2(R-r)-2 d \mu]$.
} 


$$
E U(R)=U(\mu)+\mathbb{U}\left(U, \mu, R^{o}\right) \cdot \mathrm{SwV}
$$

where $=E(R), \operatorname{SwV}=2 E(R-r)-2 d \mu$, as shown in (1), and $\mathbb{U}\left(U, \mu, R^{o}\right)$ is the function of $\mathbb{U}(\cdot)$ at some point of return, $R^{o} \in(-1,1)$, so that equation (3) equals the expected value of equation (2). ${ }^{6}$ It is important to note that equation (3) holds for all forms of the utility functions in which $\mathbb{U}\left(U, \mu, R^{o}\right)$ is negative, zero, and positive for concave, linear, and convex function, respectively. $^{7}$

\section{A. MSwV Stochastic Dominance Rules}

The implication of equation (3) is crucial. First, with no assumption on the form of either utility function or that of return distribution, the expected utility can be characterized as a function of the mean $(\mu)$ and $\mathrm{SwV}$. Second, the mean-SwV transformation makes the consistency between the expected utility maximization and the prospect theory, where the probability distribution is not necessarily required in decision making.

\footnotetext{
${ }^{6}$ Let $f(R)$ be the continuous probability density function of return distribution, and assume $R \in[-1,1]$. Based on the mean value theorem for integrals, there exists $R^{o}$ in $(-1,1)$ such that $E U(R)=U(\mu)+\int_{-1}^{1} \mathbb{U}(U, \mu, R)[2(R-$ $r)-2 d \mu] f(R) d R=U(\mu)+\mathbb{U}\left(U, \mu, R^{o}\right) \int_{-1}^{1}[2(R-r)-2 d \mu] f(R) d R=U(\mu)+\mathbb{U}\left(U, \mu, R^{o}\right) \cdot \operatorname{SwV}$.

${ }^{7}$ For any risk-averse investor, the concave utility must be no greater than the equivalently risk-neutral utility (i.e., graphically, the tangency line at any return level) due to the utility-discount of risk. That is, $E U(R)-U(\mu) \leq 0$. Since $E(R-r)-d \mu=\ln (1+\mu)-E[\ln (1+R)] \geq 0$ because of the concavity of logarithmic function, i.e., $\mathbb{U}\left(U, \mu, R^{o}\right)=\frac{E U(R)-U(\mu)}{(\mathrm{SwV}-2 d \mu)} \leq 0$. On the other hand, for convex utilities, $E U(R)-U(\mu) \geq 0$, and $\mathbb{U}\left(U, \mu, R^{o}\right)>0$.
} 
Theorem 1 (First Degree Stochastic Dominance)

Let $R_{i}$ and $R_{j}$ be two uncertain prospects. Based on equation (3), the conditions, $\mu_{i} \geq \mu_{j}$ and $\mathrm{SwV}_{i}=\mathrm{SwV}_{j}$, are necessary and sufficient to have $E U\left(R_{i}\right) \geq E U\left(R_{j}\right)$ for all utility functions.

Theorem 2 (Second Degree Stochastic Dominance: The Mean-Swap Variance Dominance) Let $R_{i}$ and $R_{j}$ be two uncertain prospects. Based on equation (3), the conditions, $\mu_{i} \geq \mu_{j}$ and $\mathrm{SwV}_{i} \leq \mathrm{SwV}_{j}$, are necessary and sufficient conditions to ensure that $E U\left(R_{i}\right) \geq E U\left(R_{j}\right)$ for all concave utility functions.

The proof of Theorems 1 and 2 is given in the Appendix. The main contribution of the above theorems is the convergence of the SD rules from the comparison of entire probability distributions to the two-statistic (MSwV) analysis that retains the same simplicity as the MV model. The theorems indicate that the $\mathrm{SwV}$ is more generalized risk proxy than the variance is for all riskaverse expected utility maximizers. Notably, there are risk characters, embedded in the $\mathrm{SwV}$, other than return volatility that risk-averse investors care about and the variance fails to measure them.

The following numerical example shows that the MSwV approach correctly discriminates SSD inefficient assets, but the MV model fails to do so. Suppose returns on two securities, $R_{1}$ and $R_{2}$, that are lognormally distributed, where $r_{1} \sim N(0.1,0.22)$ and $r_{2} \sim N(-0.15,0.24)$, respectively. Apparently, $R_{2}$ is stochastically dominated by $R_{1}$, and a profitable investment can be formed by a long/short position between $R_{1}$ and $R_{2}$, if investors know the form of return distributions. Now, 
without the knowledge of distributional forms, suppose investors employ the three methods, MV, SSD and MSwV for security selection. I have the following results:

\begin{tabular}{cccc}
\hline & \multicolumn{3}{c}{ Log-Normality } \\
\cline { 2 - 4 } & Security 1 & Security 2 \\
\hline$\mu$ & 0.132 & $>$ & -0.114 \\
$\sigma^{2}$ & 0.0636 & $>$ & 0.0465 \\
$\mathrm{SwV}$ & 0.0484 & $<$ & 0.0576 \\
$S S D$ & $\int_{-1}^{R} \frac{1}{2}+\frac{1}{2} \operatorname{erf}\left[\frac{\ln (1+t)-0.1}{0.22 \sqrt{2}}\right] d t^{8}$ & $<9$ & $\int_{-1}^{R} \frac{1}{2}+\frac{1}{2} \operatorname{erf}\left[\frac{\ln (1+t)+0.15}{0.24 \sqrt{2}}\right] d t$ \\
\hline
\end{tabular}

According to the MV tradeoff $\left(\sigma_{1}^{2}>\sigma_{2}^{2}\right.$ and $\left.\mu_{1}>\mu_{2}\right)$, incorrectly, no dominance between the two securities makes them as efficient as to each other. Nevertheless, consistent with SSD ordering, the $\mathrm{MSwV}$ rule $\left(\mu_{1}>\mu_{2}\right.$, but $\left.\mathrm{SwV}_{1}<\mathrm{SwV}_{2}\right)$ enables one to correctly discriminate the dominated security $R_{2}$ from the dominating one, $R_{1}$. This example highlights a significant bias of the traditional MV model and the superiority of the MSwV analysis under the conventional assumption of log-normality. The implication of this example is that if returns on risky assets are asymmetrically distributed, then many efficient assets or portfolios determined by the MV analysis are in fact inefficient. The MSwV, on the other hand, used as conveniently as the MV, provides unbiased results.

\footnotetext{
${ }^{8} \operatorname{erf}(\cdot)$ is error function, and it is monotonically increasing in its whole definition of domain.

${ }^{9}$ The "<" holds when the upper bound of holding period return is 16.28 , so I consider asset 1 second-degree stochastically dominates asset 2 .
} 


\section{B. $\quad$ MVA and Stochastic Dominance Efficiency}

To further examine how return-variation other than volatility affects expected utility of investors, I separate the second order of return-moment from the $\mathrm{SwV}$ and focus on the asymmetries in returns. Again, without loss of generality, the utility function (2) can be further decomposed as follows:

$$
U(R)=U(\mu)+U^{\prime}(\mu)(R-\mu)+\frac{1}{2} U^{\prime \prime}(\mu)(R-\mu)^{2}+\mathbb{U}^{(3)}(U, \mu, R) \cdot \mathcal{A}
$$

Where $\mathcal{A}=[2(R-r)-2 d \mu]-\left(\frac{R-\mu}{1+\mu}\right)^{2}, \mathbb{U}^{(3)}(U, \mu, R)=\sum_{k=3}^{\infty} \omega_{k} \mathfrak{U}^{(k)}<0$, and where $\mathfrak{U}^{(k)}=$ $\left[\frac{(-1)^{k}(1+\mu)^{k}}{2(k-1) !} U^{(k)}(\mu)\right]$ and $\omega_{k}=\left[\frac{2(-1)^{k}}{k}\left(\frac{R-\mu}{1+\mu}\right)^{k}\right] / \mathcal{A} \cdot{ }^{10}$ I note that $\mathcal{A}$ depicts the asymmetries in return (see Figure 1 for the case that $\mu=0$ ). The quantity $\mathcal{A}$ is negative (positive) if $R$ is greater (less) than $\mu$. Further, the inequality, $\mathbb{U}^{(3)}(U, \mu, R)<0$, holds if $U^{\prime \prime \prime}>0 .{ }^{11}$ Now, from (1), (3), and

${ }^{10} U(R)=U(\mu)+U^{\prime}(\mu)(R-\mu)+\frac{1}{2} U^{\prime \prime}(\mu)(R-\mu)^{2}+\sum_{k=3}^{\infty}\left[\frac{(-1)^{k}(1+\mu)^{k}}{2(k-1) !} U^{(k)}(\mu)\right]\left[\frac{2(-1)^{k}}{k} \frac{(R-\mu)^{k}}{(1+\mu)^{k}}\right]$. Now, let $\mathfrak{U}^{(k)}=$ $\left[\frac{(-1)^{k}(1+\mu)^{k}}{2(k-1) !} U^{(k)}(\mu)\right], B_{k}=\left[\frac{2(-1)^{k}}{k} \frac{(R-\mu)^{k}}{(1+\mu)^{k}}\right], \mathcal{B}=\frac{1}{(1+\mu)}(R-\mu)+\sum_{k=3}^{\infty} B_{k}=[2(R-r)-2 d \mu]-\left(\frac{R-\mu}{1+\mu}\right)^{2}$, and $\omega_{k}=\frac{B_{k}}{\mathcal{B}}$. Define $\mathbb{U}^{(3)}(U, \mu, R)=\sum_{k=3}^{\infty} w_{k} \mathfrak{U}^{(k)}=\frac{1}{\mathcal{B}} \sum_{k=3}^{\infty} \mathfrak{U}^{(k)} B_{k}$. We have $\sum_{k=3}^{\infty} \mathfrak{U}^{(k)} B_{k}=\mathbb{U}^{(3)}(U, \mu, R)\{[2(R-$ $\left.r)-2 d \mu]-\left(\frac{R-\mu}{1+\mu}\right)^{2}\right\}$, and consequently, $U(R)=U(\mu)+U^{\prime}(\mu)(R-\mu)+\frac{1}{2} U^{\prime \prime}(\mu)(R-\mu)^{2}+$ $\mathbb{U}^{(3)}(U, \mu, R)\left\{[2(R-r)-2 d \mu]-\left(\frac{R-\mu}{1+\mu}\right)^{2}\right\}$.

${ }^{11}$ This is to prove that if $U^{\prime \prime \prime}(R)>0$, then $\mathbb{U}^{(3)}(U, \mu, R)<0$. Take the Taylor Expansion on $U^{\prime \prime \prime}(R)$ around $\mu$, $U^{\prime \prime \prime}(R)=U^{\prime \prime \prime}(\mu)+U^{(4)}(\mu)(R-\mu)+\sum_{k=5}^{\infty} \frac{U^{(k)}(\mu)}{(k-3) !}(R-\mu)^{k-3}$. Define $q(R)=\int_{\mu}^{R} U^{\prime \prime \prime}(s) d s, q(R)=U^{\prime \prime \prime}(\mu)(R-$ $\mu)+\frac{U^{(4)}(\mu)}{2}(R-\mu)^{2}+\sum_{k=5}^{\infty} \frac{U^{(k)}(\mu)}{(k-2) !}(R-\mu)^{k-2}$. Since $U^{\prime \prime \prime}(R)>0, q(R)>0$ as $R>\mu$ while $q(R)<0$ as $R<\mu$. Now consider $Q(R)=\int_{\mu}^{R} q(s) d s$. Then $Q(R)=\frac{U \prime \prime \prime}{2 !}(\mu)(R-\mu)^{2}+\frac{U^{(4)}(\mu)}{3 !}(R-\mu)^{3}+\sum_{k=5}^{\infty} \frac{U^{(k)}(\mu)}{(k-1) !}(R-\mu)^{k-1}$. Because of the property of $q(R), Q(R)$ reaches its minimum as $R=\mu$. Thus, $Q(R)>0$. ;'Now, consider $\mathbb{Q}(R)=$ $\int_{\mu}^{R} Q(s) d s$. Then $\mathbb{Q}(R)=\frac{U ! \prime \prime(\mu)}{3 !}(R-\mu)^{3}+\frac{U^{(4)}(\mu)}{4 !}(R-\mu)^{4}+\sum_{k=5}^{\infty} \frac{U^{(k)}(\mu)}{k !}(R-\mu)^{k}$. Since $Q(R)>0$ for all $R$. 
(4), I can rewrite the expected utility as a function of mean, variance, and the asymmetry measure $\mathbb{A}$ as follows:

$$
E U(R)=U(\mu)+\frac{1}{2} U^{\prime \prime}(\mu) \cdot \sigma^{2}+\mathbb{U}^{(3)}\left(U, \mu, R^{o}\right) \cdot \mathbb{A}
$$

where $\mathbb{A}=\operatorname{SwV}-\left(\frac{\sigma}{1+\mu}\right)^{2}$. Since $\mathbb{U}^{(3)}\left(U, \mu, R^{o}\right)$ is non-positive, the larger (smaller) the asymmetric risk and the more positive (negative) the value of $\mathbb{A}$, the lower (higher) the expected utility. Also, since the odd higher moments embedded in $\mathbb{A}$ distinguish the prospect of potential gain/loss, a high (low) $\mathbb{A}$ results from either a significant chance of loss (gain) or a probability of substantially negative (positive) returns. In the next theorem, I show that for all risk-averse investors who also prefer (dislike) positively (negatively) asymmetric payoffs, the preference of choice can be made by the orders of the three parameters: mean, variance, and asymmetry, respectively.

Theorem 3 (The Mean-Volatility-Asymmetry (MVA) Dominance and Efficiency) Let $R_{i}$ and $R_{j}$ be two uncertain prospects. Based on equation (5), these inequalities, $\mu_{i} \geq \mu_{j}, \sigma_{i} \leq$ $\sigma_{j}$, and $\mathbb{A}_{i} \leq \mathbb{A}_{j}$ are the sufficient condition for the expected utility inequality, $E U\left(R_{i}\right) \geq E U\left(R_{j}\right)$, and for all utility functions with $U^{\prime}>0, U^{\prime \prime}<0$, and $U^{\prime \prime \prime}>0$. Since MVA dominance must be the SSD dominance but not vice versa, the SSD efficient set is thus a subset of the MVA efficiency.

$\mathbb{Q}(R)$ is a monotonic increasing function with $\mathbb{Q}(\mu)=0$, and thus $\mathbb{Q}(R)>0$ as $R>\mu$ while $\mathbb{Q}(R)<0$ as $R, \mu$. Compared to equation $(4), \mathbb{Q}(R)=\mathbb{U}^{(3)}(U, \mu, R) \cdot \mathcal{A}$. So $\mathbb{U}^{(3)}(U, \mu, R)<0$ for all $R$. 
The proof of Theorem 3 is similar to that of Theorems 1 and 2, except that the dominance of MVA is not a necessary condition of expected utility. ${ }^{12}$ Intuitively, the MVA model based on (4) and (5) takes both aversion of symmetric volatility $\left(U^{\prime \prime}<0\right)$ and that of asymmetric variation $\left(\mathbb{U}^{(3)}<0\right)$ into consideration. Also, from (4), the inequality of $U^{\prime \prime \prime}>0$ ensures that of $\mathbb{U}^{(3)}<0$. That indicates the efficient assets in the MVA set include those that are chosen by investors who prefer upside skewed outcomes as well as those who are downside asymmetry averse. Noticeably, the MVA approach reduces to the MV model if either $U^{\prime \prime \prime}$ or $\mathbb{A}$ is zero.

To illustrate that some SSD (or MSwV) inefficient assets for risk-averse investors may not be viewed as the inferior assets for those who also prefer positively asymmetric outcomes, I use a simple counterexample. Consider two random prospects $X$ and $Y$ with discrete distributions of returns. Both $X$ and $Y$ have two possible investment outcomes: -0.20 with a probability of $90 \%$ and 0.65 with a probability of $10 \%$, as well as -0.20 with a probability of $40 \%$ and -0.05 with a probability of $60 \%$, respectively. We summarize the key statistics as follows:

\footnotetext{
${ }^{12}$ Specifically, the non-necessity of MVA to expected utility dominance is because it is impossible that both $\frac{U^{\prime \prime}(\cdot)}{\mathbb{U}^{(3)}(\cdot)}$ and $\frac{U^{\prime}(\cdot)}{\mathbb{U}^{(3)}(\cdot)}$ simultaneously approach zero for non-decreasing concave utility functions with a non-negative $U^{\prime \prime \prime}$.
} 


\begin{tabular}{|c|c|c|c|c|c|c|}
\hline & & \multicolumn{5}{|c|}{ Upside Gain Preference } \\
\hline & & $X$ & Prob. & & $Y$ & Prob. \\
\hline & Outcome 1 & -0.20 & $90 \%$ & & -0.20 & $40 \%$ \\
\hline & Outcome 2 & 0.65 & $10 \%$ & & -0.05 & $60 \%$ \\
\hline$\mu$ & & -0.115 & & $<$ & -0.110 & \\
\hline$\sigma^{2}$ & & 0.065 & & $>$ & 0.005 & \\
\hline SwV & & 0.057 & & $>$ & 0.007 & \\
\hline $\mathbb{A}$ & & -0.026 & & $<$ & 0.000 & \\
\hline
\end{tabular}

Based on the $\mathrm{MSwV}$ and $\mathrm{MV}$ ranking rules, asset $Y$ is superior to $X$ in that the mean $(\mathrm{SwV}$ or variance) of $Y$ is higher (lower) than that of $X$. Also, from the aspect of the probability distribution, $X$ is also dominated by $Y$ under the SSD rule. Nevertheless, investors may be unwilling to discriminate $X$ as a dominated choice in that a prospect of dramatic positive-payoff (0.65) could be attractive as compared with the alternative $Y$ that has all negative investment outcomes. Consequently, if I take those investors who care about the upside potential into consideration, $X$ may then be as efficient as $Y$ in the risk-return tradeoff. The MVA model can detect this efficiency; correctly, the negative $\mathbb{A}$ shows that asset $X$ has positively asymmetric (skewed) payoff and thus low asymmetric risk, which increases the expected utility as shown in (5). For a graphical illustration, I depict the relationship of efficiency among the first-degree 
stochastic dominance (FSD), the mean-variance-asymmetry(MVA), the second-degree stochastic dominance (SSD), and the mean-variance (MV) in the following chart:

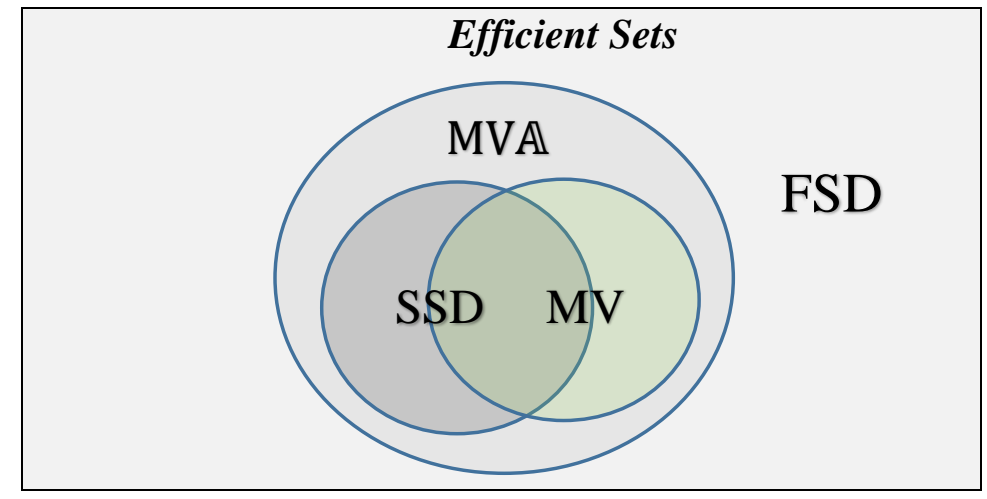

Apparently, the investment alternative $X$ in the previous example can be viewed as a lottery-type security, defined by Kumar (2009), that has low negative expected returns, high variance, and a small probability of a substantial payoff (i.e., a significantly negative $\mathbb{A}$ ). My analysis above indicates that the lottery-type securities, although they are dominated assets under the SSD and MV framework, could still be expected to be utility efficient for investors who have preference of upside potential even if they are risk-averse in general. Therefore, the traditional methodologies of security selection and portfolio efficiency analysis under the classical riskaversion assumption may be too restrictive.

In addition to the upside gain-preference, the MSwV and MVA approaches are also useful in detecting investors' aversion toward downside losses (disappointment), which the MV model fails to do. ${ }^{13}$ For example, consider two mutually exclusive investment projects, $G$ and $H$, have an

13 The downside asymmetry-aversion is closely related to the notion of disappointment aversion in Gul (1991). 
almost identical mean return. As shown in the following table, $G$ dominates $H$ in the mean-variance tradeoff in that the variance of project $G(0.014)$ is lower than that of project $H(0.016)$ :

\begin{tabular}{|c|c|c|c|c|c|c|}
\hline & & \multicolumn{5}{|c|}{ Downside Loss Aversion } \\
\hline & & $G$ & Prob. & & $H$ & Prob. \\
\hline & Outcome 1 & 0.18 & $90 \%$ & & 0.01 & $50 \%$ \\
\hline & Outcome 2 & -0.225 & $10 \%$ & & 0.26 & $50 \%$ \\
\hline$\mu$ & & 0.140 & & $>$ & 0.135 & \\
\hline$\sigma^{2}$ & & 0.015 & & $<$ & 0.016 & \\
\hline SwV & & 0.014 & & $>$ & 0.012 & \\
\hline $\mathbb{A}$ & & 0.003 & & $>$ & 0.000 & \\
\hline
\end{tabular}

Therefore, project $H$ is undoubtedly out of the MV efficient set. Nevertheless, from the prospect payouts shown in the above table, downside loss-averse investors could view $H$ as a more efficient investment choice than $G$ due to $G$ 's substantial loss of -0.225 even though the possibility of occurrence is relatively small, where, attractively, the investment returns of alternative $H$ are all positive. In fact, $H$ stochastically dominates $G$ because $G$ has a higher $\mathrm{SwV}$ than $H$, and the downside asymmetry-loss $(\mathbb{A})$ of project $G$ is greater than that of project $H$ as well. In short, unlike the variance, the sign of $\mathbb{A}$ derived from the $\mathrm{SwV}$ provides valuable indications for the preference of choice between the upside gain-preference and the downside loss-aversion. 
Although the simplicity of $\mathrm{MSwV}$ and $\mathrm{MV} \mathbb{A}$ rules shown in the above theorems demonstrates their superiority to the conventional SD approach, the goal of this dissertation is to apply these theorems to the development of SD portfolio efficiency and equilibrium, consisting with the notion of expected utility maximization. In the next section, I extend the MSwV and MVA to the marginal and conditional ordering conditions of assets within a portfolio for serving as an essential step toward the development of SD optimization and capital market equilibrium. 


\section{Co-SwV, Co-Asymmetry, and MCSD}

Let $R_{p}\left(=\sum_{i=1}^{N} w_{i} R_{i}\right)$ be the return on a core portfolio of $N$ risky assets, where $w_{i}$ is the share of wealth invested in asset $i$, and $\sum_{i=1}^{N} w_{i}=1$. I assume investors are maximizing their expected utility of $R_{p}$. Shalit and Yitzhaki (1984) showed this inequality

$$
E\left[U^{\prime}\left(R_{p}\right)\left(R_{i}-R_{j}\right)\right] \geq 0
$$

is the necessary and sufficient condition for all risk-averse investors to prefer the marginal increase of the share of one asset over another in the core portfolio. In other words, asset $i$ is said to marginally and conditionally stochastically dominate (MCSD) asset $j$, if and only if the inequality (6) holds.

\section{A. The Co-Swap Variance and MCSD}

Analogical to (3), I transform the difference of expected marginal utility between returns on component assets $i$ and $j$ of a portfolio $p$ as:

$$
E\left[U^{\prime}\left(R_{p}\right)\left(R_{i}-R_{j}\right)\right]=U^{\prime}\left(R_{p}\right)\left(\mu_{i}-\mu_{j}\right)+\mathbb{U}\left(U, \mu_{p}, R_{p}^{o}\right)\left[\operatorname{CoSwV}\left(R_{i}, R_{p}\right)-\operatorname{CoSwV}\left(R_{j}, R_{p}\right)\right]
$$

where $\operatorname{CoSwV}\left(R_{i}, R_{p}\right)$ is the co-swap variance $(\mathrm{CoSwV})$ between returns on asset $i$ and those on

the portfolio, and $\mathbb{U}\left(U, \mu_{p}, R_{p}^{o}\right)$, previously defined in (3), is non-positive in value. ${ }^{14}$ The formulation of the $\mathrm{CoSwV}$ is shown in the following equation:

\footnotetext{
${ }^{14}$ Equation (7) can be derived as follows: $E\left[U^{\prime}\left(R_{p}\right)\left(R_{i}-R_{j}\right)\right]=E\left[U^{\prime}\left(R_{p}\right)\left(\mu_{i}-\mu_{j}\right)\right]+E\left\{U^{\prime}\left(R_{p}\right)\left[\left(R_{i}-\mu_{i}\right)-\right.\right.$ $\left.\left.\left(R_{j}-\mu_{j}\right)\right]\right\}$, where $E\left\{U^{\prime}\left(R_{p}\right)\left[\left(R_{i}-\mu_{i}\right)-\left(R_{j}-\mu_{j}\right)\right]\right\}=E\left\{\left[U^{\prime}\left(\mu_{p}\right)+\sum_{k=2}^{\infty} \frac{1}{k !} U^{(k)}\left(\mu_{p}\right)\left(R_{p}-\mu_{p}\right)^{k-1}\right]\left[\left(R_{i}-\mu_{i}\right)-\right.\right.$
} 


$$
\begin{aligned}
\operatorname{CoSwV}\left(R_{i}, R_{p}\right) & =2 E\left[\left(\frac{R_{i}-\mu_{i}}{R_{p}-\mu_{p}}\right)\left(R_{p}-r_{p}\right)\right]-2 d \mu_{p} \\
& =\frac{\operatorname{Cov}\left(R_{i}, R_{p}\right)}{\left(1+\mu_{p}\right)^{2}}+\sum_{k=3}^{\infty}(-1)^{k}\left(\frac{2}{k}\right) \frac{\operatorname{CoN}^{k}\left(R_{i}, R_{p}\right)}{\left(1+\mu_{p}\right)^{k}}
\end{aligned}
$$

where $r_{p}=\ln \left(1+R_{p}\right), \quad d \mu_{p}=\mu_{p}-\ln \left(1+\mu_{p}\right), \quad \operatorname{CoV}\left(R_{i}, R_{p}\right)=E\left[\left(R_{i}-\mu_{i}\right)\left(R_{p}-\mu_{i}\right)\right], \quad$ and $\operatorname{CoM}^{k}\left(R_{i}, R_{p}\right)=E\left[\left(R_{i}-\mu_{i}\right)\left(R_{p}-\mu_{p}\right)^{k-1}\right]$ is the $k$-th order co-moment between $R_{i}$ and $R_{p}$, accordingly. ${ }^{15}$

Equation (7) shows that the marginal expected utility of return can be characterized by the mean and $\mathrm{CoSwV}$ without any restriction on the form of the utility functions and that of the return distributions. Although the covariance plays the key role for risk-diversification, the higher orders of co-moments between assets and the portfolio, from equations (7) and (8), are crucial for the determination of portfolio efficiency. I show, in the following theorems, that the mean and CoSwV can be employed to determine the necessary and sufficient condition for the MCSD.

$\left.\left.\left(R_{j}-\mu_{j}\right)\right]\right\}=E \sum_{k=2}^{\infty} \frac{\left(1+\mu_{p}\right)^{k}}{2(k-1) !}(-1)^{k} U^{(k)}\left(\mu_{p}\right)\left\{\frac{(-1)^{k}}{k\left(1+\mu_{p}\right)^{k}}\left(R_{p}-\mu_{p}\right)^{k-1}\left[\left(R_{i}-\mu_{i}\right)-\left(R_{j}-\mu_{j}\right)\right]\right\}$ $=\mathbb{U}\left(U, \mu_{p}, R_{p}^{o}\right)\left[\operatorname{CoSwV}\left(R_{i}, R_{p}\right)-\operatorname{CoSwV}\left(R_{j}, R_{p}\right)\right]$.

${ }^{15}$ The derivation of the closed-formed $\operatorname{CoSwV}$ is as follows: $\operatorname{CoSwV}\left(R_{i}, R_{p}\right)=\sum_{k=2}^{\infty} \frac{2(-1)^{k}}{k\left(1+\mu_{p}\right)^{k}} \int_{-1}^{b}\left(R_{i}-\right.$ $\left.\mu_{i}\right)\left(R_{p}-\mu_{p}\right)^{k-1} d F\left(R_{i}, R_{p}\right)=\int_{-1}^{b} \frac{\left(R_{i}-\mu_{i}\right)}{\left(R_{p}-\mu_{p}\right)}\left[\sum_{k=2}^{\infty} \frac{2(-1)^{k}}{k\left(1+\mu_{p}\right)^{k}}\left(R_{p}-\mu_{p}\right)^{k}\right] d F\left(R_{i}, R_{p}\right)=2 E\left[\left(\frac{R_{i}-\mu_{i}}{R_{p}-\mu_{p}}\right)\left(R_{p}-r_{p}\right)\right]-2 d \mu_{p}$. 


\section{Theorem 4 (Mean-CoSwV MCSD)}

Assume $R_{i}$ and $R_{j}$ are two uncertain prospects in a portfolio $R_{p}$. Based on equation (7), the conditions $\mu_{i} \geq \mu_{j}$ and $\operatorname{CoSwV}\left(R_{i}, R_{p}\right) \leq \operatorname{CoSwV}\left(R_{j}, R_{p}\right)$ are necessary and sufficient for $R_{i}$ to marginally and conditionally dominate $R_{j}$ for all concave utilities. ${ }^{16}$

If returns on assets are symmetrically distributed, then from the above theorem, risk averse investors prefer to hold those assets with the larger expected return and lower correlations with the core portfolio.

Further, let $\operatorname{CoA}\left(R_{i}, R_{p}\right)=\left[\operatorname{CoSwV}\left(R_{i}, R_{p}\right)-\frac{\operatorname{Cov}\left(R_{i}, R_{p}\right)}{\left(1+\mu_{p}\right)^{2}}\right]$ be the sensitivity of $i$-th asset's return to the symmetric (asymmetric) price movement of the core portfolio. Equation (7) can then be expanded as:

$$
\begin{aligned}
E\left[U^{\prime}\left(R_{p}\right)\left(R_{i}-R_{j}\right)\right]= & U^{\prime}\left(R_{p}\right)\left(\mu_{i}-\mu_{j}\right)+U^{\prime \prime}\left(R_{p}\right)\left[\operatorname{CoV}\left(R_{i}, R_{p}\right)-\operatorname{CoV}\left(R_{j}, R_{p}\right)\right] \\
& +\mathbb{U}^{(3)}\left(U, \mu_{p}, R_{p}^{o}\right)\left[\operatorname{CoA}\left(R_{i}, R_{p}\right)-\operatorname{CoA}\left(R_{j}, R_{p}\right)\right]
\end{aligned}
$$

where $\operatorname{CoV}\left(R_{i}, R_{p}\right)$ is the covariance between returns on asset $i$ and those on the portfolio, and $\mathbb{U}^{(3)}\left(U, \mu_{p}, R_{p}^{o}\right)$, previously defined in (5), is non-positive in value. ${ }^{17}$

\footnotetext{
${ }^{16}$ Analogous to these of Theorems 2 and 3, we omit the proof of this theorem.

17 The derivation of equation (10) is shown as follows: $E\left[U^{\prime}\left(R_{p}\right)\left(R_{i}-R_{j}\right)\right]=E\left[U^{\prime}\left(R_{p}\right)\left(\mu_{i}-\mu_{j}\right)\right]+$ $E\left\{U^{\prime}\left(R_{p}\right)\left[\left(R_{i}-\mu_{i}\right)-\left(R_{j}-\mu_{j}\right)\right]\right\}$, where $E\left\{U^{\prime}\left(R_{p}\right)\left[\left(R_{i}-\mu_{i}\right)-\left(R_{j}-\mu_{j}\right)\right]\right\}=E\left\{\left[U^{\prime}\left(\mu_{p}\right)+U^{\prime \prime}\left(\mu_{p}\right)\left(R_{p}-\mu_{p}\right)+\right.\right.$ $\left.\left.\sum_{k=3}^{\infty} \frac{1}{(k-1) !} U^{(k)}\left(\mu_{p}\right)\left(R_{p}-\mu_{p}\right)^{k-1}\right]\left[\left(R_{i}-\mu_{i}\right)-\left(R_{j}-\mu_{j}\right)\right]\right\}=U^{\prime \prime}\left(\mu_{p}\right)\left[\operatorname{CoV}\left(R_{i}, R_{p}\right)-\operatorname{CoV}\left(R_{j}, R_{p}\right)\right]+$ $E \sum_{k=3}^{\infty} \frac{k\left(1+\mu_{p}\right)^{k}}{2(k-1) !}(-1)^{k} U^{(k)}\left(\mu_{p}\right)\left\{\frac{(-1)^{k} 2}{k\left(1+\mu_{p}\right)^{k}}\left(R_{p}-\mu_{p}\right)^{k-1}\left[\left(R_{i}-\mu_{i}\right)-\left(R_{j}-\mu_{j}\right)\right]\right\}=U^{\prime \prime}\left(\mu_{p}\right)\left[\operatorname{CoV}\left(R_{i}, R_{p}\right)-\operatorname{CoV}\left(R_{j}, R_{p}\right)\right]+$ $\mathbb{U}^{(3)}\left(U, \mu_{p}, R_{p}^{o}\right)\left[\left(\operatorname{CoSwV}\left(R_{i}, R_{p}\right)-\frac{\operatorname{CoV}\left(R_{i}, R_{p}\right)}{\left(1+\mu_{p}\right)^{2}}\right)-\left(\operatorname{CoSwV}\left(R_{j}, R_{p}\right)-\frac{\operatorname{Cov}\left(R_{j}, R_{p}\right)}{\left(1+\mu_{p}\right)^{2}}\right)\right]$.
} 


\section{B. The Co-Asymmetry and MCSD}

In the following theorem, I demonstrate that for those investors who care about the potential gain/loss due to asymmetries in returns additional to price fluctuations, the co-asymmetry $(\mathrm{CoA})$, in addition to the mean and variance, is an important ranking criterion for determining portfolio efficiency.

\section{Theorem 5 (Mean- $\mathrm{CoV}$-CoA MCSD)}

Let $R_{i}$ and $R_{j}$ be two uncertain prospects, and $\operatorname{CoA}_{i . p}=\left[\operatorname{CoSwV}\left(R_{i}, R_{p}\right)-\frac{\operatorname{CoV}\left(R_{i}, R_{p}\right)}{\left(1+\mu_{p}\right)^{2}}\right]$. The inequalities: $\mu_{i} \geq \mu_{j}, \operatorname{CoV}\left(R_{i}, R_{p}\right) \leq \operatorname{CoV}\left(R_{j}, R_{p}\right)$, and $\operatorname{CoA}\left(R_{i}, R_{p}\right) \leq \operatorname{CoA}\left(R_{j}, R_{p}\right)$ are sufficient conditions for $R_{i}$ to marginally and conditionally dominate $R_{j}$ and for all utility functions with $U^{\prime}>0, U^{\prime \prime}<0$, and $U^{\prime \prime \prime}>0$.

The MCSD in Theorems 4 and 5 shows the essential roles of $\operatorname{CoSwV}, \operatorname{CoV}$, and $\operatorname{CoA}$ in portfolio risk diversification. Specifically, the minimization of these co-variations of asset returns maximizes the portfolio efficiency. In the next section, I demonstrate that similar to the portfolio variance, the $\mathrm{SwV}$ and $\mathbb{A}$ measures of a portfolio is a weighted sum value of component assets' CoSwV and CoAl, respectively. Consequently, the classical approach of portfolio optimization can be applied to the determination of SD equilibrium. 


\section{SSD and MVA Optimization \& Equilibrium}

Based on (8), I show that the $\mathrm{SwV}$ of a portfolio is a weighted sum of $\mathrm{CoSwV}$ between returns on an asset and returns in the portfolio: 18

$$
\operatorname{SwV}_{p}=2 E\left(R_{p}-r_{p}\right)-2 d \mu_{p}=\sum_{i=1}^{N} w_{i} \cdot \operatorname{CoSwV}\left(R_{i}, R_{p}\right)
$$

Recall in Theorem 2, the SSD is indeed a tradeoff between mean and the SwV in which expected risk-averse utility maximizing investors, who have no knowledge about the form of return distributions, prefer an investment alternative with high mean and low SwV. Consequently, the SSD optimization and efficiency can be determined by choosing a securities mix that minimizes the $\mathrm{SwV}$ of the portfolio given its expected rate of return.

\section{A. Minimum-SwV Portfolios and MSwV Asset Pricing Model}

Proposition 1 (SSD Optimization and Efficiency)

Suppose there are $N$ assets and short selling is allowed. The SSD optimal portfolios can be determined by

$$
\underset{w_{i}}{\operatorname{Min}} \operatorname{Sw} V_{p}
$$

Subjects to $\mu_{p}=\sum_{i=1}^{N} w_{i} E\left(R_{i}\right)$.

\footnotetext{
${ }^{18} S w V_{p}=2 E\left(R_{p}-r_{p}\right)-2 d \mu_{p}=2 E\left[\left(\frac{R_{p}-\mu_{p}}{R_{p}-\mu_{p}}\right)\left(R_{p}-r_{p}\right)\right]-2 d \mu_{p}=2 E\left[\left(\frac{\sum_{i=1}^{N} w_{i}\left(R_{i}-\mu_{i}\right)}{R_{p}-\mu_{p}}\right)\left(R_{p}-r_{p}\right)\right]-2 d \mu_{p}=$ $\sum_{i=1}^{N} w_{i} \times\left\{2 E\left[\left(\frac{R_{i}-\mu_{i}}{R_{p}-\mu_{p}}\right)\left(R_{p}-r_{p}\right)\right]-2 d \mu_{p}\right\}=\sum_{i=1}^{N} w_{i} \cdot \operatorname{CoSwV}\left(R_{i}, R_{p}\right)$.
} 
Based on equations (8) and (10), the SSD optimal portfolios satisfy the following first order condition:

$$
E\left[\frac{R_{i} R_{p *}^{S w V}}{1+R_{p *}^{S w V}}\right]=0
$$

where $R_{p *}^{S w V}=\sum_{i=1}^{N} w_{i *}^{S w V} R_{i}$, and where $w_{i *}^{S w V}$ is the SSD optimal share of wealth on $i$-th asset that satisfied the condition (12). The SSD efficient portfolios are the minimum-SwV portfolios that offer the highest expected returns for the same level of SwV. The SSD efficient frontier is concave in that the second order condition is equal to $E\left[\frac{R_{i}^{2}}{\left(1+R_{p^{*}}^{S W V}\right)^{2}}\right]$ and is non-negative, and the SSD optimal portfolio $R_{p *}^{S w V}$ is unique in the $M S w V$ space, if there is a risk-free asset.

For an illustration, I simulate the SSD efficiency from a sample set of 300 assets randomly and jointly generated from a mixture of three different forms of return distributions: normal, lognormal, and gamma, respectively. Specifically, the sample distributions have a mean ranged from -0.2 to 0.2 , and a standard deviation within a range from 0.4 to 0.7 . In addition, the correlation coefficient among assets is from -0.3 to 0.7 , accordingly. Figure 2 depicts the analytical results. For a comparison, I also identify the MV efficient portfolios in the MSwV space.

\section{[Insert Figure 2 here]}

The main implication from our simulation is twofold. First, MSwV is capable of discriminating the stochastic dominated assets where MV can't, so that the efficient frontier of 
SSD could lie above that of the MV. Second, with the risk-free asset, the portfolio-separation holds in the MSwV space as well, corresponding to an SSD efficient portfolio of risky assets.

\section{B. Minimum-SwV Hedging Approach}

The basic concept of forming a hedging portfolio is to invest in the spot market and the underlying futures market at the same time, and to reduce the risks of the hedged portfolio. Specifically, consider a portfolio consisting of one unit of long position in the spot market and $h$ units of short position in the futures market. The return on the hedged portfolio is given by

$$
R_{h}=R_{s}-h R_{f}
$$

where $R_{h}, R_{s}$ and $R_{f}$ are the returns of the hedging portfolio, underlying spot asset and futures contract, respectively. $h$ is the so-called hedge ratio.

In minimum-variance framework, hedge ratio can be easily solved as, $h=\frac{\operatorname{Cov}\left(R_{s}, R_{f}\right)}{\operatorname{Var}\left(R_{f}\right)}$, by making the variance of return on hedged portfolio the smallest (Johnson 1960).

In minimum-swap variance framework, I use swap variance instead of variance as a more general and true risk measure. Therefore, the optimal hedge ratio of minimizing swap variance of the hedged portfolio is given by

$$
\min _{h} \operatorname{SwV}\left(R_{h}\right)
$$

where $S w V\left(R_{h}\right)$ is the swap variance of returns on hedge portfolio in equation (12). The first order condition, from a direct calculation, is then given by 


$$
\frac{\mathrm{d} S w V\left(R_{h}\right)}{\mathrm{d} h}=E\left[\frac{R_{f} R_{s}-h R_{f}^{2}}{1+R_{s}-h R_{f}}\right]=0
$$

Additionally, since the second order condition, $\frac{d}{\mathrm{~d} h}\left[\frac{\mathrm{d} S w V\left(R_{h}\right)}{\mathrm{d} h}\right]=E\left[\frac{R_{f}^{2}}{\left(1+R_{S}-h R_{f}\right)^{2}}\right]$, and it is nonnegative, the set of minimum- $S w V$ hedge ratio is unique.

\section{Minimum-A Portfolios and MVA Asset Pricing Model}

To identify the efficient set of assets and portfolios that includes those that are chosen by investors who like (dislike) asymmetric gains (losses), I employ the MVA approach. Consider that the return of asymmetry of a portfolio is calculated as:

$$
\mathbb{A}_{p}=S w V_{p}-\left[\left(\frac{\sigma_{p}}{1+\mu_{p}}\right)^{2}\right]=\left[\sum_{k=3}^{\infty}(-1)^{k}\left(\frac{2}{k}\right) \frac{\mathcal{M}_{p}^{k}}{\left(1+\mu_{p}\right)^{k}}\right] .
$$

Since the value of $\mathbb{A}_{p}$ is positive (negative) if returns on the portfolio are asymmetrically and negatively (positively) distributed, the MVA efficient portfolios can be determined by minimizing $\mathbb{A}_{p}$ subject to different levels of $\mu_{p}$ and $\sigma_{p}^{2}$.

Proposition 2 (MVA Optimization and Efficiency)

Suppose there are $N$ assets and short selling is allowed. The MVA optimal portfolios can be determined by

$$
\begin{gathered}
\operatorname{Min}_{w_{i}} \mathbb{A}_{p}, \\
\text { Subject to } \mu_{p}=\sum_{i=1}^{N} w_{i} E\left(R_{i}\right) \text {, and } \sigma_{p}^{2}=\sum_{i=1}^{N} \sum_{j=1}^{N} w_{i} w_{j} \sigma_{i j}
\end{gathered}
$$


Based on equations (9) and (10), the MVA optimal portfolios satisfy the following first order condition:

$$
E\left[\frac{R_{i} R_{p *}^{\mathrm{MVA}}}{1+R_{p *}^{\mathrm{MVA}}}\right]=0
$$

where $R_{p *}^{\mathrm{MVA}}=\sum_{i=1}^{N} w_{i *}^{M V \mathbb{A}} R_{i}$, and where $w_{i *}^{M V \mathbb{A}}$ is the MVA optimal share of wealth on $i$-th asset that satisfied the first order condition (16). The efficient MVA portfolios are the minimum-A portfolios that offer the highest expected returns and the lowest variances for the same level of $S w V$. The second order condition is non-negative, and MVAl efficient space is concave. ${ }^{19}$

For a graphical illustration, Figure 3 shows that the MVA efficient portfolios are located on a spherical surface in a three-dimensional space of mean, variance, and the minimum- $\mathbb{A}$, respectively. The MVA optimal portfolio $P_{\mathrm{MVA}}^{*}$ is the point on the MVA efficient-surface to which the MVA capital market line (MVA-CML) is the tangent. Intuitively, the MVA-CML, SSD-CML and the MV-CML all converge to one line, only if asymmetry-risk (A) of all assets is zero, or none of the investors care about that.

\section{[Insert Figure 3 here]}

An important implication of Figure 3 is that with a risk-free asset, the optimal portfolio of MVA is identical to that of MSwV (SSD). The optimal portfolio of MSwV (SSD) is the tangent point on the efficient curve from the risk-free asset and is the one with the largest MSwV Sharpe

\footnotetext{
${ }^{19}$ The derivation of Proposition 2 is similar to that of Proposition 1. I omit the detail description.
} 
ratio, i.e., mathematically, $\operatorname{Min}_{w_{i}} \frac{\mu_{p}-R_{f}}{\operatorname{Sw} V_{p}}=\operatorname{Min} \frac{\mu_{p}-R_{f}}{\sigma_{p}^{2}+\mathbb{A}_{p}}$. On the other hand, the optimal portfolio of MVA in Figure 3 also has the highest Sharpe ratio in the three-dimensional MVA space, which is determined by the tangent of the angle between the MVA capital market line and its projection line on $\mathbb{A}_{p}-\sigma_{p}^{2}$ plane. Since $\mathbb{A}_{p}$ is orthogonal to $\sigma_{p}^{2}$, the optimal portfolio of MVAl can be determined from this minimization process: $\operatorname{Min}_{w_{i}} \frac{\mu_{p}-R_{f}}{\sqrt{\left(\sigma_{p}^{2}\right)^{2}+\left(\mathbb{A}_{p}\right)^{2}}}$, or equivalently, $\operatorname{Min}_{w_{i}} \frac{\mu_{p}-R_{f}}{\sigma_{p}^{2}+\mathbb{A}_{p}}$. As a result, the optimal portfolio of MVA is the SSD optimal portfolio.

Figure 3 highlights that although the tow-fund separation holds between the risk-free fund and the optimal SSD portfolio, the risk-return tradeoff of expected utility maximization is determined by the three parameters: mean, volatility and asymmetry, respectively. ${ }^{20}$ Figure 3 also shows that the bias of the MV model is from the ignorance of the impact of distributional asymmetry on investment decision making. Thus, the asymmetry in addition to mean and volatility is necessary to be jointly considered in portfolio efficiency, performance analysis, and capital asset pricing.

\footnotetext{
${ }^{20}$ Under the two-fund separation, $E U\left[(1-w) R_{f}+w R_{p *}^{S w V}\right]=E U\left[(1-w) R_{f}+w R_{p *}^{\mathrm{MVA}}\right]$. Then, according to equations (3) and (5), the risk-measure of the optimal investment can be linearly decomposed such that $\operatorname{SwV}\left(R_{p *}^{S w V}\right)=$ $\gamma \cdot \operatorname{Var}\left(R_{p *}^{\mathrm{MVA}}\right)+\delta \cdot \mathbb{A}\left(R_{p *}^{\mathrm{MVA}}\right)$, where $\gamma=\frac{U^{\prime \prime}}{2 \mathbb{U}}>0$, and $\delta=\frac{\mathbb{U}^{(3)}}{\mathbb{U}}>0$.
} 


\section{Empirical Analysis}

The primary source of sample data for my empirical analysis comes from the Center for Research in Security Prices (CRSP) equity database that covers all firms incorporated in the U.S. and listed on the NYSE, AMEX, or NASDAQ. I select stocks that have a CRSP share code of 10 or 11 to be consistent with the Fama-French asset pricing factors in Kenneth French's Database. Further, to avoid survivorship bias, stock return information before July 1969 is eliminated. The ending sample period is December 2015. Also, sample returns of 14 hedge funds listed on the Credit Suisse Hedge Fund Index over a period from April 1994 to December 2015 are employed as well.

Table 1 reports the summary statistics for 14 hedge funds ${ }^{21}, 12$ industry portfolios, and 2 Fama-French factor portfolios from January 1995 to December 2015. The first three columns report the mean, variance, and $\mathrm{SwV}$ of portfolio returns. The asymmetry equals to the combination of normalized high moments according to equation (1), and captures the variation that is measured by $\mathrm{SwV}$ but not included in variance. For most of these portfolios, asymmetries are significant, although they are very small. Then I compute the Sharpe ratios under MV and MSwV framework, and rank portfolio performance based on these two Sharpe ratios. The ranks are different, especially among the hedge funds. In the last three columns, I report the $\beta^{\mathrm{MV}}$ and $\beta^{\mathrm{MSwV}}$ for each portfolio, as well as the differences between two betas. The significance of beta difference suggests that the

\footnotetext{
${ }^{21}$ https://secure.hedgeindex.com/hedgeindex/en/indexoverview.aspx?cy=USD\&indexname=HEDG
} 
effect of high moments cannot be ignored even considering market movement. Furthermore, the beta differences for most portfolios are positive, especially for hedge funds.

\section{[Insert Table 1 here]}

\section{A. The Impact of Return Asymmetry on Portfolio Performance}

The difference between $\mathrm{SwV}$ and variance is symmetries in returns is shown in (1). Therefore, to illustrate the impact of asymmetry on portfolio performance, I apply both models of MV and MSwV to hedge fund index data. Table 1 presents the summary statistics of my analysis. Although the $\mathrm{SwV}$ of funds seems to be similar to their variance in value, a significant difference appears in the ranking of Sharpe ratios. The number of the ranking inconsistency is nine out of 14. This piece of evidence demonstrates that the impact of distributional asymmetry of returns on fund performance analysis is significant and should not be ignored. Also, Table 1 shows the considerable distinction between MV-beta and MSwV-beta that highlights the importance of return co-asymmetry (e.g., co-skewness and higher co-moments) in the systematic-risk determination. Specifically, for all hedge fund data, the MV-beta is significantly larger than MSwV-beta, which suggests that the co-asymmetry of hedge funds tends to be positive and provides diversification benefits, according to (7) and (8).

Traditional portfolio theory suggests return volatility $(\sigma)$ can be reduced by forming portfolios if returns on assets are not perfectly correlated. Is this true as well for the return asymmetry $(\mathbb{A})$ ? Further, unlike the volatility, the quantity $\mathbb{A}$ could be negative (positive) 
corresponding to the prospect of potential upside-gains (downside-loss). Is the risk-diversification concerning return asymmetry different between the aspect of downside and that of upside, and which type of portfolio performs better among positive asymmetry, symmetry, and negative asymmetry? I find the answer to the above questions in Table 2 empirically.

\section{[Insert Table 2 here]}

\section{B. Volatility, Asymmetry, Diversification, and Stability}

Twenty equally weighted portfolios are formed by grouping all stocks in our database according to their $\mathbb{A}$ measures. The average value of individual stocks' $\mathbb{A}$ ranges from -483.28 to 265.50 basis-point (b.p.). To examine the consistency between ex-post and ex-ante measurements, I conduct analysis under both the in-sample and the out-of-sample frameworks. Table 2 illustrates that the relationship between $\mathbb{A}$ and $\sigma$ is truncated and concave; the higher (lower) the positive (negative) $\mathbb{A}$, the larger the $\sigma$. That is consistent with the theory shown in Figure 3 . Table 2 also demonstrates that forming a portfolio significantly reduces the magnitude of asymmetry of individual assets. The range of $\mathbb{A}$ of the 20 sorted portfolios decreases to -7.37 (-14.04) b.p. to 6.27 (6.38) b.p. from the in-sample (out-of-sample) analysis. Interestingly, the portfolio of stocks that have the most negatively asymmetric returns (portfolio \#20) has the most significant reduction of Al (from 265 to 3.92). Thus, the implication is that returns on portfolios are more symmetrically distributed than those on individual securities. Since a portfolio's $\mathbb{A}$ is a weighted sum of component assets' CoA (see Sections 2 and 3), the magnitude deduction of $\mathbb{A}$ from portfolio 
formation is due to the effects of the co-asymmetry of individual securities. Implicitly, assets have a relatively high prospect of downside losses (upside gains) and tend to have more negative (positive) co-asymmetry with the core portfolio.

Table 2 depicts that the ex-post estimate of return asymmetry is consistent with the ex-ante measure. Again, the ranking difference between Sharpe ratios of MV and $\mathrm{MSwV}$ indicates the importance of asymmetry in portfolio performance analysis. Portfolios with slightly negative asymmetry (positive $\mathbb{A}$ ) perform better than others. Regardless of in-sample or out-of-sample, the worst performed portfolio (\#20) is the one that has the most highly negative return-asymmetry. From the MV Sharpe ratios, it shows that portfolio \#1 (the one with most positively skewed returns) has the best performance; however, the MSwV and MVA analyses do not show that. As I have discussed in Section II, highly upside skewed securities (e.g., lottery-type stocks) are SSD inefficient assets with substantial volatility. They may be MVA efficient but are probably not dominating alternatives for all risk-averse investors. Also, these securities tend to be positively correlated, and portfolio \#1 should not outperform the overall market. This again highlights the potential bias of the MV model in fund performance analysis that ignores the impact of returnasymmetry.

\section{Performance of the Optimal MSwV and MVA Market Portfolios}

One of the main contributions of this dissertation is the development of optimal SD portfolios based on simple and basic optimization procedures shown in Propositions 1 and 3, respectively. Since the optimal market portfolio shown in Figure 3 should outperform other index 
portfolios in theory, it is important to examine empirically the performance of MSwV and MVA market portfolios. For developing market indexes, I determine the optimal weights according to the MSwV and MVA optimization procedures based on the past 60 monthly excess returns on all CRSP stocks. I then apply the optimal weights to the following month to calculate the returns on indexes. Therefore, the MSwV and MVA optimal indexes are tradeable funds.

\section{[Insert Table 3 here]}

For comparison purposes, Table 3 summarizes the basic statistics and Sharpe ratios of the MSwV and MVA optimal market funds vs. Fama-French's factor portfolios as well as major U.S. market indexes including S\&P500 (SPX), Dow Jones Industrial Average (DOW) and NASDAQ, accordingly. Noticeably, the quantity $\mathbb{A}$ for all market and factor indexes is negative in value indicating return distribution of all indexes are positively skewed, and the magnitude of asymmetry is positively correlated with the volatility. Corresponding to Figure 3, the optimal market portfolio of MVA converges to that of MSwV (SSD) in the MVA space. Although all other indexes may be located on the MVA efficient plane, the slope of their capital allocation lines will be lower than that of the optimal portfolio. The empirical evidence that supports my theoretical argument from the Sharpe ratios is shown in Table 3. Specifically, the distributional statistics of MSwV and MVA optimal (market) portfolios are almost identical, and they have the highest Sharpe ratios among all funds. 


\section{Mean-Variance, Mean-Swap Variance, and SSD Efficient Sets}

This dissertation compares the asset allocation under MV and MSwV framework, using SSD as a benchmark. I form efficient sets under three criteria from the whole set including 14 portfolios from the Kenneth French Database ${ }^{22}$, which includes three different size portfolios (Small Size, Medium Size and Large Size); three B/M portfolios (Growth, Neutral and Value); one Momentum portfolio (MOM); one reversal portfolio (REV); five industry portfolios (Cnsmr, Manuf, Hitec, Hlth, and Other); and market portfolio (MKT). If a portfolio is not dominated by any other portfolio, it is considered as an efficient portfolio, and thus included in the efficient set. Table 4 reports the efficient sets of each year from 2006 to 2015 based on weekly returns. The results show that the MV and MSwV efficient sets are almost the same except for year 2014. There are two reasons. The first reason is that equity returns tend to be normally distributed in a long time period. The second reason is two or three portfolios perform very well during several years, much better than all the other portfolios. Thus, no matter according to which rule, the efficient sets only consist within these portfolios (e.g. 2007, 2008, 2011, 2015).

[Insert Table 4 here]

${ }^{22}$ http://mba.tuck.dartmouth.edu/pages/faculty/ken.french/data_library.html 


\section{E. Mean-Variance and Mean-Swap Variance Hedging}

I use daily spot and futures prices of the SPX and WTI Crude Oil. The SPX spot price is downloaded from CRSP. The SPX futures price, crude oil spot price, and crude oil futures price are obtained from the CME group. The future contracts used in this study are the existing contracts with the nearest delivery date. I make adjustments for rollover based on the principal on the CME website ${ }^{23}$. The sample period for SPX covers from April 21, 1982, to August 12, 2016, and the sample period of Crude Oil futures covers from March 29, 1990, to August 12, 2016. To investigate the optimal hedge ratios, I calculate the minimizing-variance and minimizing-swap variance hedge ratios using returns from the previous 60 consecutive trading days.

Figure 4 and Figure 5 show the moving patterns of hedge ratios on SPX and Crude Oil markets over time. Panel A plots the minimizing-variance hedge ratio, Panel B plots the minimizing-swap variance hedge ratio, and Panel $\mathrm{C}$ plots the difference between the above two hedge ratios. From Panel A and Panel B, I observe that hedge ratios increase when there were market shocks, such as in 1998 and 2008. Although Panel A and Panel B show very similar patterns, I find that in Panel $\mathrm{C}$ the difference between hedge ratios of minimizing-variance and minimizingswap variance are time varying. To further test the dependence of this difference of hedge ratios on market conditions, I run regression of the difference with the VIX index.

\section{[Insert Figure 4 and Figure 5 here]}

\footnotetext{
${ }^{23}$ According to CME principal, the rollover date is 8 days before the announced expiration date.
} 
Table 5 reports the regression results of the difference between the minimizing-swap variance hedge ratio and the minimizing-variance hedge ratio over the CBOE VIX index. The beta coefficients for the SPX and the crude oil are both negative and significant; the coefficient for the SPX is -0.0056 and -0.0135 for the crude oil. This means the minimizing-swap variance hedge ratio is positively deviated from the minimizing-variance hedge ratio when the market is stable (small VIX), and the minimizing-swap variance hedge ratio is negatively deviated from the minimizing-variance hedge ratio when the market is volatile (large VIX). This suggests the traditional minimizing-variance hedge is over hedged when the market is volatile. When considering the generalized risk measures, the $\mathrm{SwV}$, the optimal hedge ratio suggests to hedge less than the minimizing-variance hedge ratio under bad market conditions.

[Insert Table 5 here]

\section{Conclusion}

The SwV, formulated merely by the twice expected difference of arithmetic and logarithmic returns adjusted by the mean, summarizes the entire probability distribution of returns. Since variance measures the quadratic (symmetric) variation of returns, the difference between $\mathrm{SwV}$ and the variance thus characterizes the asymmetries (denoted $\mathbb{A}$ ) in returns. I prove mathematically that the expected utility can be completely transformed as a function of mean and $\mathrm{SwV}$ as well as that of mean, variance, and $\mathbb{A}$, accordingly, without any restriction on the form of 
utility functions and that of return distributions. Therefore, the MSwV and MVA analyses, consistent with expected utility maximization, serve as an extension of the classical MV model by considering distributional asymmetries. Importantly, the MSwV efficiency is necessarily and sufficiently SSD efficient for all risk-averse investors. The efficient set of MVA, on the other hand, is much broader than that of SSD in that it also includes investors who prefer (dislike) the prospect of potential upside gains (downside losses). That makes some of the highly risky assets, e.g., the lottery-type securities, to be included in the MVA efficient set but to be excluded from the SSD efficient set.

Similar to the portfolio variance, the $\mathrm{SwV}$ of a portfolio is also a weighted sum of $\mathrm{CoSwV}$ between individual assets and the portfolio, where $\mathrm{CoSwV}$ is the covariance plus a polynomial combination of all higher co-moments. Thus, the $\mathrm{CoSwV}$ is different from covariance by the coasymmetry (denoted CoA), which captures the jointly asymmetric variation between an asset and the core portfolio. The return asymmetry of a portfolio is then a weighted sum of CoA . Consequently, the SSD efficient frontier can be determined from the minimum SwV assets in the mean-SwV space, and the MVA efficient plane can be defined by the minimum $\mathbb{A}$ portfolios in a three-dimensional mean-variance-asymmetry space.

Using spot and futures contracts data of SPX and crude oil, I compare the new hedging methods with traditional MV methods. The results show that the difference of hedging effects under minimizing variance and minimizing swap variance methods is very small during normal time; however, it is much larger when market shock occurs. Moreover, these small differences 
have significant negative correlations with market conditions measured by the implied volatility index.

In summary, the simplicity and generality of MSwV and MVA approaches make them a powerful tool in analyzing investment decision making under risk and uncertainty. Instead of replacing the MV model, the MVA analysis enhances the conventional methods of security selection, asset allocation, portfolio efficiency analysis as well as the asset valuation to a general framework by taking asymmetries in return as well as investors' prospect of gain and loss into consideration. 
Chapter 3

Mean-Swap Variance Asset Pricing Model 


\section{Introduction}

The traditional CAPM, formulated by Treynor (1961), Sharpe (1964), Lintner (1965), and Mossin (1966), assumes that investors have knowledge of either their utility functions or the forms of assets' return distribution. Specifically, if returns on assets are elliptically distributed or utility function is quadratic, then the market-equilibrium relationship between individual assets and MV efficient portfolios can be determined. To modify the weakness of traditional CAPM, numerous studies have proposed new asset pricing approaches to measure security returns, in which the Fama-French model is well-accepted. Fama and French $(1993,1996)$ proposed a three-factor model that includes size and value effects. They showed that the returns on the stocks of small firms covary more with one another than with returns on the stocks of large firms, and returns on high $\mathrm{B} / \mathrm{M}$ (value) stocks covary more with one another than with returns on low $\mathrm{B} / \mathrm{M}$ (growth) stocks. In their model, SMB (small minus big), the difference between the returns on diversified portfolios of small and big stocks, quantifies size effect, and HML (high minus low), the difference between the returns on the diversified portfolios of high and low B/M stocks, quantifies value

effect. Meanwhile, behavior finance has become a hot topic in recent years. Kahneman and Tversky (1979) propose the principal of prospect theory. Under prospect theory, investors tend to think in terms of gains and losses rather than in terms of their net assets, and therefore, investors encode choices in terms of deviations from a reference point. Moreover, investors treat gains differently than losses in that individuals tend to be risk-averse with respect to gains and riskaccepting with respect to losses. Tversky and Kahneman (1991) point out that the central assumption of prospect theory is that losses and disadvantages have greater impact on preferences 
than gains and advantages. The dissertaton develops asset valuation approaches considering human decision makers' behavior biases in utility optimization based on the idea of Arbitrage Pricing Theory (Ross, 1976) and shows the explanatory power to the cross-sectional expected returns on assets compared to Fama-French factors.

I first show that the mean-SwV (MSwV) transformation of the expected utility function allows the derivation of both the necessary and sufficient condition for SD, enabling risk-averse investors to discard from the efficient set of prospects that are stochastically dominated by others. Therefore, the MSwV approach separates both the knowledge of all prospects' probability distribution and that of investors' preference functions from the decision process on utility maximization. In the application of $\mathrm{MSwV}$ to portfolio theory, I demonstrate that similar to the formulation of portfolio variance, the $\mathrm{SwV}$ of a portfolio is also a weighted sum of the co-swapvariance $(\mathrm{CoSwV})$ between each component asset and the portfolio. Structurally, the CoSwV contains not only the covariance but a summary of all higher order co-moments of return; thus, the larger the odd co-moments (e.g., co-skewness), the smaller the $\mathrm{CoSwV}$, the better the riskdiversification, and the higher the portfolio efficiency. ${ }^{24}$ Consequently, the $\mathrm{SwV}$ can replace the

\footnotetext{
${ }^{24}$ Mounting empirical evidence suggests that higher-order market co-moments associated with distributional variations in addition to the market volatility explain the expected returns on financial assets. Notably, Harvey and Siddique (2000) demonstrated that under a quadratic pricing kernel, conditional skewness explains the cross-sectional variation in expected returns across assets. Dittmar (2002) extended the pricing kernel to be a cubic in the market return and showed that asset returns are affected by covariance, co-skewness, and co-kurtosis with return on aggregate wealth. From an aspect of asset pricing, Vendrame, Tucker, and Guermat (2016) found that covariance is associated with a positive factor premium, co-skewness demands a negative premium, and co-kurtosis has a positive premium, respectively. Furthermore, Chung, Johnson, and Schill (2006) argued that although higher moment measures such as skewness and kurtosis individually provide some information about the tail of the investment return distribution, they fall far short of specifying the tail precisely. Therefore, the likelihood of extreme outcomes of an investment must be
} 
variance, and the $\mathrm{CoSwV}$ can substitute covariance needed in portfolio theory whenever the MV model fails to provide consistent results of the utility maximization. Precisely, I prove that the mean and $\mathrm{CoSwV}$ dominance is a necessary and sufficient condition for the second-degree marginal conditional stochastic dominance (MCSD) of Shalit and Yitzhaki (1994) for all concaved utility functions. As a result, analogous to the MV analysis, an efficient set of SSD portfolios can be determined by minimizing the portfolio's $\mathrm{SwV}$ for each given mean-return without searching through all possible combinations of assets as the traditional SSD algorithm requires.

Based on the decomposition of $\mathrm{SwV}$ shown in (1), I further quantify the expected utility as a function of three-parameters: mean, variance, and asymmetry (MVA), respectively. Serving as an extension of the SSD approaches, I show that MVA efficiency is robust to risk-averse investors and to those who prefer a prospect of upside-skewed payoffs but are averse to that of downside losses, where both MV and SSD efficient sets of assets are subsets of the MVA efficiency. ${ }^{25}$ Notably, the MVA efficient set includes lottery-type securities (Kumar, 2009) that are SSD inefficient and commonly viewed as highly risky assets. The MVA optimal portfolios can then be identified by minimizing $\mathbb{A}$ of assets for every level of the mean and variance.

Again, the main advantage of MSwV and MVA optimization is that the expected utility maximization of investors can be distinguished entirely by a function of finite summary statistics independent of individual preference function or the knowledge of probability or decision weight

measured jointly by the entire set of all possible moments and co-moments. To specify the distributional tails of returns (or the sensitivity to the market tails) ideally, it requires information of an infinite number of moments and co-moments.

${ }^{25}$ The MVA inefficient assets must also be dominated by SSD or MV rules. Note that the neither the MV efficient set is a subset of SSD, nor vice versa. 
distribution. Consequently, the MSwV and MVA optimal portfolios allow me to derive the SD equilibrium return on assets as well as the SD systematic risk measures. Specifically, I show that similar to the MV beta coefficient in form, the MSwV-beta (or the SSD-beta) is a ratio between $\mathrm{CoSwV}$ and the market $\mathrm{SwV}$. Since $\mathrm{CoSwV}$ accommodates all possible higher order co-moments of returns between an asset and the SSD optimal (market) portfolio, the MSwV-beta is sensitive to the asymmetries in market returns. It makes $\mathrm{MSwV}$-beta become a more general proxy of systematic risk than the traditional MV-beta. Finally, incorporating with upside-skewness preference and downside-asymmetry aversion, I develop a two-factor linear model as a result of the MVA equilibrium. This model is an extension of the MSwV approach for quantifying the systematic impacts of symmetry and asymmetry separately on the required return of risky assets. Empirically, the MVA two-factor pricing model is statistically valid as compared with the conventional multi-factor models.

The rest of this chapter is organized as follows: Based on the MSwV and MVA optimization, the SD oriented asset pricing models are developed in Section II. Section III demonstrates the application of MSwV and MVA to the determination of a human decision maker's loss aversion and gain preference. Section IV illustrates the empirical analysis, and section V contains concluding remarks. 


\section{SSD and MVA Optimization \& Equilibrium}

The traditional CAPM, formulated by Treynor (1961), Sharpe (1964), Lintner (1965), and Mossin (1966), assumes that investors have knowledge of either their utility functions or the forms of assets' return distribution. Specifically, if returns on assets are elliptically distributed or utility function is quadratic, then the market-equilibrium relationship between individual assets and MV efficient portfolios can be determined. In this section, the dissertation develops the asset valuation theory for investors holding MSwV portfolios without the utility and distributional assumptions that the MV model requires.

To formulate the CAPM in the MSwV, this study retains the central assumptions of the classical CAPM. These assumptions include single-period analysis, the existence of a risk-free asset, and perfect competition in the securities market. According to equation (3) in chapter one, investors' expected utility is a function of mean-swap variance (MSwV). Investors then maximize expected utility with respect to only two parameters: expected return and $\mathrm{SwV}$. Consequently, the SSD optimization and efficiency can be determined by choosing a securities mix that minimizes the $\mathrm{SwV}$ of the portfolio given its expected rate of return. 
Proposition 1 (The SSD Equilibrium)

Assume short-sell is allowed and investors are permitted to borrow and lend at the risk-free rate of return $\left(R_{f}\right)$. Based on equation (3), if investors are risk-averse, then the expected utility is a function of two parameters: $\mu$, and $S w V$, respectively. If investors are maximizing expected utilities of returns on an MSwV (SSD) efficient market portfolio, $R_{m}^{S w V}$, the risk-premium of risky assets in equilibrium, can be calculated by the following equation:

$$
E\left(R_{i}-R_{f}\right)=\beta_{i}^{S w V} \lambda_{\mathrm{m}}
$$

where

$$
\begin{gathered}
\beta_{i}^{S w V}=\frac{\operatorname{CoS} w V\left(R_{i}, R_{m}^{S w V}\right)}{\operatorname{SwV}\left(R_{m}^{S w V}\right)} . \\
\lambda_{\mathrm{m}}=E\left(R_{m}^{S w V}-R_{f}\right)
\end{gathered}
$$

The formulation of $S w V$ and CoSwV is shown in equations (1) and (8), accordingly.

The derivation of equations (17.1) and (17.2) is shown in the Appendix. The SSD equilibrium is similar to the MV equilibrium in form; however, the benchmark portfolio and the formulation of beta coefficient are different. As I have discussed in the previous chapter, although the SSD efficiency is robust to risk-aversion with downside asymmetry on returns, some of the SSD inefficient assets with a prospect of upside potential could be efficient for investors who have upside skewness preference. Consequently, the single factor equilibrium model in (17) could be biased, if I take the preference behavior of prospective gain into consideration. 
For developing the MVA equilibrium, it is necessary to identify two orthogonal benchmark portfolios that mimic the symmetry and asymmetry of returns on the SSD optimal market portfolio. First, I identify the efficient portfolios with symmetric returns by minimizing $\mathrm{SwV}_{p}$ subject to $\mu_{p}=\sum_{i=1}^{N} w_{i} E\left(R_{i}\right)$, and $\mathbb{A}_{p}=0$. Then, the optimal symmetry-factor portfolio, with returns denoted $R_{m}^{\mathbb{S}^{\perp}}\left(=\sum_{i=1}^{N} w_{i *}^{\mathbb{S}^{\perp}} R_{i}\right)$, is the one with the highest Sharpe ratio. Second, returns on the factor portfolio of asymmetry (denoted $R_{m}^{\mathbb{A}^{\perp}}$ ) have to be independent to $R_{m}^{\mathbb{S}^{\perp}}$, but the sum of these two returns must be proportionally equal to $R_{m}^{S w V}$, the returns on the SSD optimal portfolio. Mathematically, $R_{m}^{\mathbb{A}^{\perp}}$ must then satisfy the following two conditions:

$$
w_{i *}^{\mathrm{A}^{\perp}}=(1-\theta) w_{i *}^{S W V}-w_{i *}^{S^{\perp}} \text { for all } i,
$$

and

$$
\operatorname{CoV}\left(R_{m}^{\mathrm{A}^{\perp}}, R_{m}^{\mathbb{\perp}^{\perp}}\right)=0,
$$

where $0 \leq \theta \leq 1$. Finally, solve for $\theta$ and $w_{i *}^{\mathbb{A}^{\perp}}$ from the equations (18.1) and (18.2) simultaneously. I then can calculate returns on the optimal asymmetry-factor such that $R_{m}^{\mathbb{A}^{\perp}}=$ $\sum_{i=1}^{N} w_{i *}^{\mathrm{A}^{\perp}} R_{i}$.

From Figure 3 and Theorem 3, although the optimal portfolio of MVA is equivalent to that of SSD, the efficient set of MVA is larger than that of SSD. That is, the MVA equilibrium is more general than the SSD equilibrium in that the MVA efficiency is valid not only for risk-averse investors but also for those who have upside (downside) asymmetry preference (aversion). I 
formally derive the formulation of risk-premium for individual assets under the MVA equilibrium in the following proposition:

\section{Proposition 2 (The MVA Equilibrium)}

Assume short sell is allowed and investors are permitted to borrow and lend at $R_{f}$. Based on equation (5), for all utility functions with $U^{\prime}>0, U^{\prime \prime}<0$, and $U^{\prime \prime \prime}>0$, the expected utility can be transformed as a function of three parameters: $\mu, \sigma^{2}$, and $\mathbb{A}$, respectively. Let $R_{m}^{\mathbb{S}^{\perp}}$ and $R_{m}^{\mathbb{A}^{\perp}}$ be orthogonal returns on the symmetric and asymmetric factor portfolios determined from the SSD optimal portfolio based on (18.1) and (18.2), respectively. The risk-premium of risky assets, in equilibrium, can be calculated by the following equation:

$$
E\left(R_{i}-R_{f}\right)=\beta_{i}^{\mathbb{S}} \lambda_{\mathbb{S}}+\beta_{i}^{\mathbb{A}} \lambda_{\mathbb{A}}
$$

where

$$
\begin{gathered}
\beta_{i}^{\mathbb{S}}=\frac{\operatorname{Cov}\left(R_{i} R_{m}^{\mathbb{S}^{\perp}}\right)}{\operatorname{Var}\left(R_{m}^{\mathbb{S}^{\perp}}\right)}, \\
\beta_{i}^{\mathbb{A}}=\left[\frac{\operatorname{CoSwV}\left(R_{i}, R_{m}^{\mathbb{A}^{\perp}}\right)-\frac{\operatorname{Cov}\left(R_{i}, R_{m}^{\mathbb{A}}\right)}{\left[1+E\left(R_{m}^{\mathbb{A}}\right)\right]^{2}}}{\operatorname{SwV}\left(R_{m}^{\mathbb{A} \perp}\right)-\frac{\operatorname{Var}\left(R_{m}^{\mathbb{A}^{\perp}}\right)}{\left[1+E\left(R_{m}^{\mathbb{A}}\right)\right]^{2}}}\right], \\
\lambda_{\mathbb{S}}=E\left(R_{m}^{\mathbb{S}^{\perp}}-R_{f}\right), \text { and } \lambda_{\mathbb{A}}=E\left(R_{m}^{\mathbb{A}^{\perp}}-R_{f}\right)
\end{gathered}
$$

Serving as an extension of the CAPM, the two-factor linear model (19), derived theoretically from the expected utility maximization, demonstrates that two deterministic 
components - the symmetry and the asymmetry - are sufficient to explain the market price dynamics. Again, the ignorance of the impact of asymmetry on market return variations causes the failure of the traditional CAPM. Many empirical pricing factors - such as SBM, HML, and others-successfully fulfill the incompleteness of the CAPM. Nevertheless, all those factors, perhaps, capture the systematic asymmetry in equilibrium price determination only partially.

\section{Behavioral Asset Pricing Models}

The formulation of the MSwV-beta coefficient in equation (17.2) is structurally similar to that derived from the MV-CAPM but with different co-variation and variation measures. Thus, at this point, it is important to draw the analogy and the distinction between the two systematic risk measures. It can be shown that if returns are symmetrically distributed, $\beta^{S w V}$ reduces to $\beta^{V}$ in that from Taylor Expansion, the higher moments and co-moments of the distributions are irrelevant to the beta derivation. In other words, the dissimilarity between the two beta measures is caused by the distributional asymmetry in returns.

To further investigate the difference between $\beta_{i}^{S w V}$ and $\beta_{i}^{V}$, this study focuses on the conventional single linear factor market model.

$$
R_{i}^{e}=a_{i}+b_{i} R_{m}^{e}+\varepsilon_{i}
$$

It is well-known that the condition $\operatorname{Cov}\left(\varepsilon_{i}, R_{m}^{e}\right)=0$, is crucial for the validity of the model in (20). The violation of this condition indicates that the market factor is insufficient, and additional factors 
exist in determining assets' returns. A question arises: if MSwV-CAPM is a correct model, will replacing $b_{i}$ by the $\beta_{i}^{S w V}$ ensure that $\operatorname{Cov}\left(\varepsilon_{i}, R_{m}^{e}\right)=0$ ? The answer to this question is no, because $\operatorname{Cov}\left(\varepsilon_{i}, R_{m}^{e}\right)=0$ guarantees that $b_{i}=\beta_{i}^{M V}$ and vice versa. ${ }^{26}$ Therefore, if $b_{j}=\beta_{i}^{S w V} \neq \beta_{i}^{V}$, then $\operatorname{Cov}\left(\varepsilon_{i}, R_{m}^{e}\right) \neq 0$. I show that the non-zero of residual covariance directly results from the beta difference such that ${ }^{27}$

$$
\beta_{i}^{S w V} \lambda_{\mathrm{m}}-\beta_{i}^{\mathbb{S}} \lambda_{\mathbb{S}}=\beta_{i}^{\mathbb{A}} \lambda_{\mathbb{A}}
$$

where

$$
\beta_{i}^{\mathbb{A}} \approx \frac{-2}{\sigma_{m}^{2}}\left[\frac{(-1)^{3} \operatorname{CoM}_{i, m}^{3}}{3\left(1+\mu_{m}\right)^{3}}+\frac{(-1)^{4} \operatorname{CoM}_{i, m}^{4}}{4\left(1+\mu_{m}\right)^{4}}+\cdots+\frac{(-1)^{N} \operatorname{CoM}_{i, m}^{5}}{N\left(1+\mu_{m}\right)^{5}}\right] \text {, and } N \rightarrow \infty
$$

The implication of (21) and (22) is that the single factor CAPM is valid if and only if $\beta_{i}^{\mathbb{A}}$ is zero. The asymmetric beta, $\beta_{i}^{\mathbb{A}}$, measures the sensitivity of an asset $i$ to the asymmetry of the market portfolio. In a negatively (positively) skewed market, assets with positive (negatively) $\beta_{i}^{\mathbb{A}}$ may be undesirable because of their possible contributions to asymmetries in the market returns. These assets therefore earn higher average returns.

${ }^{26}$ If $\operatorname{Cov}\left(\varepsilon_{j}, R_{m}^{e}\right)=0$, then from (19), $E\left(R_{i}^{e} R_{m}^{e}\right)-E\left(R_{i}^{e}\right) E\left(R_{m}^{e}\right)=b_{i}\left[E\left(R_{m}^{e^{2}}\right)-E\left(R_{m}\right)^{2}\right]$, and thus $b_{i}=\beta_{i}^{V}$. On the other hand, if $b_{i}=\beta_{i}^{V}$, then again from (19), $\operatorname{Cov}\left(\varepsilon_{j}, R_{m}^{e}\right)=E\left(\varepsilon_{i} R_{m}^{e}\right)-E\left(\varepsilon_{i}\right) E\left(R_{m}^{e}\right)=\left[E\left(R_{i}^{e} R_{m}^{e}\right)-\right.$ $\left.E\left(R_{i}^{e}\right) E\left(R_{m}^{e}\right)\right]-\beta_{i}^{M V}\left[E\left(R_{m}^{e^{2}}\right)-E\left(R_{m}\right)^{2}\right]=0$.

${ }^{27}$ Let $\delta_{i}^{S w V}=\left(R_{i}^{e}-\beta_{i}^{S w V} R_{m}^{e}\right)=a_{i}+\varepsilon_{i}$ and $\delta_{i}^{V}=\left(R_{i}^{e}-\beta_{i}^{V} R_{m}^{e}\right)$, we have $\delta_{i}^{V}=\left(\beta_{i}^{V}-\beta_{i}^{S w V}\right) R_{m}^{e}+\delta_{i}^{S w V}$. Since the single factor model is valid only if $\operatorname{Cov}\left(\delta_{i}^{V}, R_{m}^{e}\right)=\operatorname{Cov}\left(\left[\left(\beta_{i}^{V}-\beta_{i}^{S w V}\right) R_{m}^{e}+\delta_{i}^{S w V}\right], R_{m}^{e}\right)=0, \quad\left(\beta_{i}^{S w V}-\beta_{i}^{V}\right)=$ $\frac{\operatorname{Cov}\left(\varepsilon_{i}, R_{m}^{e}\right)}{\sigma_{m}^{2}}$. 
Contrary to Markowitz's assumption of rational decision makers (RDM), studies on behavior finance suggest that most investors are human decision maker (HDM). If HDM is rational without cognitive errors or emotional biases, the classical MV analysis is robust in that the volatility of returns is the center of concern (See Blay \& Markowitz, 2013). Now, I consider a HDM with behavior bias. First, Benartzi and Thaler (1995) proposed that investors are assumed to be loss averse, so they are unwilling to recognize loss and tend to afford more risk. As a result, the risk aversions of investors are lower when returns are negative (or below their expectations). On the other side, Kumar (2009) posited that individual investors prefer stocks with lottery features, which means HDM may tolerate more risk to pursue potential gain. So HDM involves three fundamental tendencies of behavior, including the symmetric volatility riskaversion, the asymmetric downside loss-aversion, and the tailed gain-preference, respectively. Therefore, the insufficiency of the traditional MV models results from the asymmetric biases. Based on the MSwV theory, I develop an equilibrium pricing condition for capital assets that accommodates the above three decisional behaviors.

From the empirical analysis shown in the next section, this dissertation finds that sorted portfolios with a higher value of the positive (negative) past $\beta^{\mathbb{A}}$ have a higher (lower) expected return. Portfolios that are insensitive to the current market asymmetry have lower future average returns. My empirical finding of the U-shape structure of expected returns and the past- $\beta^{\mathbb{A}}$ sorted portfolios significantly indicates the positive (negative) risk-premium of $\lambda_{\mathbb{L}}\left(\lambda_{\mathbb{G}}\right)$. The implication is that there are different risk-attitudes toward aggregated tails of returns. 


\section{Empirical Analysis}

\section{A. Testing for MSwV (SSD) and MVA Asset Pricing Models}

In this chapter, I derive the asset pricing models under the MSwV and MVA frameworks following the same derivation procedures as that of CAPM. To examine the validity of these models, I follow the Fama-MacBeth (1973) two-stage testing methodology. Based on equations (17.2), (19.2), and (19.3), over the sample period, I first calculate the estimates of factor loadings, $\hat{\beta}_{i}^{S w V}, \hat{\beta}_{i}^{\mathbb{S}}$, and $\hat{\beta}_{i}^{\mathrm{A}}$, on the monthly basis for all securities $i$ with respect to the past 60 monthly returns on indexes, $R_{m}^{S w V}, R_{m}^{\mathbb{S}}$, and $R_{m}^{\mathbb{A}}$, accordingly. Second, to eliminate the impact of idiosyncratic risk of securities on the analysis and have a focus on the systematic risk premium, at the beginning of each period I form 60 equal-sized portfolios, sorted by the factor loadings of all individual securities that estimated from the first step. I then regress cross-sectional returns on the

sixty portfolios against their factor loadings to estimate the factor premium, $\hat{\lambda}_{S w V}, \hat{\lambda}_{\mathbb{S}}$, and $\hat{\lambda}_{\mathbb{A}}$, respectively.

\section{[Insert Table 6 here]}

Table 6 presents the results of the Fama-MacBeth test. It appears that all estimates of factor premium are statistically significant at least at the five percent level. Thus, the empirical evidence supports that from a cross-sectional aspect, $\lambda_{S w V}$ is a common pricing factor for risk-averse and expected utility maximizing investors. If investors also have preference (aversion) for (to) the prospect of potential upside gains (downside losses), then the common factors, $\lambda_{\mathbb{S}}$ and $\lambda_{\mathbb{A}}$, are 
necessary to be considered in the determination of return generating process for all risky assets. That is, the MVA asset pricing model can be viewed as an important extension of the traditional approach purely based on risk-aversion assumption in that it takes the main argument of the prospect theory into consideration.

To further examine the robustness of the MVA pricing model, I test the sufficiency of the common factors in explaining the equilibrium returns on assets. If MVA model shown in (19) is valid, then the residual returns of individual assets, $\varepsilon_{j, t}=R_{j, t}-\left(\hat{\beta}_{j}^{\mathbb{S}} R_{m, t}^{\mathbb{S}}+\hat{\beta}_{j}^{\mathbb{A}} R_{m, t}^{\mathbb{A}}\right)$, should be idiosyncratic. Thus, no other common factors would have explanatory power to $\varepsilon_{j, t}$. For an illustration, in this paper, I focus on four important empirical factors of Fama and French (1993, 2016: $S M B, H M L, R M W$, and $C M A$, respectively. Again, by employing the Fama-MacBeth approach, I first calculated the factor loadings from the following regression model: $\varepsilon_{j, t}=\alpha_{j}+$ $\beta_{j}^{S M B} S M B_{t}+\beta_{j}^{H M L} H M L_{t}+\beta_{j}^{R M W} R M W_{t}+\beta_{j}^{C M A} C M A_{t}+e_{j, t}$, over the past 60 months. Then, at the beginning of each period, 60 equal-sized portfolios sorted by the beginning-of-period beta estimates are formed from the entire sample. To calculate estimates of factor-premium, $\hat{\lambda}_{S M B}$, $\hat{\lambda}_{H M L}$, and $\hat{\lambda}_{R M W}$, and $\hat{\lambda}_{C M A}$, accordingly, I then, in a cross-sectional framework, regress all portfolio residuals, $\varepsilon_{p}$, against multiple beta estimates of factor loading, $\hat{\beta}_{p}^{S M B}, \hat{\beta}_{p}^{H M L}, \hat{\beta}_{p}^{R M W}$, and $\hat{\beta}_{p}^{C M A}$, respectively.

[Insert Table 7 here] 
Panel 1 of Table 7 reports factor premium estimates of the Fama-French original two-factor approach. I exclude the market factor in that it is already embedded in the MVA factors. Panel 2 shows the results from the multiple cross-sectional regression of Fama-French newly proposed with four empirical pricing factors. Statistically, I found none of the $\lambda$ estimates is significant, indicating the Fama-French empirical pricing factors have no impact on the residual returns of assets calculated from the MVA model. The MVA asset pricing model is robust in describing the cross-sectional returns on risky equity securities. From the previous discussion, the traditional MV model is a valid approach, if returns on the asset are symmetrically distributed. Therefore, intuitively, the difference between MVA and MV models is merely the impact of asymmetries in returns, and the asymmetry factor $\lambda_{\mathbb{A}}$ characterizes this difference.

In short, logically, the symmetry is unique. However, the appearance of asymmetry could be infinite; similar to the case that there is an endless number of distributional moments in determining the return asymmetry. Therefore, at least in theory, it is possible to have infinite amounts of empirical factors identified from the sample data that can describe the phenomenon of pricing asymmetry in equilibrium. The contribution of this dissertation is to provide a simple methodology that converges all possible distributional or pricing asymmetries into a summary statistic or a common factor.

\section{B. Mean-Variance and Mean-Swap Variance Betas}

This dissertation uses monthly returns of portfolios from the Kenneth French Database over the 1932 to 2015 sample period. The six different portfolios are three size-sorted and three-value 
sorted portfolios according to the Kenneth French Database. I compute betas using portfolio returns and market return over the past 60 months. Mean-variance betas are computed using singlefactor CAPM; MSwV betas are computed by the MSwV asset pricing model that was introduced in the previous section, and tail betas are the difference between two betas. Table 2 reports the descriptive statistics of portfolio betas.

[Insert Table 8 here]

On average, tail betas located in quintiles 2-4 are approximately equal to 0 on all six portfolios. But tail betas on extreme conditions are far different than 0. Except in large-size portfolios, tail betas are smaller than -0.15 on lower quintile, and larger than 0.10 on higher quintile. The result shows that under extreme conditions $\mathrm{MV}$ beta and $\mathrm{MSwV}$ beta are significantly different, and traditional MV beta may lose information on high moments. Moreover, comparing across different portfolios, small size portfolios and high B/M portfolios have very large tail betas; large size portfolios, oppositely, have small tail betas.

\section{C. $\quad$ Factor Portfolios Mimicking Loss Aversion and Gain Preference}

To investigate how asymmetric risk is priced in the cross-section of equity returns, I follow Fama and French's (1993) factor generating process. I construct a set of assets that are sufficiently diverse in exposure to asymmetric risk by sorting firms on absolute values of beta difference over 
the past month with daily data. I compute betas for all stocks on CRSP with share code 10 and 11, and with more than 17 daily observations for each month. In a setting in which coefficients potentially vary over time, a one-month window with daily data is a natural compromise between estimating coefficients with a reasonable degree of precision and pinning down conditional coefficients in an environment with time-varying factor loadings. At the end of each month, I sort stocks into quintiles, based on the value of the realized $\beta_{i}^{L}$ and $\beta_{i}^{G}$ coefficients over the past month. Firms in quintile 1 have the lowest coefficients, while firms in quintile 5 have the highest beta loadings. Within each quintile portfolio, I value weight the stocks. I link the returns across time to form one series of post-ranking returns for each quintile portfolio.

\section{[Insert Table 9 here]}

Table 9 reports summary statistics for quintile portfolios sorted by past $\beta_{i}^{L}$ and $\beta_{i}^{G}$ over the previous month using equation (21). The first three columns report the mean, standard deviation and square root of $\mathrm{SwV}$ of monthly holding period returns. In the column under the heading preformation $\beta_{i}^{\mathbb{A}} / \beta_{i}^{L} / \beta_{i}^{G}$, I report the pre-formation $\beta_{i}^{\mathbb{A}} / \beta_{i}^{L} / \beta_{i}^{G}$ coefficients, which are computed at the beginning of each month for each portfolio and are value weighted. The column reports the time series average of the pre-formation beta loadings across the whole sample. By construction, since the portfolios are formed by ranking on past betas, the pre-formation beta loadings monotonically increase from portfolio 1 to portfolio 5 . The $\beta_{i}^{\mathbb{A}}$ ranking portfolio returns show a U-shape; applying stocks with very low or very high pre-formation $\beta_{i}^{\mathbb{A}}$ have a better sample performance. The 5-1 
spreads are not significant for both value-weighted and equal-weighted portfolios. Now I rank the stocks by $\beta_{i}^{L}$ and $\beta_{i}^{G}$, and there is a significant trend from quintile 1 to quintile 5 . In value-weighted portfolios, $\beta_{i}^{L}$ ranked portfolio monthly holding period returns increase from $0.694 \%$ for quintile 1 to $1.337 \%$ for quintile 5 , while $\beta_{i}^{G}$ ranked portfolio monthly holding period returns decrease from $1.329 \%$ for quintile 1 to $0.746 \%$ for quintile 5. Equal-weighted portfolios show the same trends. So based on the idea of Arbitrage Pricing Theory (APT), I can construct a positive symmetric risk factor and a negative symmetric risk factor using the 5-1 spreads by $\beta_{i}^{L}$ and $\beta_{i}^{G}$ sorted portfolios, respectively. Table 10 reports the correlation between different factors. Market factor, loss aversion risk factor, and size factor have positive correlation, while gain preference risk factor and value factor have positive correlation. But the correlations between factors in these two groups are negative. The negative correlation between loss aversion and gain preference factors is consistent with the $\mathrm{U}$-shape quintile portfolio returns when I rank $\beta_{i}^{\mathbb{A}}$.

\section{[Insert Table 10 here]}

In addition, this study computes the asymmetric risk factor after controlling the effect of Fama and French's size and value factors. First, I run the Fama-French three factor model, and find the residuals that exclude the component related to size and value. Mathematically, $\operatorname{Res}_{i}=$ $R_{i}-\beta_{S M B} S M B-\beta_{H M L} H M L$. This residual contains the information of market return but is uncorrelated with size and value factors. Then I compute MV beta and MSwV beta using market return and this residual, and then I sort quintile portfolios by the new beta difference. Table 11 reports the off-sample performance of quintile portfolios after controlling size and value factors. 
The results show the same pattern as before the adjustment. For both equal-weighted and valueweighted portfolios, $\beta_{i}^{\mathbb{A}}$ sorted quintile portfolio returns show U-shape, positive $\beta_{i}^{\mathbb{A}}\left(\beta_{i}^{L}\right)$ sorted quintile portfolio returns increase significantly from quintile 1 to quintile 5 , and negative $\beta_{i}^{\mathbb{A}}\left(\beta_{i}^{G}\right)$ sorted quintile portfolio returns decrease significantly. The results of robustness tests empirically support that positive and negative asymmetric risk factors are critical in asset pricing.

\section{[Insert Table 11 here]}

Moreover, Figure 6 shows the security market plane (SMP) in three-dimensions according to the U-shape return premium of asymmetric beta. The SMP represents the equilibrium asset pricing result of the MSwV approach in that $\beta^{S w V}$ is the co-effect of $\beta^{S}$ and $\beta^{\mathbb{A}}$. Note that for a level of systematic risk, securities that are insensitive to the distributional asymmetries in market returns (i.e. $\beta^{\mathbb{A}}=0$ ) would have the lowest expected return. For instance, the expected return of asset $i$ (j) with a positive (negative) $\beta_{i}^{\mathbb{A}}$ should have higher expected returns than those determined from the SML. The curvature of the SMP could attribute to the fact that the risk premium of individual assets are determined by two fundamentally different factors: the systemic and an upside distributional asymmetry (or a downside asymmetry). The positive (negative) factor risk-premium also intuitively implies that investors are gain-preference (loss-averse) toward upside (downside) market return-asymmetry. Nevertheless, to theoretically formulate the SMP as the equilibrium pricing results of the expected utility optimization, it is necessary to redefine utility functions for incorporating with the shift of investor risk attribute toward return-asymmetry. 
[Insert Figure 6 here]

\section{Testing for Behavioral Asset Pricing Model}

This dissertation explores the cross-sectional return characteristics of portfolios based on size and also based on B/M value over the 1969-2015 sample period. My empirical tests are in the spirit of Fama and MacBeth (1973). Fama and MacBeth test the CAPM with a two-pass procedure that first sorts stocks into portfolios on the basis of historical beta estimates and then estimates the mean cross-sectional relationship between the portfolio returns and portfolio betas for each period. At the end of each calendar year, I rank all ordinary common stocks included in the CRSP file that have share code 10 or 11 by different betas and divide the sample into 60 portfolios of equal size. The portfolios increase from about 431 stocks per portfolio in 1969 to about 747 stocks in 2015. For each period, I estimate a cross-sectional regression of the period portfolio returns on the loadings on MKT, SMB, HML, and asymmetric factor loadings, and then average the $T$ estimates to produce a sample Fama-MacBeth coefficient estimate.

\section{[Insert Table 12 here]}

Table 12 reports the results for a three-factor model with market, loss aversion, and gain preference, as well as a five-factor model adding size and value factors. For each period, portfolio returns are regressed on these five factor loadings. These loadings are computed by regressing 
portfolio returns over the past 60 periods on the MKT, $f_{L}, f_{G}$, SMB and HML, respectively. The dissertation finds the asymmetric factor loading has significant explanatory power for portfolio returns for most of the sorting methods. The factor price for loss aversion beta is positive, while the factor price for gain preference beta is negative. Moreover, when including the asymmetric factor, size factor still has impact on asset return, but value factor seems to lose its influence on asset pricing. 


\section{Conclusion}

By employing conventional methods of expected utility optimization, I develop the equilibrium pricing models under the frameworks of MSwV and MVA, respectively. The MSwV approach is a single factor model and is similar to the CAPM. However, for calculating the beta coefficient, the market factor needs to be replaced by the MSwV optimal portfolio, and the covariance (variance) has to be substituted by the $\mathrm{CoSwV}(\mathrm{SwV})$. I show empirically that the $\mathrm{MSwV}$ model is superior to the MV approach mainly for returns that are asymmetrically distributed.

The MVAl asset pricing approach, a two-factor model that serves as an extension of the CAPM, quantifies the deterministically systematic components of equilibrium returns on risky assets between symmetry and asymmetry, respectively. Crucially, the MVA model is unbiased not only to risk-aversion but also to upside gain-preference as well as to downside loss-aversion. Based on the Fama-MacBeth tests, I show that the MVA is empirically robust. Based on data from the U.S. equity markets, I further find that with the MVA factors of symmetry and asymmetry, the conventional empirical pricing factors lose their explanatory power to the cross-sectional expected returns on assets. My analysis implies that since only two fundamental factors are sufficient for determining the systematic risk of assets, most empirically defined factors perhaps capture just parts of the phenomenon of pricing asymmetry in equilibrium.

Moreover, this dissertation develops asymmetric-risk factors following Fama and French's (1992) approach and extends the MSwV asset pricing model to a multifactor model based on the 
idea of APT. The empirical results show that the portfolios with higher loss aversion have higher consequent returns, while the portfolios with higher gain preference have lower consequent returns. That means the expected return corresponded to loss aversion is positive, while expected return corresponded to gain preference is negative, suggesting investors have different attitudes to risk on the two sides. This result is consistent with behavior theory that investors gain preference when they realize large profits, and they become loss averse when they suffer large losses. 


\section{Appendix}

\section{Proof of Theorems 1 and 2}

Suppose $R_{i}$ stochastically dominate $R_{j}$ such that $E U\left(R_{i}\right) \geq E U\left(R_{j}\right)$. From (3), I have

$$
E U\left(R_{i}\right)-E U\left(R_{j}\right)=U\left(\mu_{i}\right)-U\left(\mu_{j}\right)+\theta \cdot\left(\mathrm{SwV}_{i}-\mathrm{SwV}_{j}\right) \geq 0
$$

where $\theta=\frac{\mathbb{U}\left(U, \mu_{i}, R_{i}^{o}\right) S w V_{i}-\mathbb{U}\left(U, \mu_{j}, R_{j}^{o}\right) S w V_{j}}{S w V_{i}-S w V_{j}}$. Based on mean value theorem, $\theta$ is a number between $\mathbb{U}\left(U, \mu_{i}, R_{i}^{o}\right)$ and $\mathbb{U}\left(U, \mu_{j}, R_{j}^{o}\right)$, and thus $\theta \leq 0$. The conditions that $\mu_{i} \geq \mu_{j}$, and $\operatorname{SwV}_{i}=\operatorname{SwV}_{j}$ are necessary to ensure the inequality (A-1) for all investors who prefer more to less $\left(U^{\prime} \geq 0\right)$ without further restriction on the utility function. For risk-averse investors where $\mathbb{U}\left(U, \mu, R^{o}\right) \leq 0$, in addition to higher mean return, the condition $S w V_{i} \leq S w V_{j}$ is necessary for the inequality (A-1).

To prove the sufficiency of FSD, consider risk-neutral investors in which $\frac{\theta}{U^{\prime}(0)}$ approaches zero, the condition $\mu_{i} \geq \mu_{j}$ must hold to have the inequality (A-1). Even for the most risk-averse (risk-loving) investors, where the ratio $\frac{\theta}{U^{\prime}(0)}$ is extremely positive (negative), the condition $S w V_{i}=$ $S w V_{j}$ is sufficient to have the stochastic dominance.

The sufficiency of SSD can be determined by considering the most (least) risk-averse investors. That is, even if the ratio $\frac{\theta}{U^{\prime}(0)}$ is extremely negative (approaches zero) in value, the condition, $\mathrm{SwV}_{i} \leq \mathrm{SwV}_{j}\left(\mu_{i} \geq \mu_{j}\right)$ must hold for the stochastic dominance. 


\section{Derivation of Proposition 1}

Suppose the optimal market portfolio is MSwV efficient with returns denoted $R_{m}^{S w V}$, I define the Lagrange function of expected utility with respect to its mean and $\mathrm{SwV}$ as well as the risk-free rate.

$$
L=E U\left[\mu\left(R_{m}^{S w V}\right), S w V\left(R_{m}^{S w V}\right)\right]-\lambda\left(1-\sum_{i} w_{i}-f\right),
$$

where $\lambda$ is the Lagrange multiplier, and $f$ is the weight of risk-free asset. Now, take the partial derivative of the Lagrange function with respect to $w_{i}$ and $f$, respectively, I have

$$
\frac{\partial L}{\partial w_{i}}=\frac{\partial E U\left[\mu\left(R_{m}^{S w V}\right), S w V\left(R_{m}^{S w V}\right)\right]}{\partial \mu\left(R_{m}^{S w V}\right)} * \frac{\partial \mu\left(R_{m}^{S w V}\right)}{\partial w_{i}}+\frac{\partial E U\left[\mu\left(R_{m}^{S w V}\right), S w V\left(R_{m}^{S w V}\right)\right]}{\partial S w V\left(R_{m}^{S w V}\right)} * \frac{\partial S w V\left(R_{m}^{S w V}\right)}{\partial w_{i}}-\lambda=0,
$$

and

$$
\frac{\partial L}{\partial f}=\frac{\partial E U\left[\mu\left(R_{m}^{S w V}\right), S w V\left(R_{m}^{S w V}\right)\right]}{\partial \mu\left(R_{m}^{S w V}\right)} * \frac{\partial \mu\left(R_{m}^{S w V}\right)}{\partial f}+\frac{\partial E U\left[\mu\left(R_{m}^{S w V}\right), S w V\left(R_{m}^{S w V}\right)\right]}{\partial S w V\left(R_{m}^{S w V}\right)} * \frac{\partial S w V\left(R_{m}^{S w V}\right)}{\partial f}-\lambda=0 .
$$

Subtract (A-4) from (A-3), and note that $\frac{\partial S w V\left(R_{m}^{S w V}\right)}{\partial w_{i}}=\operatorname{CoSwV}\left(R_{i}, R_{m}^{S w V}\right), \frac{\partial S w V\left(R_{m}^{S w V}\right)}{\partial f}=0$, and $\left(\frac{\partial \mu\left(R_{m}^{S w V}\right)}{\partial w_{i}}-\frac{\partial \mu\left(R_{m}^{S w V}\right)}{\partial f}\right)=E\left(R_{i}-R_{f}\right)$, I obtain the equilibrium condition for individual assets corresponding to the optimal portfolio as:

$$
E\left(R_{i}-R_{f}\right)=\frac{-\operatorname{CoSwV}\left(R_{i}, R_{m}^{S w V}\right) \frac{\partial E U\left[\mu\left(R_{m}^{S W V}\right), S w V\left(R_{m}^{S w V}\right)\right]}{\partial S w V\left(R_{m}^{S w V}\right)}}{\frac{\partial E U\left[\mu\left(R_{m}^{S w V}\right), S w V\left(R_{m}^{S w V}\right)\right]}{\partial \mu\left(R_{m}^{S W W}\right)}}
$$

The condition in (A-5) also holds for the market portfolio that

$$
E\left(R_{m}^{S w V}-R_{f}\right)=\frac{-S w V\left(R_{m}^{S w V}\right) \frac{\partial E U\left[\mu\left(R_{m}^{S w V}\right), S w V\left(R_{m}^{S w V}\right)\right]}{\partial S w V\left(R_{m}^{S w V}\right)}}{\frac{\partial E U\left[\mu\left(R_{m}^{S w V}\right), S w V\left(R_{m}^{S w V}\right)\right]}{\partial \mu\left(R_{m}^{S w V}\right)}}
$$

Finally, divide (A-5) by (A-6), we have equations (17.1) and (17.2). 


\section{Proof of Proposition 2:}

Suppose the optimal market portfolio is MVA efficient with returns denoted $R_{m}^{\mathrm{MVA}}\left(=R_{m}^{\mathbb{S}^{\perp}}+R_{m}^{\mathrm{A}^{\perp}}\right)$. I define the Lagrange function of expected utility with respect to its mean, variance and $\mathbb{A}$, as well as the risk-free rate.

$$
L=E U\left[\mu\left(R_{m}^{\mathrm{MVA}}\right), \operatorname{Var}\left(R_{m}^{\mathrm{MVA}}\right), \mathbb{A}\left(R_{m}^{\mathrm{MVA}}\right)\right]-\lambda\left(1-\sum_{i} w_{i}-f\right),
$$

Since $U$ is the aggregated utility, the optimal portfolio is the market portfolio in equilibrium. Then, the first order condition of (A-7) can be written as:

$$
\frac{\partial L}{\partial w_{i}}=\left[\frac{\partial E U}{\partial \mu\left(R_{m}^{\mathrm{MVA}}\right)} \cdot \frac{\partial \mu\left(R_{m}^{\mathrm{MVA}}\right)}{\partial w_{i}}\right]+\left[\frac{\partial E U}{\partial \operatorname{Var}\left(R_{m}^{\mathrm{MVA}}\right)} \cdot \frac{\partial \operatorname{Var}\left(R_{m}^{\mathrm{MVA}}\right)}{\partial w_{i}}\right]+\left[\frac{\partial E U}{\partial \mathbb{A}\left(R_{m}^{\mathrm{MVA}}\right)} \cdot \frac{\partial \mathbb{A}\left(R_{m}^{\mathrm{MVA}}\right)}{\partial w_{i}}\right]-\lambda=0,
$$

and

$$
\frac{\partial L}{\partial f}=\frac{\partial E U}{\partial \mu\left(R_{m}^{\mathrm{MVA}}\right)} \cdot \frac{\partial \mu\left(R_{m}^{\mathrm{MVA}}\right)}{\partial f}-\lambda=0
$$

Since $\operatorname{Var}\left(R_{m}^{\mathrm{MVA}}\right)=\operatorname{Var}\left(R_{m}^{\mathbb{S}^{\perp}}\right)$, and $\mathbb{A}\left(R_{m}^{\mathrm{MV} \mathbb{A}}\right)=\mathbb{A}\left(R_{m}^{\mathbb{A}^{\perp}}\right)$, equation A-8 can be rewritten as:

$$
\frac{\partial L}{\partial w_{i}}=\left[\frac{\partial E U}{\partial \mu\left(R_{m}^{\mathrm{MVA}}\right)} \cdot \frac{\partial \mu\left(R_{m}^{\mathrm{MVA}}\right)}{\partial w_{i}}\right]+\left[\frac{\partial E U}{\partial \operatorname{Var}\left(R_{m}^{\mathbb{S}^{\perp}}\right)} \cdot \frac{\partial \operatorname{Var}\left(R_{m}^{S^{\perp}}\right)}{\partial w_{i}}\right]+\left[\frac{\partial E U}{\mathbb{A}\left(R_{m}^{\mathbb{A}^{\perp}}\right)} \cdot \frac{\partial \mathbb{A}\left(R_{m}^{\mathbb{A}^{\perp}}\right)}{\partial w_{i}}\right]-\lambda=0,
$$

Subtract (A-9) from (A-10), and note that $\frac{\partial \operatorname{Var}\left(R_{m}^{\mathbb{S}^{\perp}}\right)}{\partial w_{i}}=\operatorname{CoV}\left(R_{i}, R_{m}^{\mathbb{S}^{\perp}}\right), \frac{\partial \mathbb{A}\left(R_{m}^{\mathbb{A}^{\perp}}\right)}{\partial w_{i}}=\operatorname{CoS} w V\left(R_{i}, R_{m}^{\mathrm{A}^{\perp}}\right)-$ $\frac{\operatorname{Cov}\left(R_{i}, R_{m}^{A^{\perp}}\right)}{\left[1+\mu\left(R_{m}^{\mathrm{A}}\right)\right]^{2}}$, and $\left[\frac{\partial \mu\left(R_{m}^{\mathrm{MVA}}\right)}{\partial w_{i}}-\frac{\partial \mu\left(R_{m}^{\mathrm{MVA}}\right)}{\partial f}\right]=\left[E\left(R_{i}\right)-R_{f}\right]$, I obtain the following equation for individual assets corresponding to the optimal portfolio:

$$
E\left(R_{i}\right)-R_{f}=\frac{-\left[\frac{\partial E U}{\partial \operatorname{Var}\left(R_{m}^{S^{\perp}}\right)}\right]}{\left[\frac{\partial E U}{\partial \mu\left(R_{m}^{\mathrm{MVA}}\right)}\right]} \operatorname{CoV}\left(R_{i}, R_{m}^{S^{\perp}}\right)+\frac{\left[\frac{\partial E U}{\mathbb{A}\left(R_{m}^{\mathbb{A}^{\perp}}\right)}\right]}{\left[\frac{\partial E U}{\partial \mu\left(R_{m}^{\mathrm{MVA}}\right)}\right]}\left[\operatorname{CoSwV}\left(R_{i}, R_{m}^{\mathbb{A}^{\perp}}\right)-\frac{\operatorname{CoV}\left(R_{i}, R_{m}^{A^{\perp}}\right)}{\left[1+\mu\left(R_{m}^{\mathbb{A}^{\perp}}\right)\right]^{2}}\right]
$$




$$
\begin{aligned}
& E\left(R_{m}^{\mathbb{S}^{\perp}}-R_{f}\right)=\frac{-\left[\frac{\partial E U}{\partial \operatorname{Var}\left(R_{m}^{S^{\perp}}\right)}\right]}{\left[\frac{\partial E U}{\partial \mu\left(R_{m}^{\mathrm{MVA}}\right)}\right]} \operatorname{Var}\left(R_{m}^{S^{\perp}}\right) \\
& E\left(R_{m}^{\mathbb{A}^{\perp}}-R_{f}\right)=\frac{\left.\left[\frac{\partial E U}{\mathbb{A}\left(R_{m}^{\mathbb{A}}\right)}\right]\right]}{\left[\frac{\partial E U}{\partial \mu\left(R_{m}^{M V A}\right)}\right]}\left[\operatorname{SWV}\left(R_{m}^{\mathbb{A}^{\perp}}\right)-\frac{\operatorname{Var}\left(R_{m}^{\mathbb{A}}\right)}{\left[1+\mu\left(R_{m}^{\mathbb{A}}\right)\right]^{2}}\right]
\end{aligned}
$$

Finally, substitute (A-12) and (A-13) into (A-11), I have (19.1) and (19.2). 
Figures and Tables 


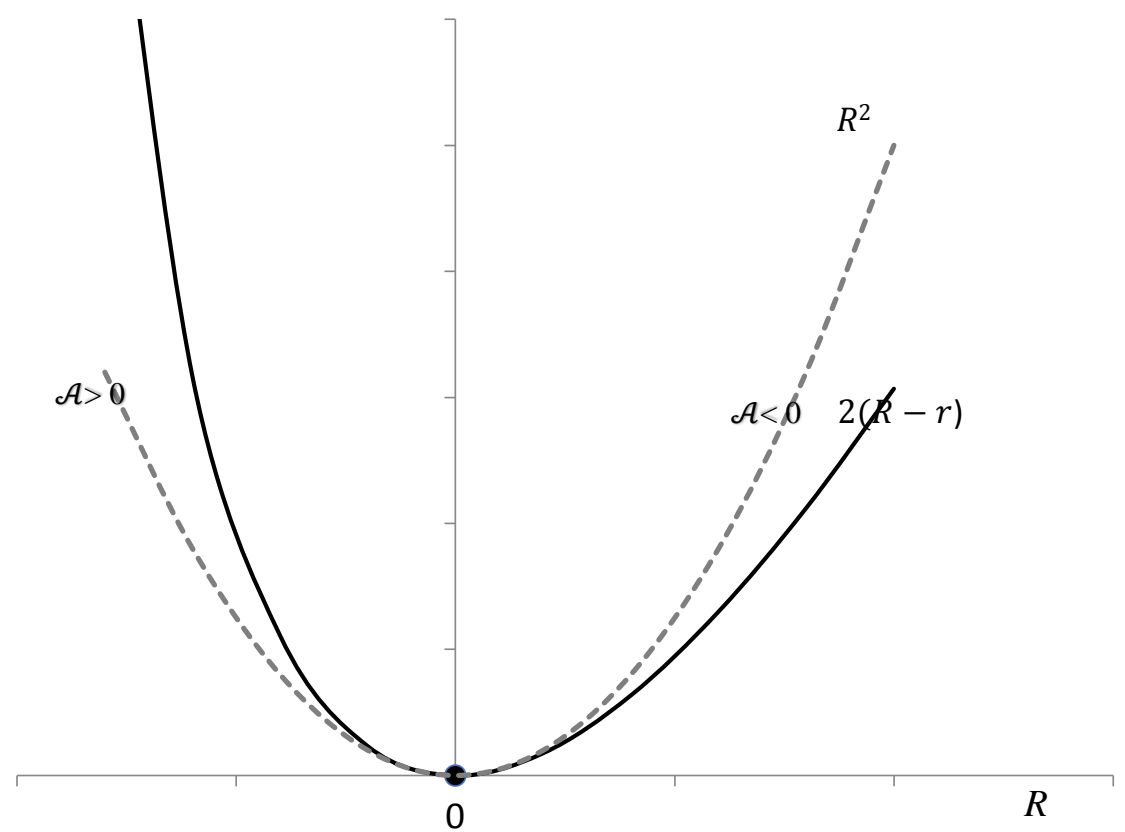

\begin{tabular}{|c|c|c|c|c|c|c|}
\hline $\mathrm{R}$ & -0.1 & -0.06 & -0.02 & 0.02 & 0.06 & 0.1 \\
\hline$\%$ Diff & $7.2 \%$ & $4.2 \%$ & $1.4 \%$ & $-1.3 \%$ & $-3.8 \%$ & $-6.2 \%$ \\
\hline
\end{tabular}

Figure 1: Symmetric $R^{2}$ vs. Asymmetric 2(R-r)

This figure shows that the asymmetries in return, quantified by the difference between $2(R-r)$ and $R^{2}$, where $R>-1, \quad r=\ln (1+R), \quad$ and $\mathcal{A}=\left[2(R-r)-R^{2}\right]=$ $\sum_{k=3}^{\infty}(-1)^{k}\left(\frac{2}{k}\right) R^{k} . R^{2}$ is less (higher) than $2(R-r)$ if $R$ is negative (positive). That implies the variance understates (overstates) the downside (upside) risk if returns are asymmetrically distributed. 


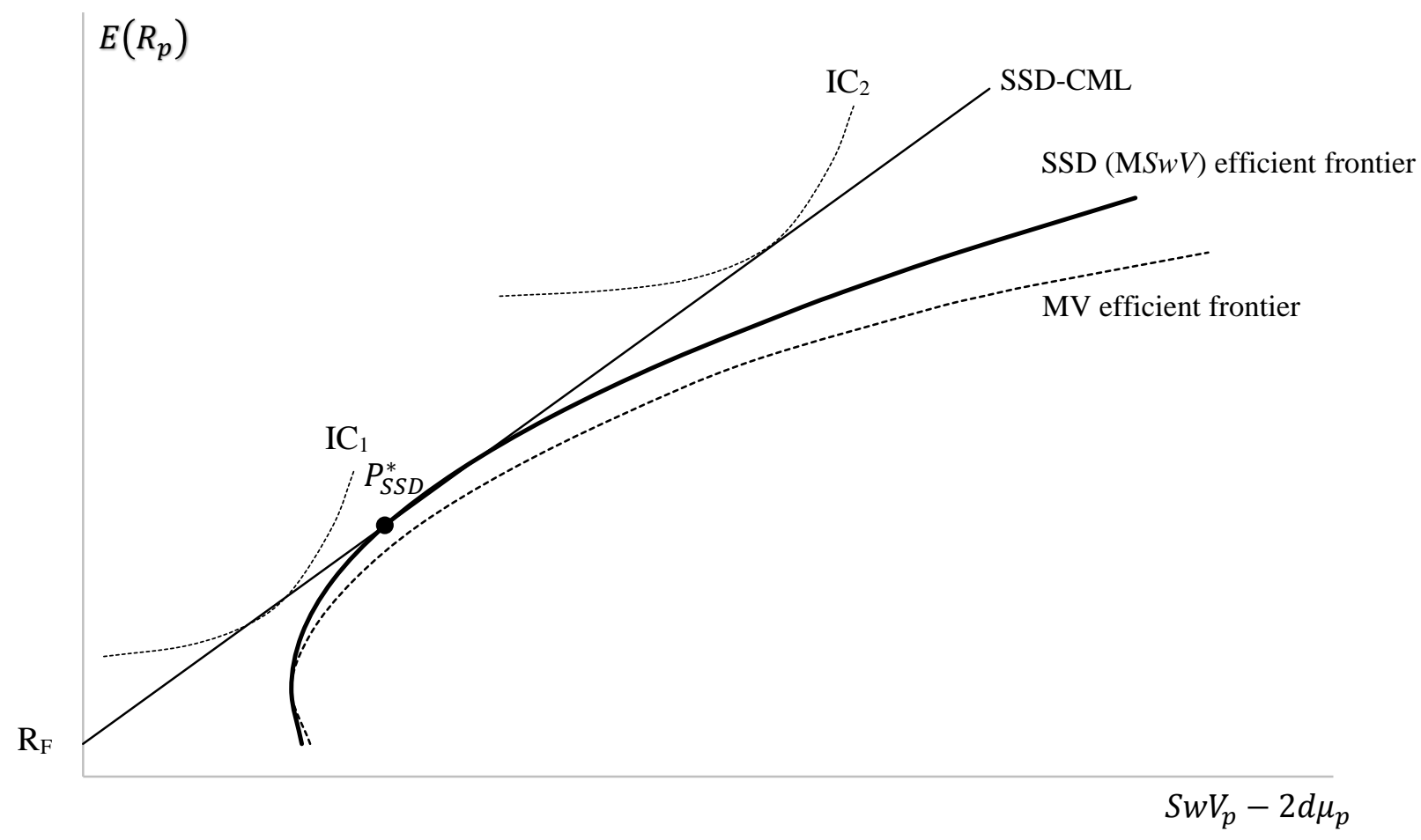

Figure 2. SSD Efficiency and Portfolio Separation This figure depicts a simulated MSwV efficient frontier of portfolios (solid line) generated from random returns of three hypothetical distributions: normal, lognormal, and gamma, respectively. The random sample has means ranging from -0.2 to 0.2 , standard deviations from 0.4 to 0.7 , and correlation coefficients from -0.3 to 0.7 , accordingly. For a comparison, we also plot the MV efficient frontier (dash line) in the MSwV space. With a risk-free asset, an optimal SSD portfolio of risky assets, denoted $P_{S S D}^{*}$, can then be determined by the point on the SSD efficient curve to which the SSD capital market line (SSD-CML) is the tangent with the highest risk-adjusted mean return. The convex curves, $\mathrm{IC}_{1}$ and $\mathrm{IC}_{2}$, are indifference curves. The convexity of indifference curve presents the diminishing marginal rates of substitution between expected return and $S w V$. 


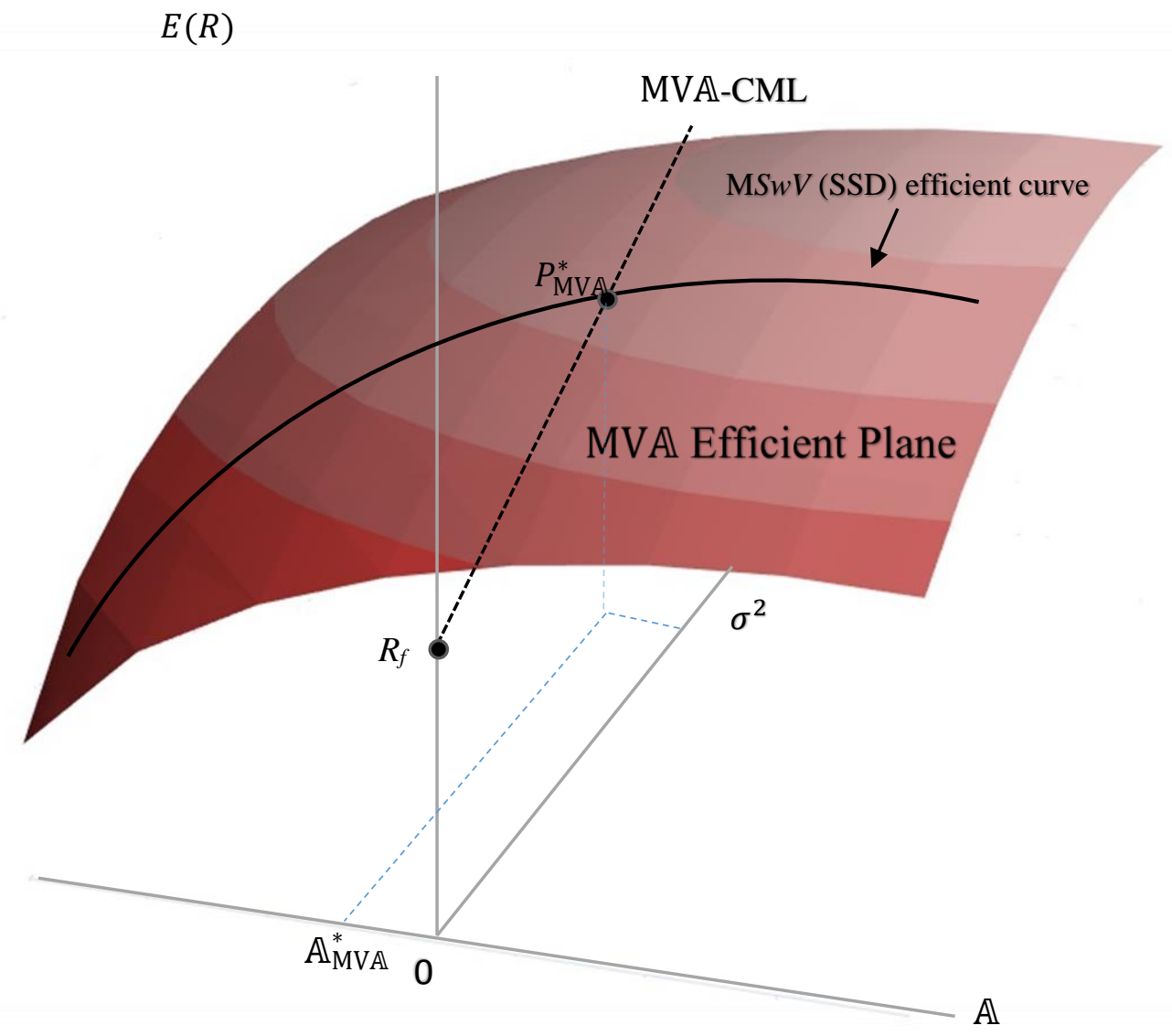

Figure 3. Stochastic Dominance Efficient Frontier and Capital Market Line (CML) This figure depicts the SSD and MVA efficient portfolios and the CMLs in a three-dimensional space with respect to mean, variance and $\mathbb{A}$, where $\mathbb{A}_{p}=S w V_{p}-\left(\frac{\sigma_{p}}{1+\mu_{p}}\right)^{2}$. The SSD (or mean$S w V)$ efficient curve is the upper part of the minimum- $S w V$ portfolios for every levels of the mean return. The MVA optimal portfolios are the minimum-Al portfolios for every levels of the mean return and those of the variance. With a risk-free asset, the SSD optimal portfolio is unique and is the point on the SSD efficient curve to which the SSD capital market line (SSDCML) is the tangent with the highest risk-adjusted mean return. 


\section{Figure 4}

\section{Moving Pattern of the Optimal Hedge Ratios for S\&P 500 Index}

Figure shows the moving patterns of hedge ratios for S\&P 500 index. Panel A shows the minimizingswap variance hedge ratio, Panel B shows the minimizing-variance hedge ratio, and Panel $\mathrm{C}$ shows the difference between the two hedge ratios.

Panel A: Minimizing-Variance Hedge Ratios

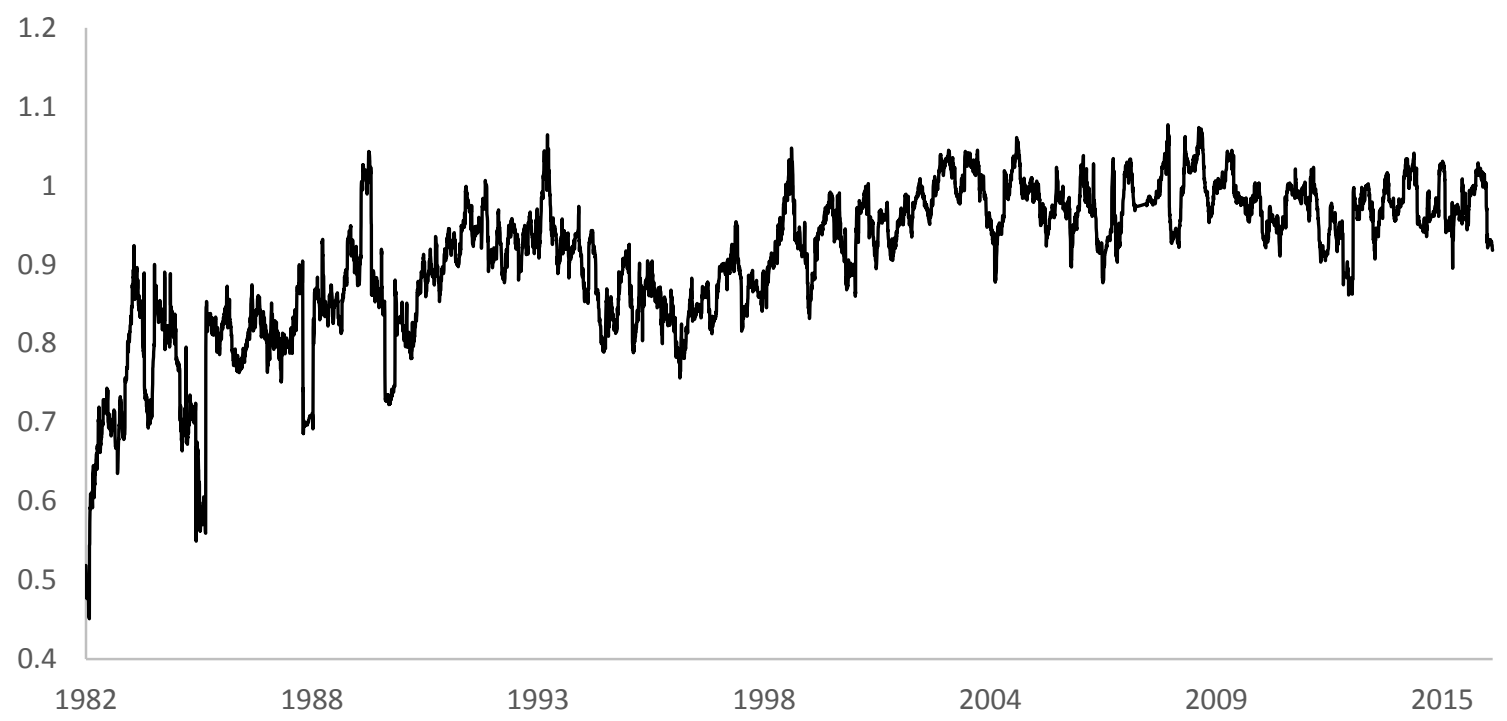


Panel B: Minimizing-Swap Variance Hedge Ratios

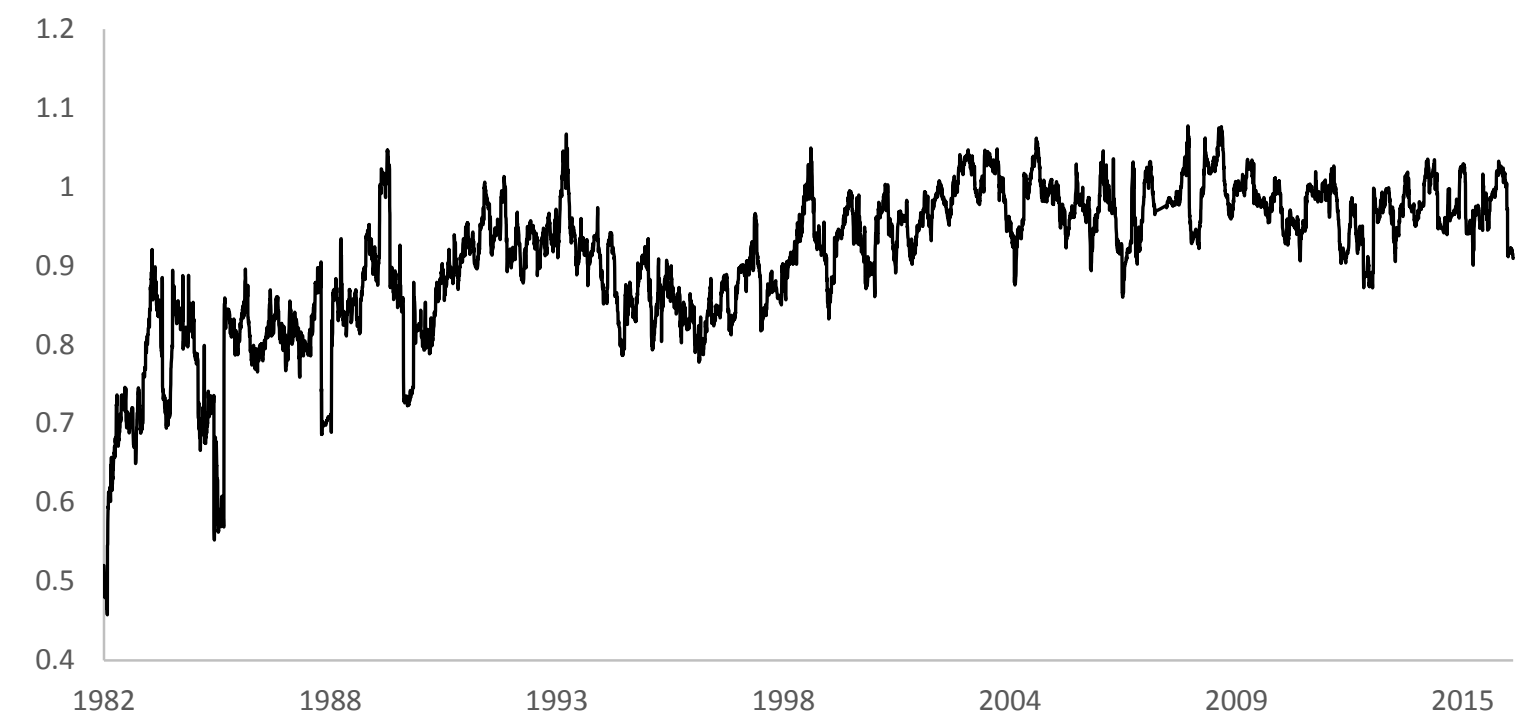

Panel C: Difference Between Hedge Ratios of Minimizing-Swap Variance and MinimizingVariance

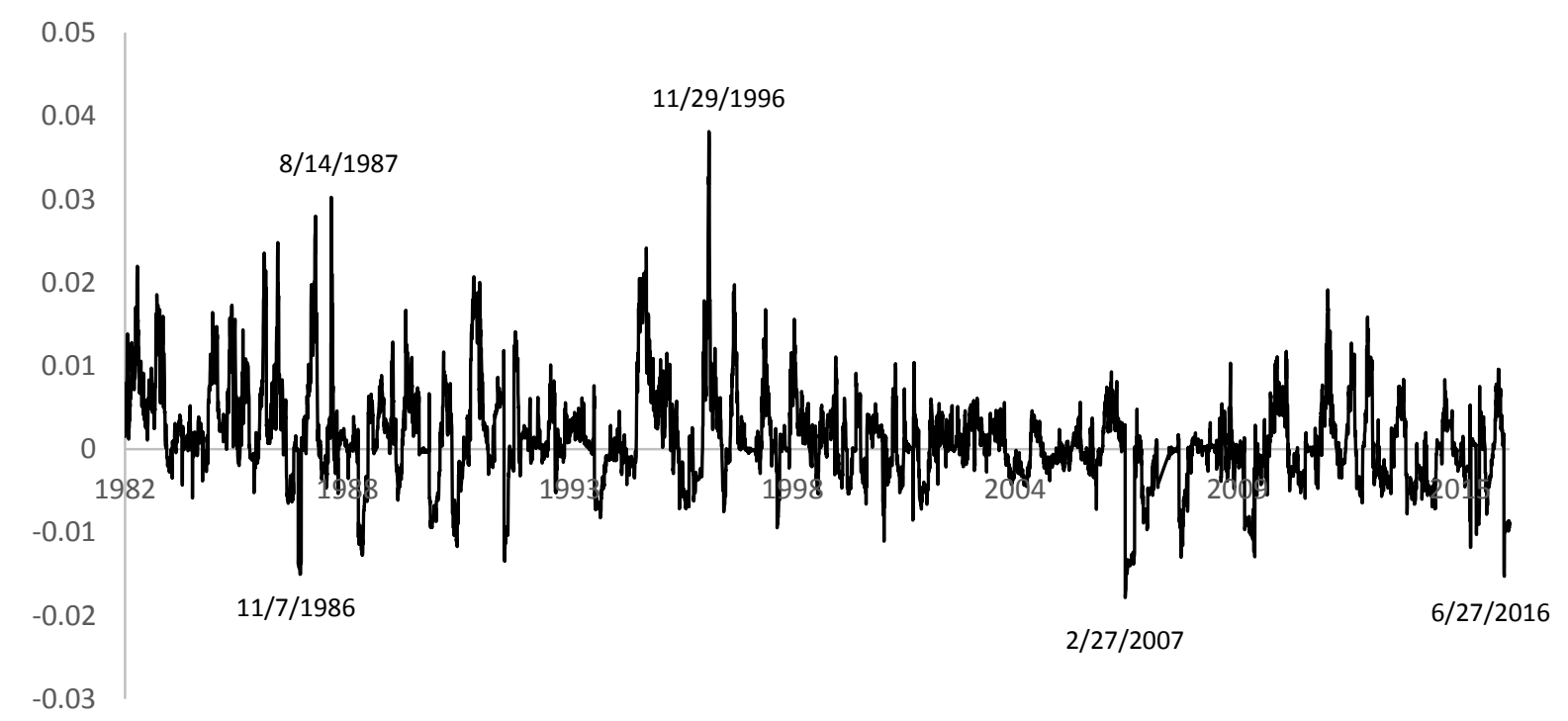




\section{Figure 5}

\section{Moving Pattern of the Optimal Hedge Ratios on the Crude Oil Markets}

Figure shows the moving patterns of hedge ratios on the WTI crude oil market. Panel A shows the minimizing-swap variance hedge ratio, Panel B shows the minimizing-variance hedge ratio, and Panel C shows the difference between the two hedge ratios.

Panel A: Minimizing-Variance Hedge Ratios

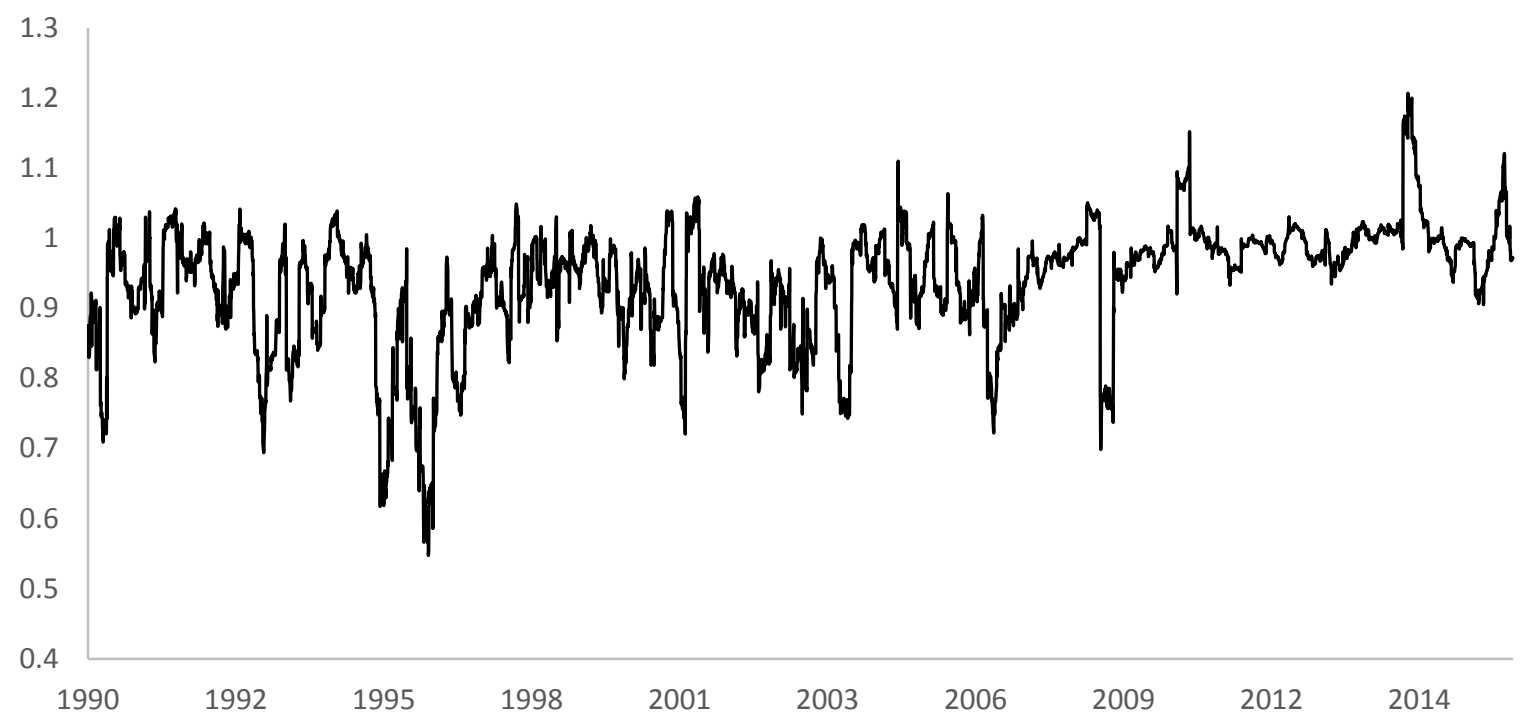


Panel B: Minimizing-Swap Variance Hedge Ratios

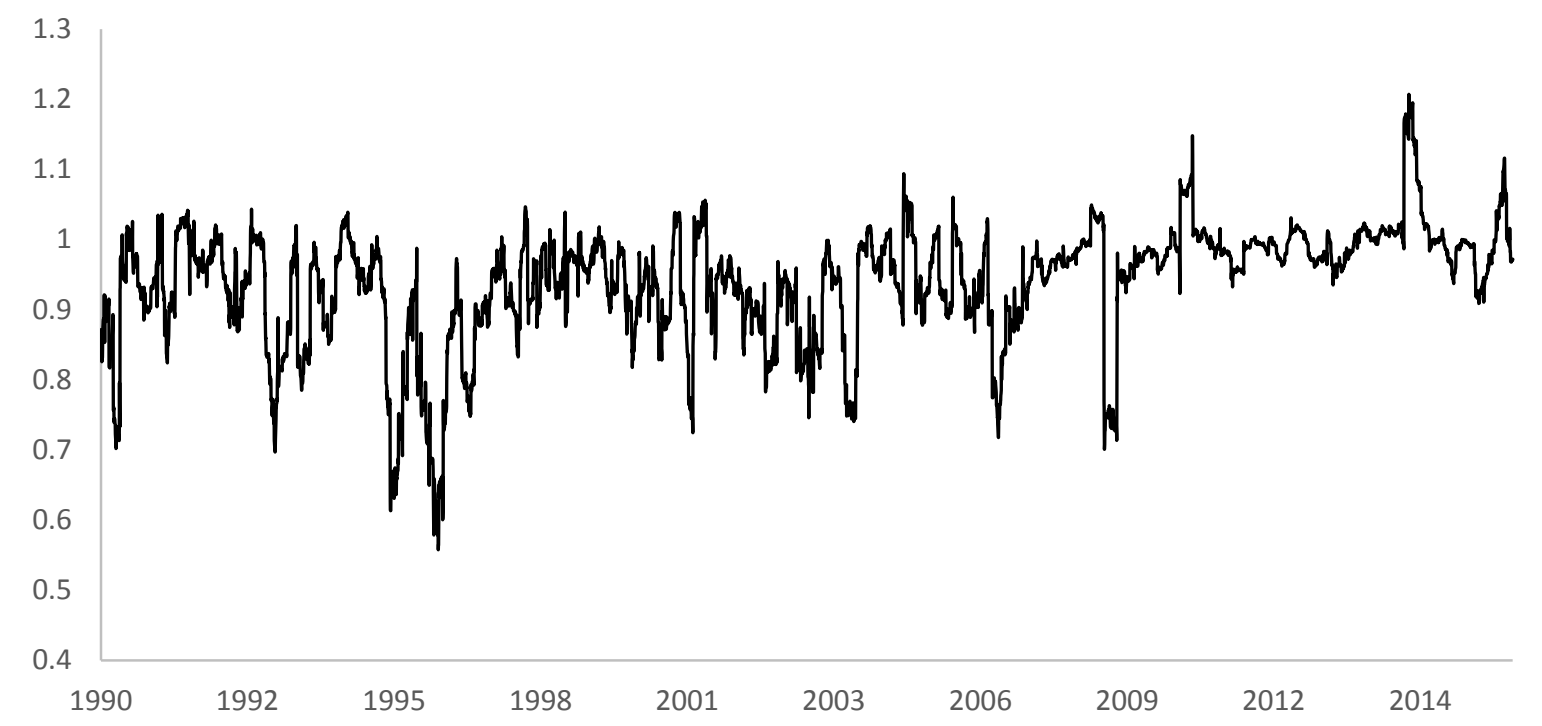

Panel C: Difference Between Hedge Ratios of Minimizing-Swap Variance and MinimizingVariance

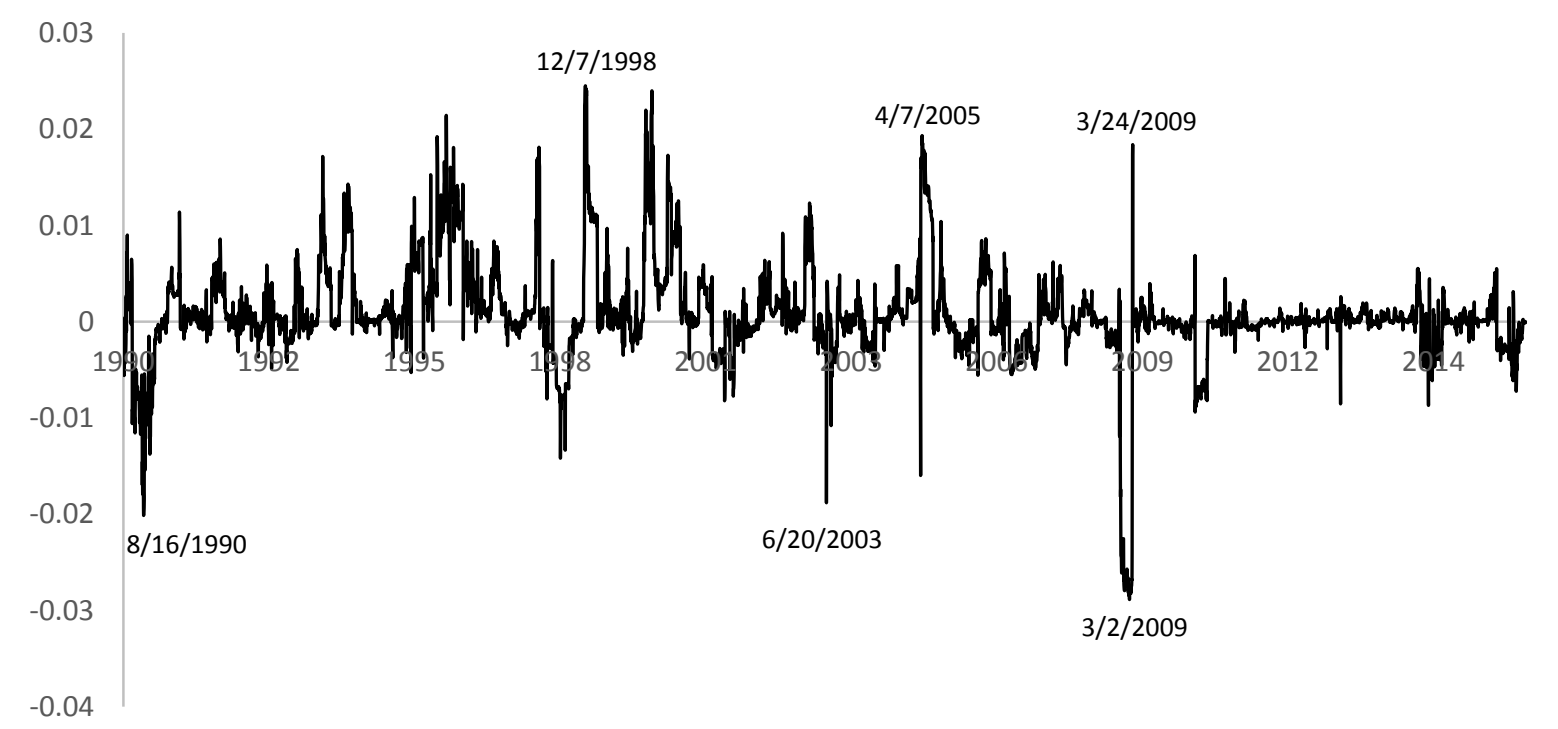




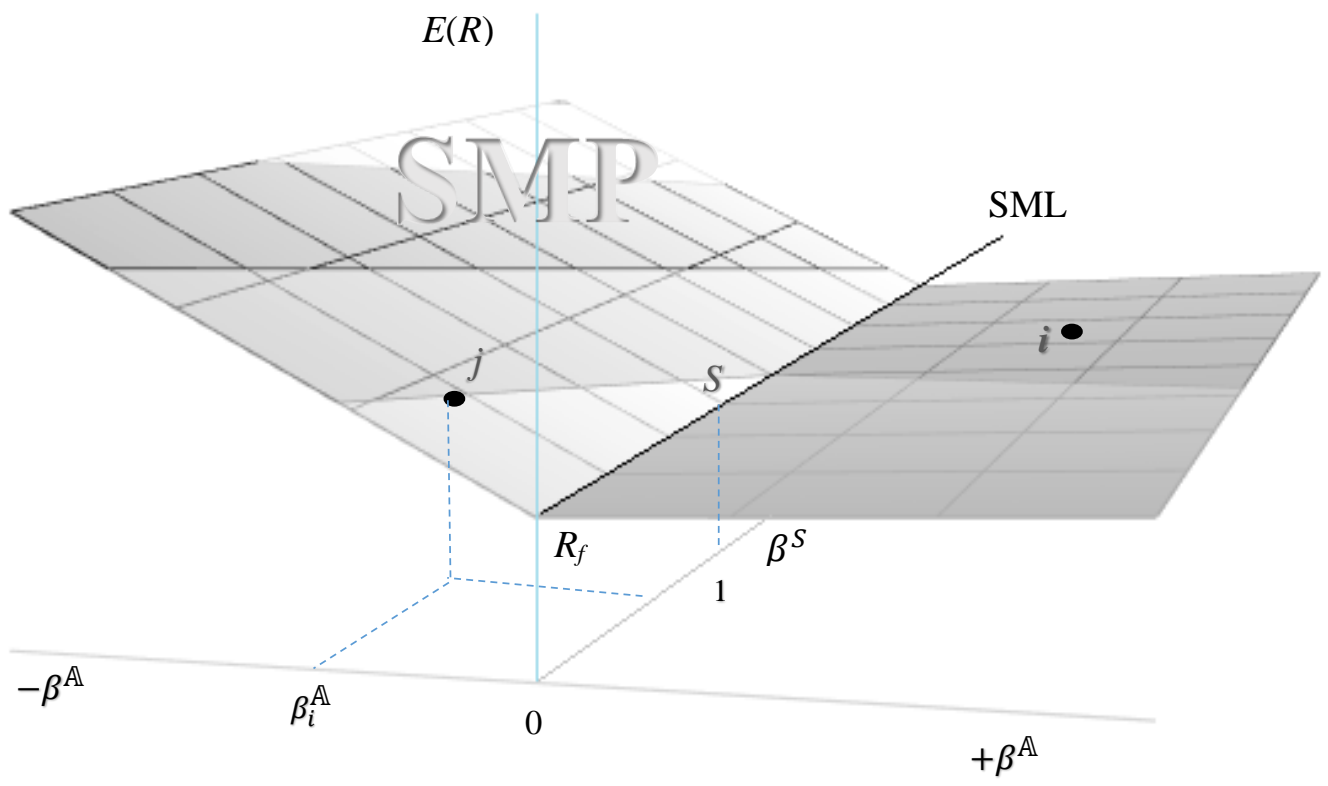

Figure 6. U-shape mean- $\boldsymbol{\beta}^{\mathbb{A}}$ and the Security Market Plane (SMP). This figure depicts the three-dimensional equilibrium risk-return relationship derived from the $\mathrm{MSwV}$ analysis. The expected return is non-linearly with respect to the asymmetric beta, $\beta^{\mathbb{A}}$, and it has a Ushape appearance as shown in the figure. Extend the curvature of mean- $\beta^{\mathbb{A}}$ to every points along the security market line (SML) in the mean- $\beta^{S}$ space, I am able to graphically identify a curved security market plane (SMP) in the three-dimensional space of mean- $\beta^{S}-\beta^{\mathbb{A}}$ in the figure. 


\section{Table 1}

Summary Statistics for Hedge Funds and Industry Portfolios

This table summarized the statistics of monthly portfolio returns from 14 hedge fund indexes (data comes from Credit Suisse Hedge Fund Index), and Kenneth French's 12 industry portfolios. The sample period is from January 1995 to December 2015. The numbers after Sharpe ratios are the ranks among hedge funds. The MSwV Sharpe ratio is the expected excess return over the square root of $\mathrm{SwV}$. If the orders are different under the two framework, the ranking numbers are in bold font. The MSwV beta is calculated based on (17.2) with respect to the MSwV optimal portfolio returns. To test the difference between MV-beta and MSwV-beta, I use Monte Carlo approach by data randomization. I randomly select 1,000 sets of 500 random returns from the total 559 observations in the sample and compute the t-test statistics.

\begin{tabular}{|c|c|c|c|c|c|c|c|c|c|c|}
\hline \multirow[b]{2}{*}{ Hedge Fund Portfolios } & \multirow{2}{*}{$\begin{array}{r}\text { Mean } \\
(\%)\end{array}$} & \multirow{2}{*}{$\begin{array}{c}\sigma^{2} \\
\left(\times 10^{4}\right)\end{array}$} & \multirow{2}{*}{$\begin{array}{l}\text { SwV } \\
\left(\times 10^{4}\right)\end{array}$} & \multicolumn{4}{|c|}{ Sharpe Ratio } & \multicolumn{3}{|c|}{ Beta Coefficient } \\
\hline & & & & MV & Rank & MSwV & Rank & MV & MSwV & Difference \\
\hline Hedge Fund Index & 0.717 & 4.098 & 2.116 & 0.251 & 5 & 0.350 & 6 & 0.281 & 0.258 & $0.023 * * *$ \\
\hline Convertible Arbitrage & 0.618 & 3.534 & 1.981 & 0.218 & 9 & 0.291 & 8 & 0.159 & 0.171 & $-0.012 * * *$ \\
\hline Dedicated Short Bias & -0.408 & 22.381 & 4.679 & -0.130 & 14 & -0.285 & 14 & -0.860 & -0.863 & $0.004 * * *$ \\
\hline Emerging Markets & 0.611 & 14.339 & 4.016 & 0.106 & 11 & 0.201 & 10 & 0.505 & 0.431 & $0.075 * * *$ \\
\hline Equity Market Neutral & 0.454 & 7.903 & 3.209 & 0.088 & 12 & 0.137 & 13 & 0.184 & 0.185 & $-0.001 * * *$ \\
\hline Event Driven & 0.722 & 3.185 & 1.906 & 0.288 & 3 & 0.372 & 5 & 0.266 & 0.250 & $0.016 * * *$ \\
\hline Distressed & 0.805 & 3.279 & 1.973 & 0.330 & 2 & 0.425 & 2 & 0.256 & 0.268 & $-0.012 * * *$ \\
\hline Multi-Strategy & 0.686 & 3.762 & 2.035 & 0.247 & 6 & 0.335 & 7 & 0.275 & 0.239 & $0.036 * * *$ \\
\hline Risk Arbitrage & 0.480 & 1.385 & 1.255 & 0.231 & 8 & 0.243 & 9 & 0.142 & 0.115 & $0.027 * * *$ \\
\hline Fixed Income Arbitrage & 0.451 & 2.372 & 1.612 & 0.158 & 10 & 0.191 & 11 & 0.115 & 0.138 & $-0.023 * * *$ \\
\hline Global Macro & 0.926 & 6.760 & 2.714 & 0.276 & 4 & 0.436 & 1 & 0.145 & 0.168 & $-0.023 * * *$ \\
\hline Long/Short Equity & 0.832 & 7.256 & 2.767 & 0.232 & 7 & 0.375 & 3 & 0.448 & 0.391 & $0.057 * * *$ \\
\hline Managed Futures & 0.471 & 11.524 & 3.371 & 0.077 & 13 & 0.143 & 12 & -0.054 & -0.012 & $-0.041^{* * *}$ \\
\hline Multi-Strategy & 0.678 & 1.900 & 1.588 & 0.341 & 1 & 0.373 & 4 & 0.137 & 0.098 & $0.039 * * *$ \\
\hline
\end{tabular}




\begin{tabular}{|c|c|c|c|c|c|c|c|c|c|c|c|}
\hline \multirow{3}{*}{$\begin{array}{l}\text { Industry Portfolios } \\
\text { NoDur }\end{array}$} & \multirow{2}{*}{$\begin{array}{r}\text { Mean } \\
(\%)\end{array}$} & \multirow{2}{*}{$\begin{array}{c}\sigma^{2} \\
\left(\times 10^{4}\right)\end{array}$} & \multirow{2}{*}{$\begin{array}{l}\mathrm{SwV} \\
\left(\times 10^{4}\right)\end{array}$} & \multicolumn{4}{|c|}{ Sharpe Ratio } & \multicolumn{4}{|c|}{ Beta Coefficient } \\
\hline & & & & MV & Rank & MSwV & Rank & MV & MSwV & Diffe & erence \\
\hline & 0.883 & 25.847 & 26.337 & 0.132 & 4 & 0.175 & 4 & 0.902 & 0.892 & 0.010 & $* * *$ \\
\hline Durbl & 0.706 & 46.854 & 47.073 & 0.072 & 12 & 0.103 & 12 & 1.232 & 1.226 & 0.006 & $* *$ \\
\hline Manuf & 0.968 & 38.057 & 39.038 & 0.122 & 6 & 0.157 & 5 & 1.164 & 1.168 & -0.004 & $*$ \\
\hline Enrgy & 0.934 & 80.569 & 82.138 & 0.080 & 11 & 0.104 & 11 & 1.125 & 1.100 & 0.025 & *** \\
\hline Chems & 0.921 & 35.212 & 36.012 & 0.119 & 7 & 0.155 & 6 & 1.070 & 1.084 & -0.014 & $* * *$ \\
\hline BusEq & 1.351 & 82.374 & 81.234 & 0.125 & 5 & 0.152 & 7 & 1.564 & 1.585 & -0.019 & $* * *$ \\
\hline Telcm & 0.914 & 75.429 & 74.115 & 0.081 & 10 & 0.107 & 10 & 1.519 & 1.533 & -0.014 & $* * *$ \\
\hline Utils & 0.978 & 12.766 & 13.616 & 0.214 & 1 & 0.275 & 1 & 0.434 & 0.393 & 0.041 & $* * *$ \\
\hline Shops & 0.922 & 38.081 & 38.032 & 0.115 & 8 & 0.151 & 8 & 1.083 & 1.078 & 0.005 & * \\
\hline Hlth & 1.461 & 59.305 & 58.829 & 0.162 & 3 & 0.194 & 3 & 1.192 & 1.198 & -0.006 & $* *$ \\
\hline Money & 1.029 & 17.800 & 18.975 & 0.194 & 2 & 0.243 & 2 & 0.720 & 0.726 & -0.006 & $*$ \\
\hline Other & 0.821 & 35.474 & 36.036 & 0.102 & 9 & 0.138 & 9 & 1.108 & 1.119 & -0.011 & $* * *$ \\
\hline
\end{tabular}

***, ** and $*$ denote statistics significant at 1 percent, 5 percent and 10 percent levels, respectively. 
Table 2

\section{MV, SSD and MVA Sharpe Ratios}

This table reports the rankings of Sharpe ratios of asymmetry portfolios (PFL) that formed according to their in-sample asymmetry measure (Pre$\mathbb{A})$. We conduct a two-stage analysis. On the first stage, 20 portfolios are formed based on sorted annualized $\mathbb{A}$, calculated from the monthly returns on all CRSP stocks with share code 10 and 11. We then report the summary statistics as well as Sharp ratios for the in-sample as well as the outof-sample (one-month lag) calculations. The sample period covers from 1969 to 2015.

\begin{tabular}{|c|c|c|c|c|c|c|c|c|c|c|c|c|c|c|c|c|c|}
\hline \multirow[b]{3}{*}{ PFL } & \multicolumn{8}{|c|}{ In-Sample Rankings } & \multirow{3}{*}{$\begin{array}{l}\text { Ave. } \\
\text { Stock } \\
\text { Pre-Al } \\
\left(\times 10^{4}\right)\end{array}$} & \multicolumn{8}{|c|}{ Out-of-Sample Rankings } \\
\hline & \multirow[b]{2}{*}{$\begin{array}{l}\mu \\
(\%)\end{array}$} & \multirow[b]{2}{*}{$\begin{array}{c}\sigma^{2} \\
\left(\times 10^{4}\right)\end{array}$} & \multirow[b]{2}{*}{$\begin{array}{c}\mathrm{SwV} \\
\left(\times 10^{4}\right)\end{array}$} & \multirow[b]{2}{*}{$\begin{array}{c}\mathbb{A} \\
\left(\times 10^{4}\right)\end{array}$} & \multicolumn{4}{|c|}{ Sharp Ratios } & & \multirow[b]{2}{*}{$\begin{array}{c}\mu \\
(\%)\end{array}$} & \multirow[b]{2}{*}{$\begin{array}{c}\sigma^{2} \\
\left(\times 10^{4}\right)\end{array}$} & \multirow[b]{2}{*}{$\begin{array}{c}\text { SwV } \\
\left(\times 10^{4}\right)\end{array}$} & \multirow[b]{2}{*}{$\begin{array}{c}\mathbb{A} \\
\left(\times 10^{4}\right)\end{array}$} & \multicolumn{4}{|c|}{ Sharp Ratios } \\
\hline & & & & & MV & 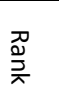 & MSwV & 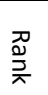 & & & & & & MV & 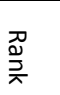 & MSwV & 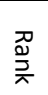 \\
\hline 1 & 5.09 & 144.71 & 144.96 & 13.92 & 3.242 & 1 & 3.236 & 1 & -371.56 & 4.13 & 128.91 & 130.13 & 11.26 & 2.900 & 6 & 2.872 & 5 \\
\hline 2 & 2.64 & 93.19 & 91.21 & 2.76 & 2.413 & 11 & 2.465 & 10 & -95.20 & 2.92 & 91.72 & 92.51 & 5.92 & 2.753 & 8 & 2.730 & 8 \\
\hline 3 & 2.09 & 64.91 & 64.99 & 2.71 & 2.606 & 8 & 2.602 & 6 & -42.58 & 2.45 & 71.46 & 73.67 & 5.58 & 2.870 & 7 & 2.784 & 7 \\
\hline 4 & 1.69 & 49.17 & 49.58 & 2.03 & 2.634 & 6 & 2.612 & 5 & -21.12 & 2.23 & 59.69 & 61.08 & 3.98 & 3.077 & 3 & 3.006 & 3 \\
\hline 5 & 1.31 & 35.46 & 36.00 & 1.46 & 2.577 & 9 & 2.537 & 7 & -10.81 & 1.62 & 40.27 & 41.76 & 2.75 & 3.031 & 4 & 2.924 & 4 \\
\hline 6 & 1.16 & 26.10 & 26.76 & 1.26 & 2.940 & 2 & 2.867 & 2 & -5.37 & 1.40 & 38.20 & 37.38 & 0.22 & 2.624 & 9 & 2.682 & 9 \\
\hline 7 & 0.92 & 19.02 & 19.38 & 0.70 & 2.731 & 4 & 2.681 & 3 & -2.40 & 1.23 & 22.80 & 24.11 & 1.86 & 3.677 & 1 & 3.477 & 1 \\
\hline 8 & 0.79 & 16.23 & 16.68 & 0.70 & 2.421 & 10 & 2.356 & 11 & -0.76 & 0.98 & 18.20 & 19.28 & 1.43 & 3.228 & 2 & 3.048 & 2 \\
\hline 9 & 0.84 & 15.94 & 16.57 & 0.90 & 2.773 & 3 & 2.667 & 4 & 0.40 & 0.93 & 18.33 & 19.26 & 1.27 & 2.938 & 5 & 2.796 & 6 \\
\hline 10 & 0.85 & 17.51 & 18.44 & 1.23 & 2.608 & 7 & 2.476 & 9 & 1.53 & 0.97 & 22.23 & 22.66 & 0.85 & 2.565 & 10 & 2.518 & 10 \\
\hline 11 & 0.91 & 19.29 & 20.45 & 1.51 & 2.652 & 5 & 2.501 & 8 & 2.86 & 0.96 & 22.44 & 23.40 & 1.38 & 2.508 & 11 & 2.405 & 11 \\
\hline 12 & 0.88 & 21.05 & 22.33 & 1.65 & 2.307 & 12 & 2.175 & 12 & 4.53 & 0.96 & 25.64 & 26.77 & 1.63 & 2.212 & 12 & 2.118 & 14 \\
\hline 13 & 0.85 & 24.86 & 26.35 & 1.90 & 1.813 & 13 & 1.711 & 13 & 6.69 & 0.92 & 29.81 & 30.49 & 1.22 & 1.745 & 19 & 1.706 & 20 \\
\hline 14 & 0.81 & 26.99 & 28.31 & 1.75 & 1.527 & 14 & 1.456 & 14 & 9.61 & 0.97 & 32.51 & 33.33 & 1.44 & 1.777 & 18 & 1.733 & 19 \\
\hline 15 & 0.76 & 29.20 & 30.43 & 1.67 & 1.238 & 15 & 1.188 & 15 & 13.55 & 1.06 & 33.23 & 34.33 & 1.80 & 1.998 & 16 & 1.934 & 16 \\
\hline 16 & 0.54 & 30.88 & 32.11 & 1.56 & 0.479 & 16 & 0.460 & 16 & 18.73 & 1.19 & 36.48 & 37.44 & 1.81 & 2.190 & 13 & 2.134 & 13 \\
\hline 17 & 0.29 & 35.51 & 37.08 & 1.78 & -0.293 & 17 & -0.281 & 17 & 26.14 & 1.18 & 39.20 & 40.07 & 1.78 & 1.998 & 15 & 1.955 & 15 \\
\hline 18 & 0.01 & 42.96 & 45.14 & 2.19 & -0.888 & 18 & -0.845 & 18 & 38.69 & 1.32 & 49.72 & 50.21 & 1.77 & 1.852 & 17 & 1.834 & 18 \\
\hline 19 & -0.60 & 55.88 & 59.76 & 3.20 & -1.789 & 19 & -1.673 & 19 & 66.91 & 2.07 & 78.66 & 76.45 & 0.94 & 2.124 & 14 & 2.185 & 12 \\
\hline 20 & -2.47 & 96.06 & 112.29 & 11.29 & -2.985 & 20 & -2.554 & 20 & 187.32 & 5.39 & 405.05 & 266.82 & -97.83 & 1.234 & 20 & 1.873 & 17 \\
\hline
\end{tabular}




\section{Table 3}

A Comparison of Market and Factor Portfolios

This table reports the summary statistics of symmetry and asymmetry of monthly returns on the MSwV (SSD) optimal portfolio, the MVA optimal portfolio, the MV optimal portfolio, FamaFrench (FF) factor portfolios, and the key US market indexes. The Sharp ratios according to MSwV and MVA models are also reported. To find the SSD and MVA optimal portfolios, we determine the optimal weights based on past 60 monthly excess returns on all CRSP stocks, and apply the optimal weights to the following month to form the portfolios. The sample period covers from 1995 to 2016.

\begin{tabular}{lrrrrrr}
\hline & & & & & \multicolumn{2}{c}{ Sharp Ratios } \\
\cline { 6 - 7 } & $\mu(\%)$ & $S w V \times 10^{4}$ & $\sigma^{2} \times 10^{4}$ & $\mathbb{A} \times 10^{4}$ & \multicolumn{1}{c}{ MV } & MSwV \\
\hline MVA $^{*}$ MKT & 1.106 & 5.918 & 10.736 & -5.798 & 0.28 & 0.37 \\
& 1.107 & 5.916 & 10.731 & -5.798 & 0.34 & 0.37 \\
FF-MKT & & & & & & \\
FF-SMB & 0.872 & 10.196 & 19.556 & -9.779 & 0.20 & 0.21 \\
FF-HML & 0.210 & 5.163 & 10.424 & -5.262 & 0.07 & 0.00 \\
FF-RMW & 0.260 & 4.959 & 9.934 & -4.991 & 0.08 & 0.03 \\
FF-CMA & 0.332 & 4.447 & 8.749 & -4.354 & 0.11 & 0.06 \\
FF-MOM & 0.283 & 2.340 & 4.681 & -2.394 & 0.13 & 0.05 \\
& 0.417 & 14.449 & 27.091 & -12.591 & 0.08 & 0.06 \\
SPX & & & & & & \\
DOW & 0.695 & 9.476 & 18.373 & -9.125 & 0.16 & 0.16 \\
NASDAQ & 0.714 & 9.172 & 17.803 & -8.887 & 0.17 & 0.17 \\
\hline
\end{tabular}




\section{Table 4}

\section{MV, SSD and MSwV Efficient sets}

14 available portfolios are compared based on mean-variance, mean-SwV and SSD categories. I use returns of portfolios from Kenneth French Data Base. There are three size portfolios (Small Size, Medium Size and Large Size), three B/M portfolios (Growth, Neutral and Value), one Momentum portfolio (MOM), one reversal portfolio (REV), five industry portfolios (Cnsmr, Manuf, Hitec, Hlth and Other), and market portfolio (MKT). The efficient sets are formed using weekly returns for each year from 2006-2015.

\section{6}

\begin{tabular}{|l|l|l|}
\hline \multicolumn{1}{|c|}{ Mean-Variance } & \multicolumn{1}{c|}{ SSD } & \multicolumn{1}{c|}{ Mean-Swapvariance } \\
\hline $\begin{array}{l}\text { Large Size, Neutral, Value, } \\
\text { Cnsmr, Other, Rev }\end{array}$ & $\begin{array}{l}\text { Large Size, Neutral, Value, } \\
\text { Cnsmr, Other, Rev }\end{array}$ & $\begin{array}{l}\text { Large Size, Neutral, Value, } \\
\text { Cnsmr, Other, Rev }\end{array}$ \\
\hline
\end{tabular}

2007

\begin{tabular}{|l|l|l|}
\hline \multicolumn{1}{|c|}{ Mean-Variance } & \multicolumn{1}{|c|}{ SSD } & Mean-Swapvariance \\
\hline Mom, Rev & Mom, Rev & Mom, Rev \\
\hline
\end{tabular}

2008

\begin{tabular}{|l|l|l|}
\hline \multicolumn{1}{|c|}{ Mean-Variance } & \multicolumn{1}{|c|}{ SSD } & Mean-Swapvariance \\
\hline Mom, Rev & Mom, Rev & Mom, Rev \\
\hline
\end{tabular}

2009

\begin{tabular}{|c|c|c|}
\hline Mean-Variance & SSD & Mean-Swapvariance \\
\hline Growth, Cnsmr, Hitec, Rev & Growth, Cnsmr, Hitec, Rev & Growth, Cnsmr, Hitec, Rev \\
\hline
\end{tabular}

2010

\begin{tabular}{|l|l|l|}
\hline \multicolumn{1}{|c|}{ Mean-Variance } & \multicolumn{1}{c|}{ SSD } & \multicolumn{1}{c|}{ Mean-Swapvariance } \\
\hline Small Size, Medium Size, & Small Size, Medium Size, & Small Size, Medium Size, \\
Neutral, Cnsmr, Mom, Rev & Neutral, Cnsmr, Mom, Rev & Neutral, Cnsmr, Mom, Rev \\
\hline
\end{tabular}

2011

\begin{tabular}{|l|l|l|}
\hline \multicolumn{1}{|c|}{ Mean-Variance } & \multicolumn{1}{|c|}{ SSD } & Mean-Swapvariance \\
\hline Hlth, Mom, Rev & Hlth, Mom, Rev & Hlth, Mom, Rev \\
\hline
\end{tabular}




\begin{tabular}{|l|l|l|}
\hline \multicolumn{1}{|c|}{ Mean-Variance } & \multicolumn{1}{|c|}{ SSD } & \multicolumn{1}{c|}{ Mean-Swapvariance } \\
\hline $\begin{array}{l}\text { Value, Cnsmr, Hlth, Other, } \\
\text { Rev }\end{array}$ & $\begin{array}{l}\text { Value, Cnsmr, Hlth, Other, } \\
\text { Rev }\end{array}$ & $\begin{array}{l}\text { Value, Cnsmr, Hlth, Other, } \\
\text { Rev }\end{array}$ \\
\hline
\end{tabular}

2013

\begin{tabular}{|l|l|l|}
\hline \multicolumn{1}{|c|}{ Mean-Variance } & \multicolumn{1}{c|}{ SSD } & \multicolumn{1}{c|}{ Mean-Swapvariance } \\
\hline Small Size, Medium Size, & Small Size, Medium Size, & Small Size, Medium Size, \\
Large Size, Growth, Hlth, & Large Size, Growth, Hlth, & Large Size, Growth, Hlth, \\
Mom, Rev, MKT & Mom, Rev, MKT & Mom, Rev, MKT \\
\hline
\end{tabular}

2014

\begin{tabular}{|c|c|c|}
\hline Mean-Variance & SSD & Mean-Swapvariance \\
\hline $\begin{array}{c}\text { Large Size, Cosmr, Hitec, } \\
\text { Hlth, Mom, Rev }\end{array}$ & $\begin{array}{c}\text { Growth, Large Size, } \\
\text { Cosmr, Hitec, Hlth, Mom, } \\
\text { Rev }\end{array}$ & $\begin{array}{c}\text { Growth, Large Size, } \\
\text { Cosmr, Hitec, Hlth, Mom, } \\
\text { Rev }\end{array}$ \\
\hline
\end{tabular}

2015

\begin{tabular}{|c|c|c|}
\hline Mean-Variance & SSD & Mean-Swapvariance \\
\hline Cosmr, Mom, Rev & Cosmr, Mom, Rev & Cosmr, Mom, Rev \\
\hline
\end{tabular}




\section{Table 5}

\section{Difference of Hedge Ratio and Volatility Index}

The table reports the regression results of differences between minimizing-variance hedge ratio and minimizing swap variance hedge ratio on the VIX index. Diff $=\alpha+\beta\left(\frac{V I X}{100}\right)+\varepsilon$. Panel A and Panel B show the results of S\&P 500 index and the WTI crude oil, respectively.

Panel A: S\&P 500 Index

\begin{tabular}{cccc}
\hline & $\alpha$ & $\beta$ \\
Coefficients & 0.0017 & & -0.0056 \\
$R^{2}$ & $(9.86)$ & & $(-6.84)$ \\
Observation & & 0.0070 & \\
\hline
\end{tabular}

Panel B: Crude Oil Market

\begin{tabular}{|c|c|c|}
\hline & $\alpha$ & $\beta$ \\
\hline & 0.0034 & -0.0135 \\
\hline \multicolumn{3}{|l|}{ Coefficients } \\
\hline & (21.33) & $(-18.13)$ \\
\hline$R^{2}$ & \multicolumn{2}{|c|}{0.0475} \\
\hline Observation & \multicolumn{2}{|c|}{6591} \\
\hline
\end{tabular}




\section{Table 6}

\section{Fama-MacBeth Tests for MSwV (SSD) and MVA Pricing Models}

Following Fama-MacBeth (1973), this table reports the estimated factor premium of MSwV model $\left(\hat{\lambda}_{S w V}\right)$ and that of MVA model $\left(\hat{\lambda}_{\mathbb{S}}\right.$, and $\left.\hat{\lambda}_{\mathbb{A}}\right)$, respectively. First, estimated factor loadings, $\hat{\beta}^{S w V}, \hat{\beta}^{\mathbb{S}}$, and $\hat{\beta}^{\mathbb{A}}$ are calculated, based on (17.2), (19.2), and (19.3), from returns on individual securities to returns on indexes, $R_{m}^{S w V}, R_{m}^{\mathbb{S}}$, and $R_{m}^{\mathbb{A}}$, respectively, over the past 60 months. Second, at the beginning of each period, sixty equal-sized portfolios sorted by the beginning-of-period estimated betas are formed from the entire sample. I then regress all portfolio returns for the period against the estimated betas to determine the risk-premium for each factor. The sample contains all CRSP-listed ordinary common equities from July 1969 to December 2015. The mean coefficient estimates $(\hat{\lambda})$ across the sample period are reported with their $t$-statistics.

\section{Panel 1: MSwV (SSD) Model}

\begin{tabular}{|c|c|c|c|}
\hline & $\hat{\lambda}_{S w V}$ & $R^{2}$ & Adj. $R^{2}$ \\
\hline$\widehat{\boldsymbol{\beta}}_{p}^{S w V}$-sorted & $\begin{array}{r}0.0057 \\
(2.04)\end{array} * *$ & 0.4971 & 0.4886 \\
\hline
\end{tabular}

Panel 2: MVA Model

\begin{tabular}{|c|c|c|c|c|}
\hline & $\hat{\lambda}_{\mathbb{S}}$ & $\hat{\lambda}_{\mathbb{A}}$ & $R^{2}$ & $\operatorname{Adj} . R^{2}$ \\
\hline$\widehat{\boldsymbol{\beta}}_{\boldsymbol{p}}^{\mathbb{S}}$-sorted & $\begin{aligned} 0.0057 & \\
(2.33) & * *\end{aligned}$ & $\begin{array}{r}-0.0508 \\
(-3.24)\end{array} * * *$ & 0.5779 & 0.5634 \\
\hline$\widehat{\boldsymbol{\beta}}_{\boldsymbol{p}}^{\mathbb{A}}$-sorted & $\begin{array}{c}0.0078 \\
(2.14)\end{array} * *$ & $\begin{array}{r}-0.0072 \\
(-1.98)\end{array} * *$ & 0.6247 & 0.6118 \\
\hline
\end{tabular}

\footnotetext{
***, $* *$ and $*$ denote statistics significant at 1 percent, 5 percent and 10 percent levels, respectively.
} 


\section{Table 7}

\section{Fama-MacBeth Tests for the Validity of MVA Pricing Model}

If MVA asset pricing model shown in (19) is valid, then the residual returns of individual assets, $\varepsilon_{j, t}=R_{j, t}-\left(\hat{\beta}_{j}^{\mathbb{S}} R_{m, t}^{\mathbb{S}}+\hat{\beta}_{j}^{\mathbb{A}} R_{m, t}^{\mathbb{A}}\right)$, should be idiosyncratic. Thus, no other common factors could explain the residual returns. To examine the validity of the MVA Model, I first calculated the factor loadings of $\varepsilon_{j, t}$ with respect to multiple common factors (e.g., $S M B$ and $H M L$ ) from the following regression model: $\varepsilon_{j, t}=\alpha_{j}+\beta_{j}^{S M B} S M B_{t}+\beta_{j}^{H M L} H M L_{t}+\beta_{j}^{R M W} R M W_{t}+\beta_{j}^{C M A} C M A_{t}$ $+e_{j, t}$, over the past 60 months. Then, at the beginning of each period, sixty equal-sized portfolios sorted by the beginning-of-period estimated betas are formed from the entire sample. We then regress all portfolio returns for each period against the estimated betas (e.g., $\hat{\beta}_{p}^{S M B}$ and $\hat{\beta}_{p}^{H M L}$ ) to determine the risk-premium for each factor. The sample contains all CRSP-listed ordinary common equities from July 1969 to December 2015. The mean coefficient estimates $(\lambda)$ across the sample period are reported with their t-statistics.

Panel 1: Two-Factor Test

\begin{tabular}{lrrrc}
\hline Portfolios & $\hat{\boldsymbol{\lambda}}_{\boldsymbol{S M B}}$ & $\hat{\boldsymbol{\lambda}}_{\boldsymbol{H} \boldsymbol{M L}}$ & $\boldsymbol{R}^{\mathbf{2}}$ & Adj. $\boldsymbol{R}^{\mathbf{2}}$ \\
\hline$\widehat{\boldsymbol{\beta}}_{\boldsymbol{p}}^{\boldsymbol{S M B}}$-sorted & 0.0003 & 0.0008 & 0.2607 & 0.2348 \\
$\widehat{\boldsymbol{\beta}}_{\boldsymbol{p}}^{\boldsymbol{H} \boldsymbol{M L} \text {-sorted }}$ & $(0.22)$ & $(0.27)$ & & \\
\hline
\end{tabular}

Panel 2: Four-Factor Test

\begin{tabular}{|c|c|c|c|c|c|c|}
\hline Portfolios & $\hat{\lambda}_{S M B}$ & $\hat{\lambda}_{H M L}$ & $\hat{\lambda}_{R M W}$ & $\hat{\lambda}_{C M A}$ & $R^{2}$ & $\operatorname{Adj} . R^{2}$ \\
\hline$\widehat{\boldsymbol{\beta}}_{\boldsymbol{p}}^{S M B}$-sorted & $\begin{array}{r}-0.0005 \\
(-0.26)\end{array}$ & $\begin{array}{r}0.0020 \\
(0.69)\end{array}$ & $\begin{array}{r}0.0018 \\
(0.89)\end{array}$ & $\begin{array}{r}-0.0020 \\
(-1.05)\end{array}$ & 0.3156 & 0.2659 \\
\hline$\widehat{\boldsymbol{\beta}}_{\boldsymbol{p}}^{\boldsymbol{M} \boldsymbol{M L}}$-sorted & $\begin{array}{r}0.0005 \\
(0.17)\end{array}$ & $\begin{array}{r}0.0013 \\
(0.54)\end{array}$ & $\begin{array}{r}0.0026 \\
(1.17)\end{array}$ & $\begin{array}{r}-0.0006 \\
(-0.32)\end{array}$ & 0.3091 & 0.2589 \\
\hline$\widehat{\boldsymbol{\beta}}_{\boldsymbol{p}}^{\boldsymbol{R} \boldsymbol{M} \boldsymbol{W}_{\text {-sorted }}}$ & $\begin{array}{r}-0.0016 \\
(-0.60)\end{array}$ & $\begin{array}{r}0.0002 \\
(0.07)\end{array}$ & $\begin{array}{r}0.0005 \\
(0.24)\end{array}$ & $\begin{array}{r}-0.0031 \\
(-1.58)\end{array}$ & 0.3274 & 0.2786 \\
\hline$\widehat{\boldsymbol{\beta}}_{\boldsymbol{p}}^{C M \boldsymbol{A}_{\text {-sorted }}}$ & $\begin{array}{r}0.0001 \\
(0.04)\end{array}$ & $\begin{array}{r}0.0008 \\
(0.32)\end{array}$ & $\begin{array}{r}0.0010 \\
(0.51)\end{array}$ & $\begin{array}{r}-0.0007 \\
(0.09)\end{array}$ & 0.3093 & 0.2591 \\
\hline
\end{tabular}

***, ** and $*$ denote statistics significant at 1 percent, 5 percent and 10 percent levels, respectively. 


\section{Table 8}

Descriptive Statistics of Betas

Table 8 provides 3 betas based on 60 months lagged values. I use 3 size-sorted and $3 \mathrm{~B} / \mathrm{M}$-sorted portfolios from Kenneth French Data Base over the 1932 to 2015. $\hat{\beta}_{p}^{S}$ represents mean-variance beta; $\hat{\beta}_{p}^{S w V}$ represents mean-SwV beta; while $\hat{\beta}_{p}^{A}$ represents tail beta. All portfolios are sorted into 5 quintiles according to their beta estimates.

\begin{tabular}{|c|c|c|c|c|c|c|}
\hline \multicolumn{2}{|c|}{ Portfolios } & Low & 2 & 3 & 4 & High \\
\hline \multirow{3}{*}{$\begin{array}{c}\text { Small } \\
\text { Size }\end{array}$} & $\hat{\beta}_{p}^{S}$ & 0.8550 & 1.0387 & 1.1922 & 1.3785 & 1.7118 \\
\hline & $\hat{\beta}_{p}^{S w V}$ & 0.5617 & 1.0350 & 1.1979 & 1.3889 & 1.9511 \\
\hline & $\widehat{\boldsymbol{\beta}}_{p}^{A}$ & -0.4237 & -0.0226 & 0.0003 & 0.0120 & 0.3918 \\
\hline \multirow{3}{*}{$\begin{array}{c}\text { Medium } \\
\text { Size }\end{array}$} & $\hat{\beta}_{p}^{S}$ & 1.0005 & 1.1128 & 1.1891 & 1.2903 & 1.3809 \\
\hline & $\hat{\beta}_{p}^{S w V}$ & 0.8287 & 1.1168 & 1.1892 & 1.2875 & 1.4353 \\
\hline & $\widehat{\boldsymbol{\beta}}_{p}^{A}$ & -0.2234 & -0.0111 & -0.0003 & 0.0055 & 0.1130 \\
\hline \multirow{3}{*}{$\begin{array}{l}\text { Large } \\
\text { Size }\end{array}$} & $\hat{\beta}_{p}^{S}$ & 0.9743 & 1.0208 & 1.0562 & 1.0870 & 1.1370 \\
\hline & $\hat{\beta}_{p}^{S w V}$ & 0.9293 & 1.0218 & 1.0584 & 1.0903 & 1.1682 \\
\hline & $\widehat{\boldsymbol{\beta}}_{p}^{A}$ & -0.0622 & -0.0041 & -0.0016 & 0.0010 & 0.0594 \\
\hline \multirow{3}{*}{ Growth } & $\hat{\beta}_{p}^{S}$ & 0.9576 & 1.1059 & 1.1903 & 1.2874 & 1.4728 \\
\hline & $\hat{\beta}_{p}^{S w V}$ & 0.8487 & 1.1063 & 1.1997 & 1.3105 & 1.6182 \\
\hline & $\widehat{\boldsymbol{\beta}}_{p}^{A}$ & -0.1620 & -0.0038 & 0.0030 & 0.0096 & 0.2225 \\
\hline \multirow{3}{*}{ Neutral } & $\hat{\beta}_{p}^{S}$ & 0.8557 & 0.9805 & 1.1147 & 1.2399 & 1.3525 \\
\hline & $\hat{\beta}_{p}^{S w V}$ & 0.6738 & 0.9806 & 1.1169 & 1.2406 & 1.4775 \\
\hline & $\widehat{\boldsymbol{\beta}}_{p}^{A}$ & -0.2525 & -0.0122 & -0.0004 & 0.0079 & 0.2028 \\
\hline \multirow{3}{*}{ Value } & $\hat{\beta}_{p}^{S}$ & 0.7668 & 0.9466 & 1.1545 & 1.2972 & 1.6950 \\
\hline & $\hat{\beta}_{p}^{S w V}$ & 0.5257 & 0.9374 & 1.1390 & 1.3029 & 1.9039 \\
\hline & $\widehat{\boldsymbol{\beta}}_{p}^{A}$ & -0.3854 & -0.0230 & -0.0028 & 0.0088 & 0.3506 \\
\hline
\end{tabular}




\section{Table 9}

Portfolio Sorted by Systematic Exposure to Asymmetries in Returns

I form equal-weighted and value-weighted quintile portfolios every month by computing the beta difference of individual stocks as in equation (21), using daily data over the previous month. Stocks are sorted into quintiles based on the $\beta_{i}^{A}, \beta_{i}^{L}$ and $\beta_{i}^{G}$ from lowest (quintile 1) to highest (quintile 5), where $\beta_{i}^{A}$ is the difference between mean-variance and mean-swap variance betas, $\beta_{i}^{L}$ is the positive observations of $\beta_{i}^{A}$, and $\beta_{i}^{G}$ is the negative observations of $\beta_{i}^{A}$. The statistics in the columns labeled Mean, Std. Dev. and $\sqrt{S w V}$ are measured in monthly percentage of portfolio returns, standard deviations, and square roots of swapvariances, respectively. The preformation betas refer to the equal-weighted and value-weighted asymmetric betas within each quintile portfolio at the start of the month. The row "5-1" refers to the difference in monthly returns between portfolio 5 and portfolio 1. $t$-statistics are reported in square brackets. The sample period is from July 1969 to December 2015.

\begin{tabular}{|c|c|c|c|c|c|c|c|c|}
\hline \multirow[b]{2}{*}{ Rank } & \multicolumn{4}{|c|}{ Equal-Weighted Portfolios } & \multicolumn{4}{|c|}{ Value-Weighted Portfolios } \\
\hline & Mean & $\begin{array}{c}\text { Std. } \\
\text { Dev. }\end{array}$ & $\sqrt{S w V}$ & $\begin{array}{c}\text { Pre- } \\
\text { Formation } \\
\beta^{A}\end{array}$ & Mean & $\begin{array}{c}\text { Std. } \\
\text { Dev. }\end{array}$ & $\sqrt{S w V}$ & $\begin{array}{c}\text { Pre- } \\
\text { Formation } \\
\beta^{A}\end{array}$ \\
\hline 1 & $1.976 \%$ & $7.280 \%$ & $7.359 \%$ & -2.4948 & $1.121 \%$ & $6.669 \%$ & $6.707 \%$ & -2.2013 \\
\hline 2 & $1.104 \%$ & $5.311 \%$ & $5.452 \%$ & -0.5533 & $0.776 \%$ & $5.075 \%$ & $5.150 \%$ & -0.5529 \\
\hline 3 & $1.136 \%$ & $5.043 \%$ & $5.139 \%$ & -0.0494 & $0.738 \%$ & $4.831 \%$ & $4.897 \%$ & -0.0491 \\
\hline 4 & $1.002 \%$ & $5.797 \%$ & $5.861 \%$ & 0.4472 & $0.644 \%$ & $5.430 \%$ & $5.496 \%$ & 0.4460 \\
\hline 5 & $1.901 \%$ & $8.068 \%$ & $8.066 \%$ & 2.3900 & $0.964 \%$ & $7.484 \%$ & $7.480 \%$ & 2.0778 \\
\hline $5-1$ & $\begin{array}{c}-0.176 \% \\
{[-1.01]}\end{array}$ & & & & $\begin{array}{c}-0.157 \% \\
{[-1.12]}\end{array}$ & & & \\
\hline Rank & Mean & $\begin{array}{l}\text { Std. } \\
\text { Dev. }\end{array}$ & $\sqrt{S w V}$ & $\begin{array}{c}\text { Pre- } \\
\text { Formation } \\
\beta^{L} \\
\end{array}$ & Mean & $\begin{array}{l}\text { Std. } \\
\text { Dev. }\end{array}$ & $\sqrt{S w V}$ & $\begin{array}{c}\text { Pre- } \\
\text { Formation } \\
\beta^{L}\end{array}$ \\
\hline 1 & $0.948 \%$ & $5.301 \%$ & $5.382 \%$ & 0.1005 & $0.694 \%$ & $5.018 \%$ & $5.085 \%$ & 0.1017 \\
\hline 2 & $1.032 \%$ & $6.116 \%$ & $6.075 \%$ & 0.3426 & $0.645 \%$ & $5.384 \%$ & $5.447 \%$ & 0.3448 \\
\hline 3 & $1.017 \%$ & $6.222 \%$ & $6.293 \%$ & 0.6906 & $0.688 \%$ & $5.950 \%$ & $6.008 \%$ & 0.6940 \\
\hline 4 & $1.050 \%$ & $6.833 \%$ & $6.893 \%$ & 1.3039 & $0.666 \%$ & $6.583 \%$ & $6.655 \%$ & 1.3055 \\
\hline 5 & $2.573 \%$ & $10.570 \%$ & $10.124 \%$ & 3.6904 & $1.337 \%$ & $9.673 \%$ & $9.260 \%$ & 3.3304 \\
\hline $5-1$ & $\begin{array}{c}1.625 \% \\
{[4.94]} \\
\end{array}$ & & & & $\begin{array}{c}0.643 \% \\
{[2.24]}\end{array}$ & & & \\
\hline Rank & Mean & $\begin{array}{l}\text { Std. } \\
\text { Dev. }\end{array}$ & $\sqrt{S w V}$ & $\begin{array}{c}\text { Pre- } \\
\text { Formation } \\
\beta^{G}\end{array}$ & Mean & $\begin{array}{l}\text { Std. } \\
\text { Dev. }\end{array}$ & $\sqrt{S w V}$ & $\begin{array}{c}\text { Pre- } \\
\text { Formation } \\
\beta^{G}\end{array}$ \\
\hline 1 & $2.579 \%$ & $8.581 \%$ & $8.636 \%$ & -3.5968 & $1.329 \%$ & $7.656 \%$ & $7.646 \%$ & -3.2280 \\
\hline 2 & $1.338 \%$ & $6.438 \%$ & $6.489 \%$ & -1.2768 & $0.936 \%$ & $5.985 \%$ & $6.061 \%$ & -1.2609 \\
\hline 3 & $1.074 \%$ & $5.541 \%$ & $5.623 \%$ & -0.6752 & $0.724 \%$ & $5.112 \%$ & $5.184 \%$ & -0.6702 \\
\hline 4 & $1.152 \%$ & $5.101 \%$ & $5.206 \%$ & -0.3244 & $0.804 \%$ & $4.845 \%$ & $4.916 \%$ & -0.3230 \\
\hline 5 & $1.217 \%$ & $5.390 \%$ & $5.460 \%$ & -0.0922 & $0.746 \%$ & $4.970 \%$ & $5.017 \%$ & -0.0938 \\
\hline $5-1$ & $\begin{array}{c}-1.362 \% \\
{[-5.60]}\end{array}$ & & & & $\begin{array}{c}-0.583 \% \\
{[-2.98]} \\
\end{array}$ & & & \\
\hline
\end{tabular}




\section{Table 10}

\section{Correlation between Factors}

This table reports the correlation between the factors in asset pricing. $f_{M K T}, f_{S M B}$ and $f_{H M L}$ are market factor, size factor and value factor in Fama-French three factor model. $f_{L}$ and $f_{G}$ are two asymmetric risk factors I construct.

\begin{tabular}{|c|c|c|c|c|c|}
\hline & $f_{M K T}$ & $f_{L}$ & $f_{G}$ & $f_{S M B}$ & $f_{H M L}$ \\
\hline$f_{M K T}$ & 1 & 0.3306 & -0.3379 & 0.2716 & -0.2748 \\
\hline$f_{L}$ & & 1 & -0.4326 & 0.3438 & -0.1742 \\
\hline$f_{G}$ & & & 1 & -0.5265 & 0.2276 \\
\hline$f_{S M B}$ & & & & 1 & -0.2130 \\
\hline$f_{H M L}$ & & & & & 1 \\
\hline
\end{tabular}




\section{Table 11}

\section{Portfolio Sorted by Systematic Exposure to Asymmetries in Returns (Adjusted)}

I form equal-weighted and value-weighted quintile portfolios every month by computing the beta difference of individual stocks as in equation (21), using daily data over the previous month. Compared to unadjusted tests in table 9, I control for the size and value factor in this table. Firstly, I run Fama-French three factor model, and compute the residuals that subtract size and value components from returns. Then I compute mean-variance and mean-swap variance betas using individual residuals and market return. Stocks are sorted into quintiles based on the $\beta_{i}^{A S}, \beta_{i}^{L}$ and $\beta_{i}^{G}$ from lowest (quintile 1) to highest (quintile 5), where $\beta_{i}^{A}$ is the difference between meanvariance and mean-swapvariance betas, $\beta_{i}^{L}$ is the positive observations of $\beta_{i}^{A}$, and $\beta_{i}^{G}$ is the negative observations of $\beta_{i}^{A}$. The statistics in the columns labeled Mean, Std. Dev. and $\sqrt{S w V}$ are measured in monthly percentage of portfolio returns, standard deviations, and square roots of swap variances, respectively. The pre-formation betas refer to the equal-weighted and value-weighted asymmetric betas within each quintile portfolio at the start of the month. The row "5-1" refers to the difference in monthly returns between portfolio 5 and portfolio 1 . $t$-statistics are reported in square brackets. The sample period is from July 1969 to December 2015.

\begin{tabular}{|c|c|c|c|c|c|c|c|c|}
\hline \multirow[b]{2}{*}{ Rank } & \multicolumn{4}{|c|}{ Equal-Weighted Portfolios } & \multicolumn{4}{|c|}{ Value-Weighted Portfolios } \\
\hline & Mean & $\begin{array}{l}\text { Std. } \\
\text { Dev. }\end{array}$ & $\sqrt{S w V}$ & $\begin{array}{c}\text { Pre- } \\
\text { Formation } \\
\beta^{A}\end{array}$ & Mean & $\begin{array}{l}\text { Std. } \\
\text { Dev. }\end{array}$ & $\sqrt{S w V}$ & $\begin{array}{c}\text { Pre- } \\
\text { Formation } \\
\beta^{A}\end{array}$ \\
\hline 1 & $1.944 \%$ & $7.314 \%$ & $7.387 \%$ & -2.3464 & $1.053 \%$ & $6.689 \%$ & $6.725 \%$ & -2.0704 \\
\hline 2 & $1.052 \%$ & $5.267 \%$ & $5.367 \%$ & -0.5156 & $0.741 \%$ & $5.066 \%$ & $5.142 \%$ & -0.5133 \\
\hline 3 & $1.203 \%$ & $5.209 \%$ & $5.298 \%$ & -0.0184 & $0.726 \%$ & $4.824 \%$ & $4.892 \%$ & -0.0164 \\
\hline 4 & $0.996 \%$ & $5.659 \%$ & $5.738 \%$ & 0.4947 & $0.700 \%$ & $5.434 \%$ & $5.505 \%$ & 0.4912 \\
\hline 5 & $1.824 \%$ & $8.049 \%$ & $8.046 \%$ & 2.3465 & $1.010 \%$ & $7.448 \%$ & $7.437 \%$ & 2.0631 \\
\hline $5-1$ & $\begin{array}{c}-0.120 \% \\
{[-0.69]}\end{array}$ & & & & $\begin{array}{c}-0.000 \% \\
{[-0.33]}\end{array}$ & & & \\
\hline Rank & Mean & $\begin{array}{l}\text { Std. } \\
\text { Dev. }\end{array}$ & $\sqrt{S w V}$ & $\begin{array}{c}\text { Pre- } \\
\text { Formation } \\
\beta^{L}\end{array}$ & Mean & $\begin{array}{l}\text { Std. } \\
\text { Dev. }\end{array}$ & $\sqrt{S w V}$ & $\begin{array}{c}\text { Pre- } \\
\text { Formation } \\
\beta^{L}\end{array}$ \\
\hline 1 & $1.091 \%$ & $5.827 \%$ & $5.797 \%$ & 0.1066 & $0.694 \%$ & $5.134 \%$ & $5.182 \%$ & 0.1068 \\
\hline 2 & $0.904 \%$ & $5.667 \%$ & $5.737 \%$ & 0.3544 & $0.631 \%$ & $5.408 \%$ & $5.464 \%$ & 0.3542 \\
\hline 3 & $0.973 \%$ & $5.956 \%$ & $6.023 \%$ & 0.7006 & $0.647 \%$ & $5.721 \%$ & $5.786 \%$ & 0.6993 \\
\hline 4 & $1.061 \%$ & $6.802 \%$ & $6.854 \%$ & 1.2872 & $0.724 \%$ & $6.625 \%$ & $6.670 \%$ & 1.2782 \\
\hline 5 & $2.554 \%$ & $10.459 \%$ & $10.048 \%$ & 3.5103 & $1.297 \%$ & $9.563 \%$ & $9.147 \%$ & 3.1697 \\
\hline $5-1$ & $\begin{array}{c}1.463 \% \\
{[4.35]}\end{array}$ & & & & $\begin{array}{c}0.603 \% \\
{[2.14]}\end{array}$ & & & \\
\hline Rank & Mean & $\begin{array}{l}\text { Std. } \\
\text { Dev. }\end{array}$ & $\sqrt{S w V}$ & $\begin{array}{c}\text { Pre- } \\
\text { Formation } \\
\beta^{G}\end{array}$ & Mean & $\begin{array}{l}\text { Std. } \\
\text { Dev. }\end{array}$ & $\sqrt{S w V}$ & $\begin{array}{c}\text { Pre- } \\
\text { Formation } \\
\beta^{G}\end{array}$ \\
\hline 1 & $2.593 \%$ & $8.765 \%$ & $8.792 \%$ & -3.4860 & $1.332 \%$ & $7.786 \%$ & $7.790 \%$ & -3.1767 \\
\hline 2 & $1.261 \%$ & $6.255 \%$ & $6.328 \%$ & -1.2489 & $0.851 \%$ & $5.962 \%$ & $6.023 \%$ & -1.2403 \\
\hline 3 & $1.084 \%$ & $5.576 \%$ & $5.674 \%$ & -0.6712 & $0.780 \%$ & $5.309 \%$ & $5.389 \%$ & -0.6693 \\
\hline 4 & $1.069 \%$ & $5.083 \%$ & $5.182 \%$ & -0.3298 & $0.753 \%$ & $4.853 \%$ & $4.925 \%$ & -0.3301 \\
\hline 5 & $1.305 \%$ & $5.458 \%$ & $5.531 \%$ & -0.0936 & $0.794 \%$ & $5.000 \%$ & $5.060 \%$ & -0.0962 \\
\hline $5-1$ & $\begin{array}{c}-1.288 \% \\
{[-5.00]}\end{array}$ & & & & $\begin{array}{c}-0.539 \% \\
{[-2.71]}\end{array}$ & & & \\
\hline
\end{tabular}


Table 12

\section{Fama-MacBeth Regression Results}

The sample consists of monthly returns of 60 equal-sized portfolios. The portfolios are sorted by beginning-of-period betas and contain all CRSP-listed ordinary common equities from 1969 to 2015 for the monthly return intervals. For each calendar period, portfolio returns are regressed on three/five factor loadings: $\hat{\beta}_{p}^{M K T}, \hat{\beta}_{p}^{L}, \hat{\beta}_{p}^{G}, \hat{\beta}_{p}^{\text {Size }}$ and $\hat{\beta}_{p}^{\text {Value }}$. The market beta, size beta and value beta are computed by regressing portfolio returns over the past 60 months on the market, SMB and HML factors. The positive and negative asymmetry betas are computed by the asymmetry factor that generated by difference of holding period return between high asymmetric portfolio and low asymmetric portfolio. The mean coefficient estimates across the sample period are reported with their $t$-statistics.

$$
R_{p}=\lambda_{0}+\lambda_{1} \hat{\beta}_{p}^{M K T}+\lambda_{2} \hat{\beta}_{p}^{L}+\lambda_{3} \hat{\beta}_{p}^{G}+\lambda_{4} \hat{\beta}_{p}^{\text {Size }}+\lambda_{5} \hat{\beta}_{p}^{\text {Value }}+\varepsilon_{p}
$$

\begin{tabular}{|l|c|c|c|c|c|c|}
\hline & $\lambda_{1}$ & $\lambda_{2}$ & $\lambda_{3}$ & $\lambda_{4}$ & $\lambda_{5}$ & Average $\mathrm{R}^{2}$ \\
\hline \multirow{3}{*}{$\hat{\beta}_{i}^{\text {MKT } \text {-sorted }}$} & 0.0016 & $0.0102^{* * *}$ & $-0.0098^{* * *}$ & & & 0.2137 \\
& $(1.30)$ & $(3.24)$ & $(-3.04)$ & & & \\
\cline { 2 - 7 } & 0.0009 & $0.0092^{* * *}$ & $-0.0068^{*}$ & -0.0004 & -0.0037 & 0.2711 \\
& $(0.42)$ & $(3.22)$ & $(-1.95)$ & $(-0.15)$ & $(-1.30)$ & \\
\hline$\hat{\beta}_{i}^{L}$-sorted & 0.0049 & $0.0079^{*}$ & $-0.0148^{* *}$ & & & 0.1997 \\
& $(0.85)$ & $(1.81)$ & $(-2.32)$ & & & \\
\cline { 2 - 7 } & 0.0181 & 0.0160 & -0.0111 & $0.0100^{*}$ & 0.0050 & 0.2524 \\
& $(1.14)$ & $(1.52)$ & $(-1.34)$ & $(1.72)$ & $(1.48)$ & \\
\hline$\hat{\beta}_{i}^{G}$-sorted & $0.0049^{* *}$ & $0.0066^{* * *}$ & $-0.0049^{* * *}$ & & & 0.2032 \\
& $(2.06)$ & $(2.70)$ & $(-2.85)$ & & & \\
\cline { 2 - 7 } & $0.0082^{* * *}$ & 0.0024 & $-0.0057^{* * *}$ & 0.0037 & 0.0028 & 0.2512 \\
& $(2.74)$ & $(0.63)$ & $(-3.73)$ & $(1.55)$ & $(0.85)$ & \\
\hline$\hat{\beta}_{i}^{\text {Size } \text {-sorted }}$ & 0.0020 & $0.0068^{* *}$ & $-0.0058^{*}$ & $0.0025^{* *}$ & 0.0005 & 0.2759 \\
& $(0.74)$ & $(2.48)$ & $(-1.85)$ & $(2.49)$ & $(0.25)$ & \\
\hline$\hat{\beta}_{i}^{\text {Value } \text {-sorted }}$ & 0.0024 & $0.0154^{* *}$ & $-0.0137^{* * *}$ & $0.0046^{* *}$ & $0.0019^{*}$ & 0.2734 \\
& $(0.48)$ & $(2.51)$ & $(-4.54)$ & $(2.01)$ & $(1.79)$ & \\
\hline
\end{tabular}




\section{References}


Ang, Andrew, and Joseph Chen. "Asymmetric correlations of equity portfolios." Journal of financial Economics 63, no. 3 (2002): 443-494.

Arkes, Hal R., and Catherine Blumer. "The psychology of sunk cost." Organizational behavior and human decision processes 35, no. 1 (1985): 124-140.

Artzner, Philippe, Freddy Delbaen, Jean-Marc Eber, and David Heath. A characterization of measures of risk. Cornell University Operations Research and Industrial Engineering, 1997.

Artzner, Philippe, Freddy Delbaen, Jean-Marc Eber, David Heath, and Hyejin Ku. "Coherent multiperiod risk measurement." Preprint, ETH (2002).

Bali, Turan G., Nusret Cakici, and Robert F. Whitelaw. "Maxing out: Stocks as lotteries and the cross-section of expected returns." Journal of Financial Economics 99, no. 2 (2011): 427-446.

Banz, Rolf W. "The relationship between return and market value of common stocks." Journal of financial economics 9, no. 1 (1981): 3-18.

Barberis, Nicholas, and Andrei Shleifer. "Style investing." Journal of financial Economics 68, no. 2 (2003): 161-199.

Barber, Brad M., Yi-Tsung Lee, Yu-Jane Liu, and Terrance Odean. "Just how much do individual investors lose by trading?." The Review of Financial Studies 22, no. 2 (2008): 609632.

Basu, Sanjoy. "Investment performance of common stocks in relation to their price-earnings ratios: A test of the efficient market hypothesis." The journal of Finance 32, no. 3 (1977): 663682.

Bawa, Vijay S., and Eric B. Lindenberg. "Capital market equilibrium in a mean-lower partial moment framework." Journal of Financial Economics 5, no. 2 (1977): 189-200.

Berger, J. M., and Benoit Mandelbrot. "A new model for error clustering in telephone circuits." IBM Journal of Research and Development 7, no. 3 (1963): 224-236.

Benartzi, Shlomo, and Richard H. Thaler. "Myopic loss aversion and the equity premium puzzle." The quarterly journal of Economics 110, no. 1 (1995): 73-92.

Bhandari, Laxmi Chand. "Debt/equity ratio and expected common stock returns: Empirical evidence." The Journal of Finance 43, no. 2 (1988): 507-528.

Blay, Kenneth, and Harry Markowitz. "Risk-return analysis: The theory and practice of rational investing (volume one)." (2013).

Blume, Marshall E., and Irwin Friend. "A new look at the capital asset pricing model." The journal of finance 28, no. 1 (1973): 19-34.

Bollerslev, Tim, Viktor Todorov, and Sophia Zhengzi Li. "Jump tails, extreme dependencies, and the distribution of stock returns." Journal of Econometrics172, no. 2 (2013): 307-324. 
Bondt, Werner FM, and Richard Thaler. "Does the stock market overreact?." The Journal of finance 40, no. 3 (1985): 793-805.

Bondt, De, F. M. Werner, and Richard H. Thaler. "Further evidence on investor overreaction and stock market seasonality." The Journal of finance 42, no. 3 (1987): 557-581.

Brockner, Joel. "The escalation of commitment to a failing course of action: Toward theoretical progress." Academy of management Review 17, no. 1 (1992): 39-61.

Budescu, David V., and Wendy Weiss. "Reflection of transitive and intransitive preferences: A test of prospect theory." Organizational Behavior and Human Decision Processes 39, no. 2 (1987): 184-202.

Campbell, John Y., and Tuomo Vuolteenaho. "Bad beta, good beta." The American Economic Review 94, no. 5 (2004): 1249-1275.

Carhart, Mark M. "On persistence in mutual fund performance." The Journal of finance 52, no. 1 (1997): 57-82.

Casey, Jeff T. "Buyers' pricing behavior for risky alternatives: Encoding processes and preference reversals." Management science 40, no. 6 (1994): 730-749.

Chabi-Yo, Fousseni, Dietmar PJ Leisen, and Eric Renault. "Aggregation of preferences for skewed asset returns." Journal of Economic Theory 154 (2014): 453-489.

Chen, Son-Nan. "An examination of risk-return relationship in bull and bear markets using timevarying betas." Journal of Financial and Quantitative Analysis 17, no. 02 (1982): 265-286.

Christie-David, Rohan, and Mukesh Chaudhry. "Coskewness and cokurtosis in futures markets." Journal of empirical finance 8, no. 1 (2001): 55-81.

Chung, Y. Peter, Herb Johnson, and Michael J. Schill. "Asset pricing when returns are nonnormal: Fama-french factors versus higher-order systematic comoments." The Journal of Business 79, no. 2 (2006): 923-940.

Daniel, Kent, David Hirshleifer, and Avanidhar Subrahmanyam. "Investor psychology and security market under-and overreactions." the Journal of Finance 53, no. 6 (1998): 1839-1885.

Dentcheva, Darinka, and Andrzej Ruszczyński. "Optimization with stochastic dominance constraints." SIAM Journal on Optimization 14, no. 2 (2003): 548-566.

Dentcheva, Darinka, and Andrzej Ruszczyński. "Portfolio optimization with stochastic dominance constraints." Journal of Banking \& Finance 30, no. 2 (2006): 433-451.

Dittmar, Robert F. "Nonlinear pricing kernels, kurtosis preference, and evidence from the cross section of equity returns." The Journal of Finance 57, no. 1 (2002): 369-403.

Embrechts, Paul, Sidney I. Resnick, and Gennady Samorodnitsky. "Extreme value theory as a risk management tool." North American Actuarial Journal 3, no. 2 (1999): 30-41. 
Eraker, Bjørn, and Mark Ready. "Do investors overpay for stocks with lottery-like payoffs? An examination of the returns of OTC stocks." Journal of Financial Economics 115, no. 3 (2015): 486-504.

Fabian, Csaba I., and Anna Veszprémi. "Algorithms for handling CVaR constraints in dynamic stochastic programming models with applications to finance." The Journal of Risk 10, no. 3 (2008): 111.

Fama, Eugene F. "Mandelbrot and the stable Paretian hypothesis." The journal of business 36, no. 4 (1963): 420-429.

Fama, Eugene F., and Kenneth R. French. "The cross-section of expected stock returns." the Journal of Finance 47, no. 2 (1992): 427-465.

Fama, Eugene F., and Kenneth R. French. "Common risk factors in the returns on stocks and bonds." Journal of financial economics 33, no. 1 (1993): 3-56.

Fama, Eugene F., and Kenneth R. French. "Size and book-to-market factors in earnings and returns." The Journal of Finance 50, no. 1 (1995): 131-155.

Fama, Eugene F., and Kenneth R. French. "Multifactor explanations of asset pricing anomalies." The journal of finance 51, no. 1 (1996): 55-84.

Fama, Eugene F., and Kenneth R. French. "Dissecting anomalies with a five-factor model." The Review of Financial Studies 29, no. 1 (2016): 69-103.

Fama, Eugene F., and James D. MacBeth. "Risk, return, and equilibrium: Empirical tests." The Journal of Political Economy (1973): 607-636.

Fang, Hsing, and Tsong-Yue Lai. "Co-kurtosis and Capital Asset Pricing. "Financial Review 32, no. 2 (1997): 293-307.

Favre, Laurent, and Jose-Antonio Galeano. "Mean-modified value-at-risk optimization with hedge funds." The journal of alternative investments 5, no. 2 (2002): 21-25.

Friend, Irwin, and Marshall Blume. "Measurement of portfolio performance under uncertainty." The American Economic Review (1970): 561-575.

Fong, Wai Mun. "Risk preferences, investor sentiment and lottery stocks: A stochastic dominance approach." Journal of Behavioral Finance 14, no. 1 (2013): 42-52.

Gul, Faruk. "A theory of disappointment aversion." Econometrica: Journal of the Econometric Society (1991): 667-686.

Hadar, Josef, and William R. Russell. "Rules for ordering uncertain prospects." American economic review 59, no. 1 (1969): 25-34.

Hanoch, Giora, and Haim Levy. "The efficiency analysis of choices involving risk." The Review of Economic Studies 36, no. 3 (1969): 335-346. 
Harlow, W. Van, and Ramesh KS Rao. "Asset pricing in a generalized mean-lower partial moment framework: Theory and evidence." Journal of Financial and Quantitative Analysis 24, no. 03 (1989): 285-311.

Harvey, Campbell R., and Akhtar Siddique. "Conditional skewness in asset pricing tests." The Journal of Finance 55, no. 3 (2000): 1263-1295.

Hershey, John C., and Paul JH Schoemaker. "Prospect theory's reflection hypothesis: A critical examination." Organizational Behavior and Human Performance 25, no. 3 (1980): 395-418.

Hong, Harrison, Jeffrey D. Kubik, and Jeremy C. Stein. "Thy neighbor's portfolio: Word-ofmouth effects in the holdings and trades of money managers." The Journal of Finance 60, no. 6 (2005): 2801-2824.

Hung, Chi-Hsiou Daniel. "The Four-Moment CAPM and Non-Linear Market Models in Momentum and Size Strategies." Working Paper (2007).

Inoue, Akihiko. "On the worst conditional expectation." Journal of Mathematical Analysis and Applications 286, no. 1 (2003): 237-247.

Levy, Haim. Stochastic dominance: Investment decision making under uncertainty. Springer, 2015.

Luedtke, James. "New formulations for optimization under stochastic dominance constraints." SIAM Journal on Optimization 19, no. 3 (2008): 1433-1450.

Jegadeesh, Narasimhan, and Sheridan Titman. "Returns to buying winners and selling losers: Implications for stock market efficiency." The Journal of finance 48, no. 1 (1993): 65-91.

Jensen, Michael C., Fischer Black, and Myron S. Scholes. "The capital asset pricing model: Some empirical tests." (1972).

Jiang, George J., and Roel CA Oomen. "Testing for jumps when asset prices are observed with noise-a "swap variance" approach." Journal of Econometrics 144, no. 2 (2008): 352-370.

Johnson, Leland L. "The theory of hedging and speculation in commodity futures." The Review of Economic Studies 27, no. 3 (1960): 139-151.

Kahneman, D. \& Tversky, A. (1979). Prospect theory, an analysis of decision under risk. Econometrica, 47(2), 264-291.

Kim, Moon K., and J. Kenton Zumwalt. "An analysis of risk in bull and bear markets." Journal of Financial and Quantitative analysis 14, no. 05 (1979): 1015-1025.

Kopa, Miloš, and Petr Chovanec. "A second-order stochastic dominance portfolio efficiency measure." Kybernetika 44, no. 2 (2008): 243-258.

Kothari, Sagar P., Jay Shanken, and Richard G. Sloan. "Another look at the cross-section of expected stock returns." The Journal of Finance 50, no. 1 (1995): 185-224. 
Kraus, Alan, and Robert H. Litzenberger. "Skewness preference and the valuation of risk assets." The Journal of Finance 31, no. 4 (1976): 1085-1100.

Krokhmal, Pavlo A. "Higher moment coherent risk measures." (2007): 373-387.

Kumar, Alok. "Who gambles in the stock market?." The Journal of Finance 64, no. 4 (2009): 1889-1933.

Kuosmanen, Timo. "Efficient diversification according to stochastic dominance criteria." Management Science 50, no. 10 (2004): 1390-1406.

Kuosmanen, Timo. "Performance measurement and best-practice benchmarking of mutual funds: combining stochastic dominance criteria with data envelopment analysis." Journal of Productivity Analysis 28, no. 1-2 (2007): 71-86.

Lakonishok, Josef, and Alan C. Shapiro. "Systematic risk, total risk and size as determinants of stock market returns." Journal of Banking \& Finance 10, no. 1 (1986): 115-132.

Lakonishok, Josef, Andrei Shleifer, and Robert W. Vishny. "Contrarian investment, extrapolation, and risk." The journal of finance 49, no. 5 (1994): 1541-1578.

Li, David X. "Value at Risk based on the Volatility, Skewness and Kurtosis."RiskMetrics Group (1999).

Lintner, John. "The valuation of risk assets and the selection of risky investments in stock portfolios and capital budgets." The review of economics and statistics (1965): 13-37.

Lozano, Sebastián, and Ester Gutiérrez. "Data envelopment analysis of mutual funds based on second-order stochastic dominance." European Journal of Operational Research 189, no. 1 (2008): 230-244.

Markowitz, Harry. "Portfolio selection*." The journal of finance 7, no. 1 (1952): 77-91.

Markowitz, Harry. "The utility of wealth." The Journal of Political Economy(1952): 151-158.

Markowitz, Harry. "The optimization of a quadratic function subject to linear constraints." Naval Research Logistics Quarterly 3, no. 1-2 (1956): 111-133.

Markowitz, Harry. "Portfolio selection: efficient diversification of investments."New York (1959).

Merton, Robert C. "An intertemporal capital asset pricing model."Econometrica: Journal of the Econometric Society (1973): 867-887.

Merton, Robert C. "Theory of rational option pricing." The Bell Journal of economics and management science (1973): 141-183.

Merton, Robert C. "Option pricing when underlying stock returns are discontinuous." Journal of financial economics 3, no. 1-2 (1976): 125-144. 
Moreno, David, and Rosa Rodríguez. "The value of coskewness in mutual fund performance evaluation." Journal of Banking \& Finance 33, no. 9 (2009): 1664-1676.

Mossin, Jan. "Equilibrium in a capital asset market." Econometrica: Journal of the econometric society (1966): 768-783.

Neuberger, Anthony. "The log contract." Journal of portfolio management 20 (1994): 74-74.

Post, Thierry. "Empirical tests for stochastic dominance efficiency." The Journal of Finance 58, no. 5 (2003): 1905-1931.

Price, Kelly, Barbara Price, and Timothy J. Nantell. "Variance and lower partial moment measures of systematic risk: some analytical and empirical results." The Journal of Finance 37, no. 3 (1982): 843-855.

Quirk, James P., and Rubin Saposnik. "Admissibility and measurable utility functions." The Review of Economic Studies (1962): 140-146.

Reinganum, Marc R. "A new empirical perspective on the CAPM." Journal of financial and quantitative analysis 16, no. 04 (1981): 439-462.

Rosenberg, Barr, Kenneth Reid, and Ronald Lanstein. "Persuasive evidence of market inefficiency." The Journal of Portfolio Management 11, no. 3 (1985): 9-16.

Ross, Stephen A. "The arbitrage theory of capital asset pricing." Journal of economic theory 13, no. 3 (1976): 341-360.

Sharpe, William F. "Capital asset prices: A theory of market equilibrium under conditions of risk*." The journal of finance 19, no. 3 (1964): 425-442.

Sharpe, William F. "Mutual fund performance." The Journal of business 39, no. 1 (1966): 119138.

Shalit, Haim, and Shlomo Yitzhaki. "Mean-Gini, Portfolio Theory, and the Pricing of Risky Assets." The journal of Finance 39, no. 5 (1984): 1449-1468.

Shalit, Haim, and Shlomo Yitzhaki. "Marginal conditional stochastic dominance." Management Science 40, no. 5 (1994): 670-684.

Smith, Daniel R. "Conditional coskewness and asset pricing." Journal of Empirical Finance 14, no. 1 (2007): 91-119.

Sortino, Frank A., and Lee N. Price. "Performance measurement in a downside risk framework." the Journal of Investing 3, no. 3 (1994): 59-64.

Stambaugh, Robert F. "On the exclusion of assets from tests of the two-parameter model: A sensitivity analysis." Journal of financial economics 10, no. 3 (1982): 237-268.

Todorov, Viktor, and Tim Bollerslev. "Jumps and betas: A new framework for disentangling and estimating systematic risks." Journal of Econometrics 157, no. 2 (2010): 220-235. 
Treynor, Jack L. "Market value, time, and risk." (1961).

Tversky, Amos, and Daniel Kahneman. "Rational choice and the framing of decisions." Journal of business (1986): S251-S278.

Tversky, Amos, and Daniel Kahneman. "Loss aversion in riskless choice: A reference-dependent model." The quarterly journal of economics 106, no. 4 (1991): 1039-1061.

Vendrame, Vasco, Jon Tucker, and Cherif Guermat. "Some extensions of the CAPM for individual assets." International Review of Financial Analysis 44 (2016): 78-85.

Von Neumann, John, and Oskar Morgenstern. "Theory of games and economic behavior, 1st Ed." Princeton University Press (1944).

Whitmore, George A. "Third-degree stochastic dominance." American Economic Review 60, no. 3 (1970): 457-59.

Whitmore, George A. "Stochastic dominance for the class of completely monotonic utility functions." In Studies in the Economics of Uncertainty, pp. 77-88. Springer New York, 1989.

Yang, Jian, Yinggang Zhou, and Zijun Wang. "Conditional coskewness in stock and bond markets: time-series evidence." Management Science 56, no. 11 (2010): 2031-2049.

Yitzhaki, Shlomo. "Stochastic dominance, mean variance, and Gini's mean difference." The American Economic Review (1982): 178-185.

You, Leyuan, and Robert T. Daigler. "Is international diversification really beneficial?" Journal of Banking \& Finance 34, no. 1 (2010): 163-173. 